Prepared in cooperation with the National Park Service

\title{
Life-History Model for Sockeye Salmon (Oncorhynchus nerka) at Lake Ozette, Northwestern Washington-Users' Guide
}

Last updated: 18 March 2019

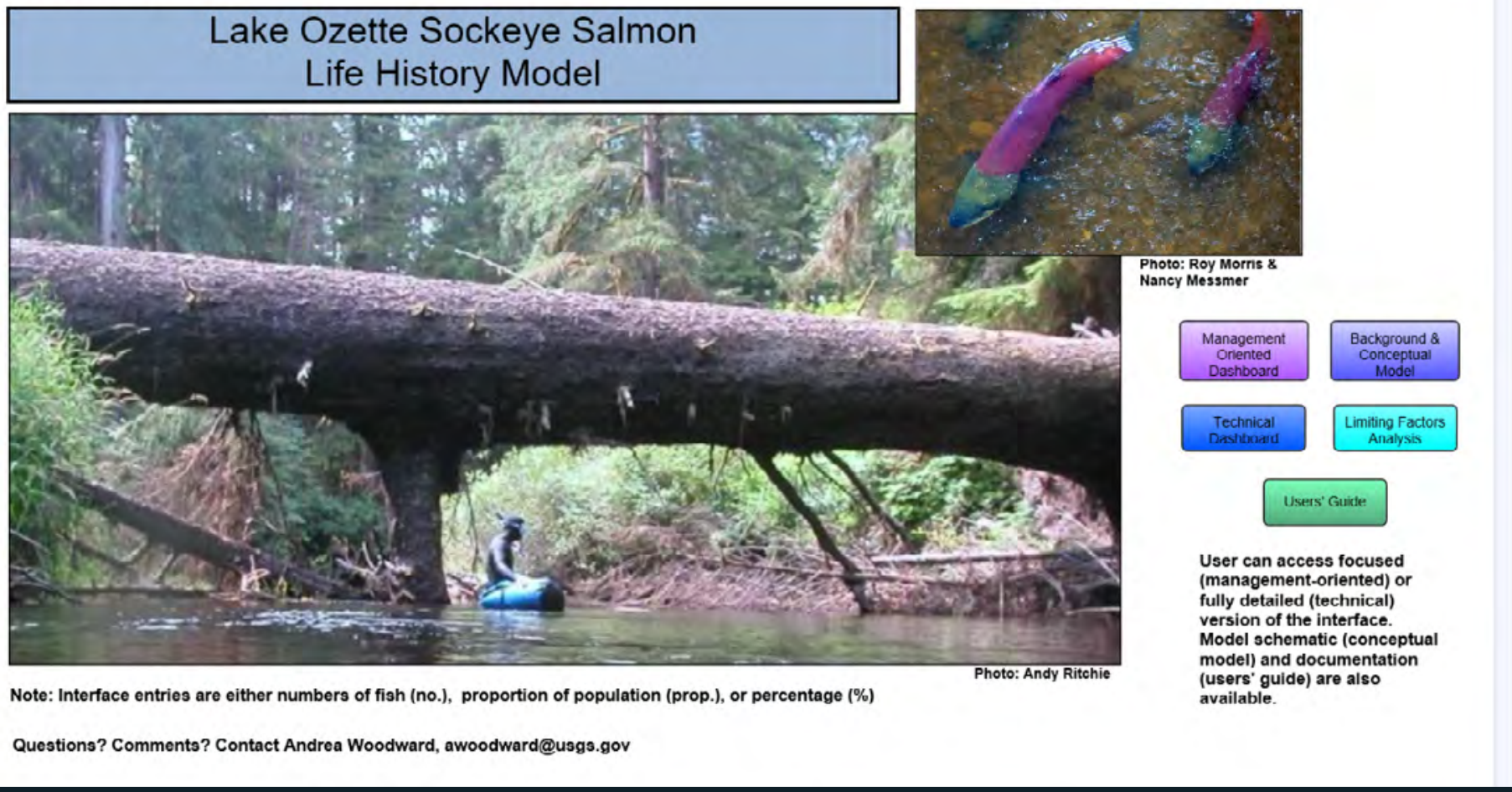

Open-File Report 2019-1031

U.S. Department of the Interior

U.S. Geological Survey 
Cover: Photographs and diagram showing interface of the Lake Ozette sockeye salmon life-history model, northwestern Washington. Main photograph: Makah Tribe member surveying Ozette River. Photograph by Andy Ritchie, Makah Tribe, June 24, 2004. Small photograph: Sockeye salmon spawning in Lake Ozette. Photograph by Roy Morris and Nancy Messmer, Clallam Bay Sekiu Lions Club, October 20, 2014, used with permission. 


\section{Life-History Model for Sockeye Salmon (Oncorhynchus nerka) at Lake Ozette, Northwestern Washington-Users' Guide}

By Andrea Woodward, Mike Haggerty, and Patrick Crain

Prepared in cooperation with the National Park Service

Open File Report 2019-1031

U.S. Department of the Interior

U.S. Geological Survey 


\section{U.S. Department of the Interior \\ DAVID BERNHARDT, Acting Secretary}

\section{U.S. Geological Survey \\ James F. Reilly II, Director}

U.S. Geological Survey, Reston, Virginia: 2019

For more information on the USGS-the Federal source for science about the Earth,

its natural and living resources, natural hazards, and the environment-visit

https://www.usgs.gov/ or call 1-888-ASK-USGS (1-888-275-8747).

For an overview of USGS information products, including maps, imagery, and publications, visit htps:/store.usgs.gov.

Any use of trade, firm, or product names is for descriptive purposes only and does not imply endorsement by the U.S. Government.

Although this information product, for the most part, is in the public domain, it also may contain copyrighted materials as noted in the text. Permission to reproduce copyrighted items must be secured from the copyright owner.

Suggested citation:

Woodward, A., Haggerty, M., and Crain, P., 2019, Life-history model for sockeye salmon (Oncorhynchus nerka) at Lake Ozette, northwestern Washington-Users' guide: U.S. Geological Survey Open-File Report 2019-1031, 79 p., https://doi.org/10.3133/ofr20191031.

ISSN 2331-1258 (online) 


\section{Contents}

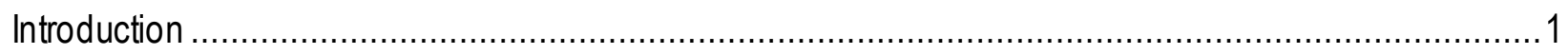

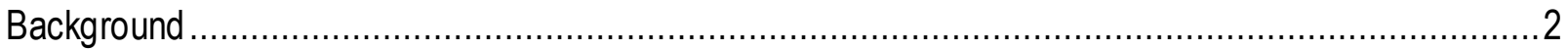

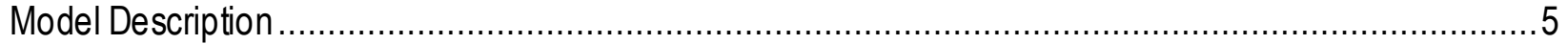

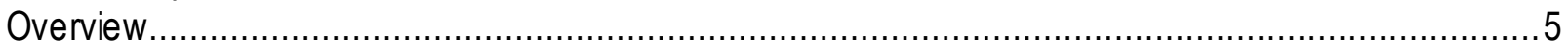

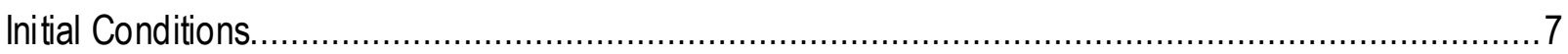

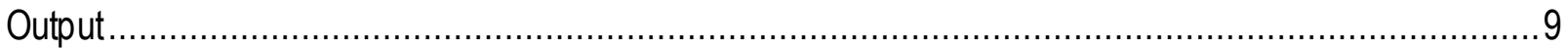

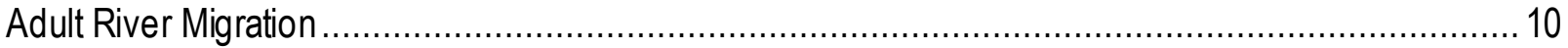

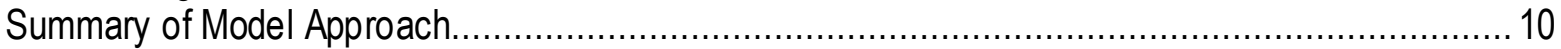

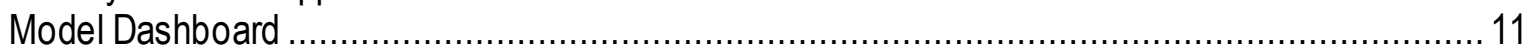

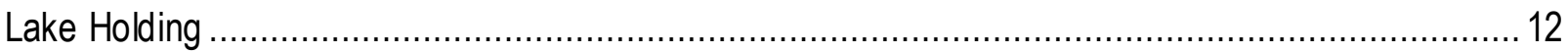

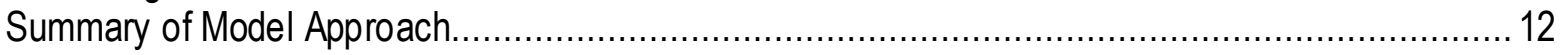

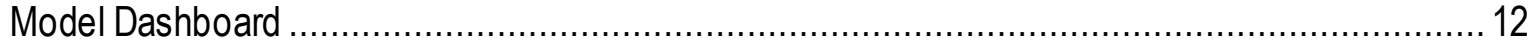

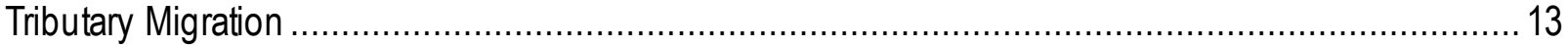

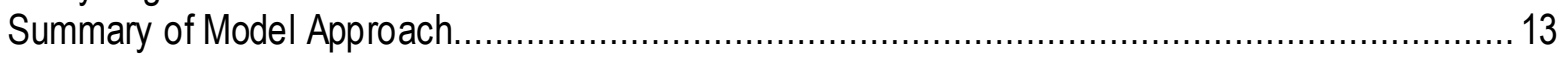

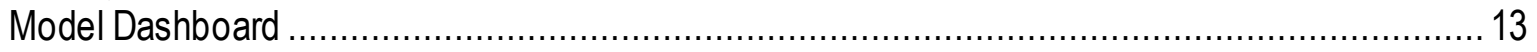

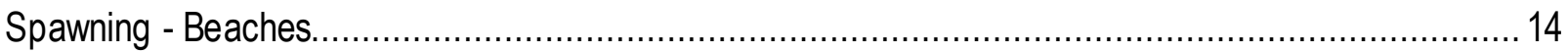

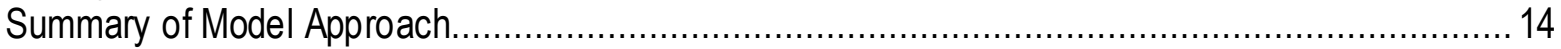

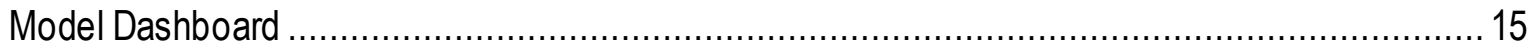

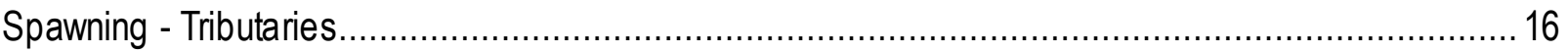

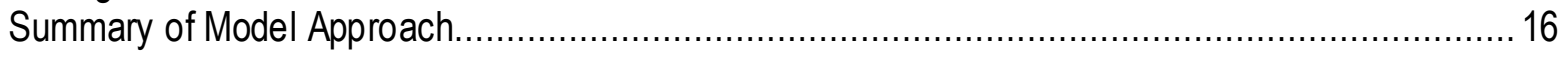

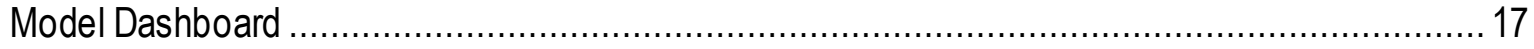

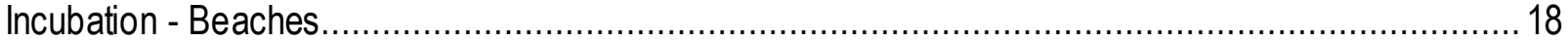

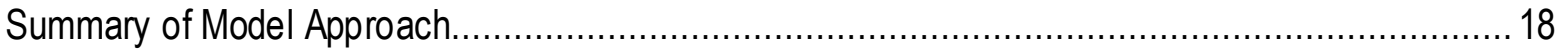

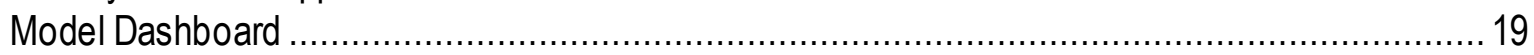

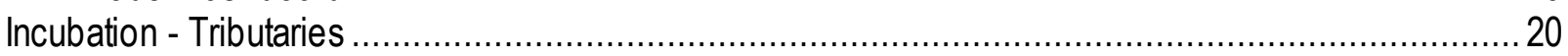

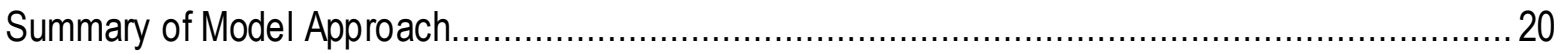

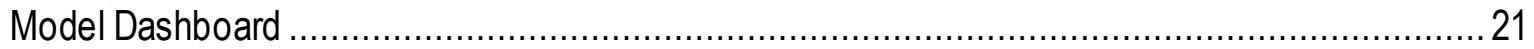

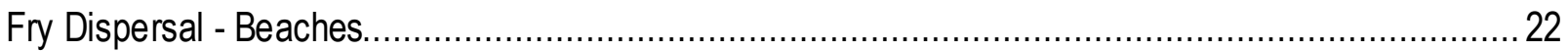

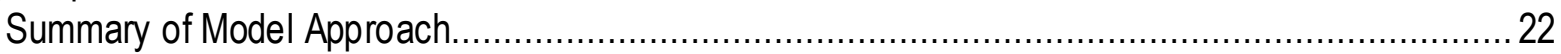

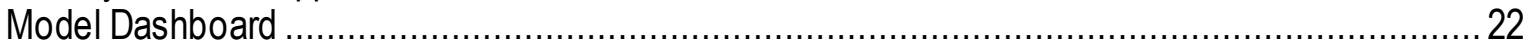

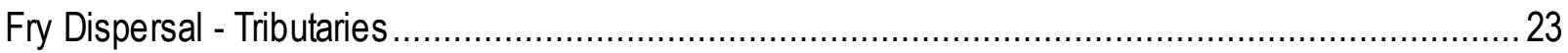

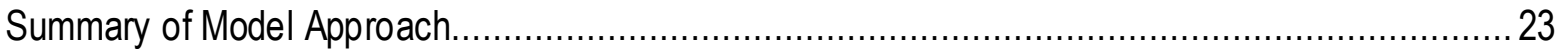

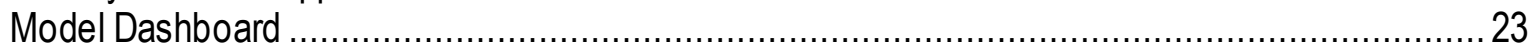

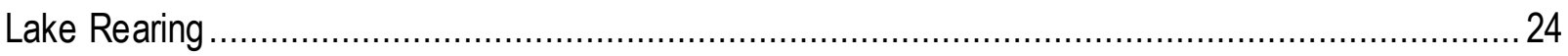

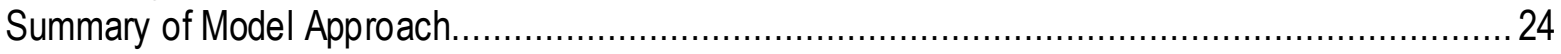

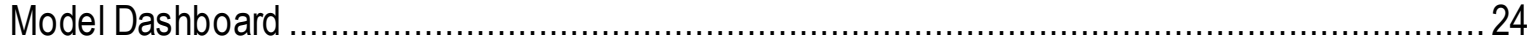

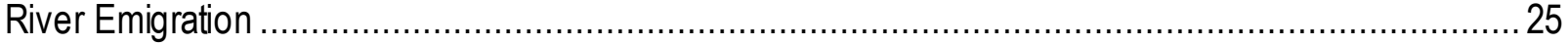

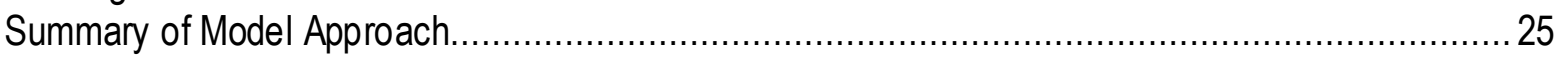

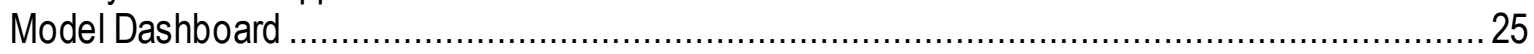

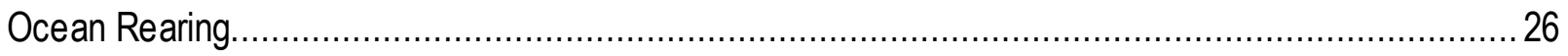

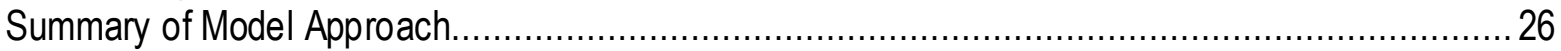

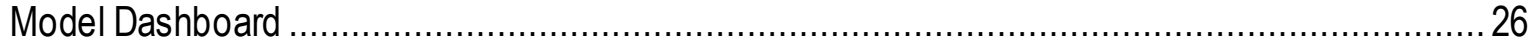

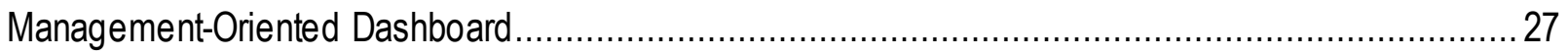




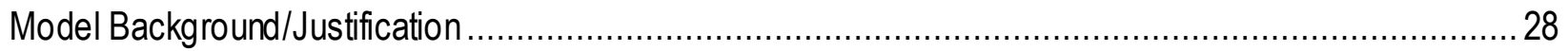

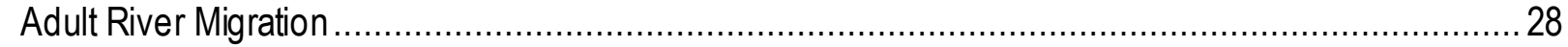

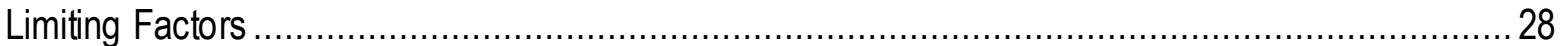

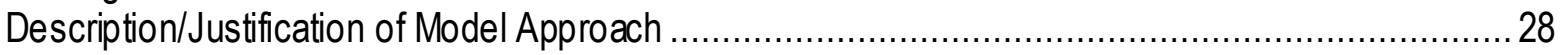

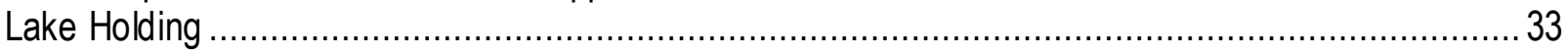

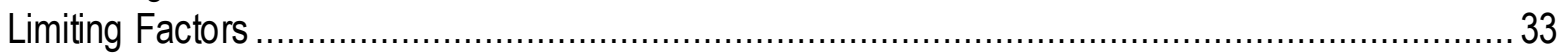

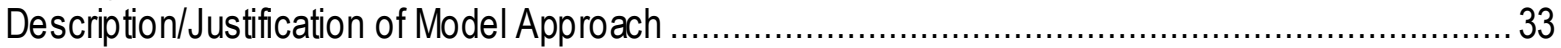

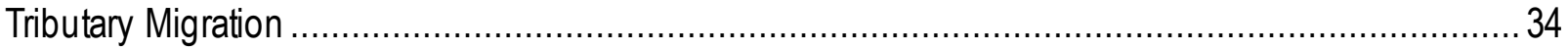

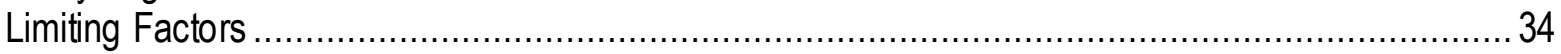

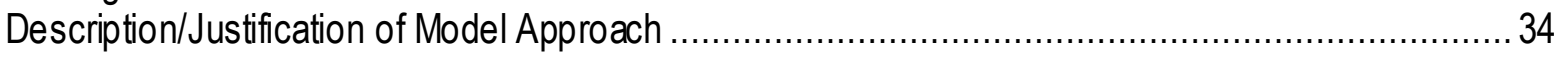

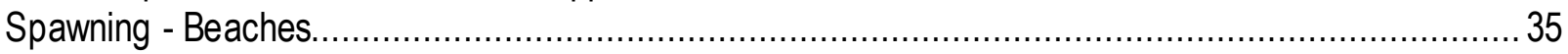

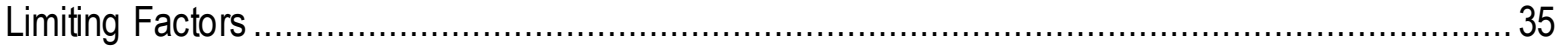

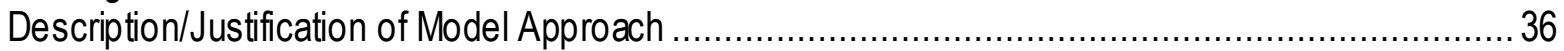

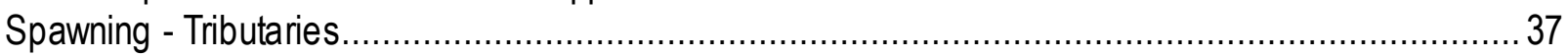

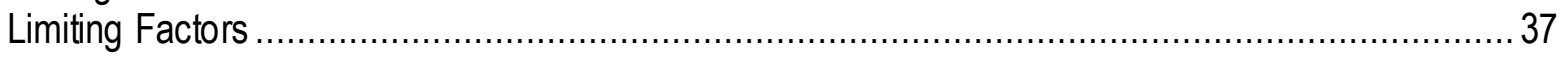

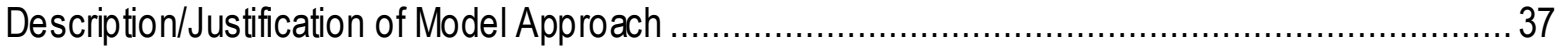

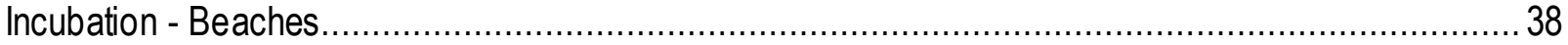

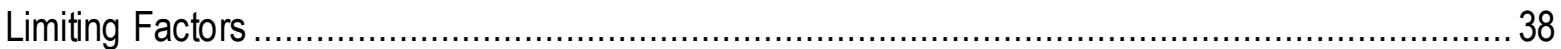

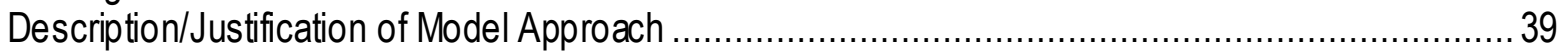

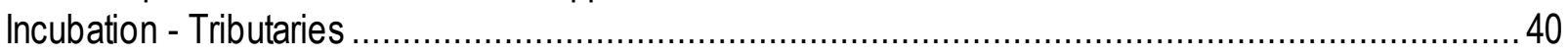

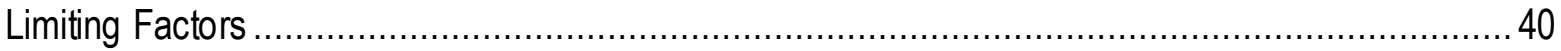

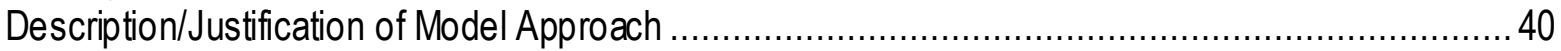

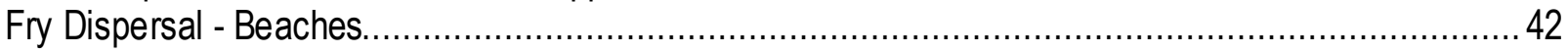

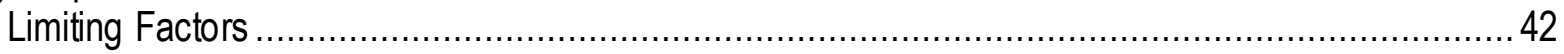

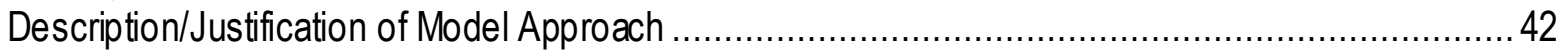

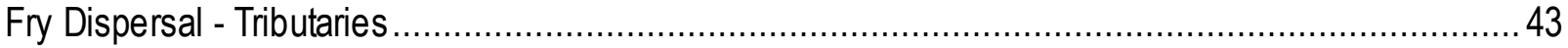

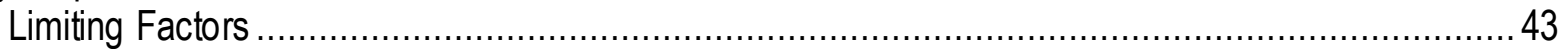

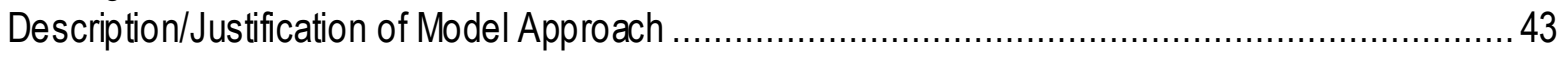

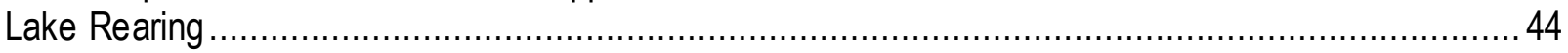

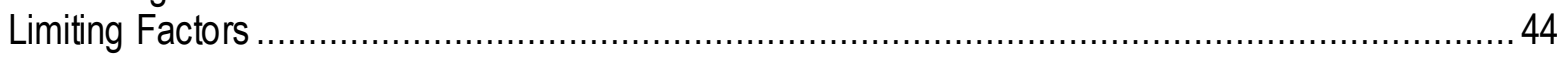

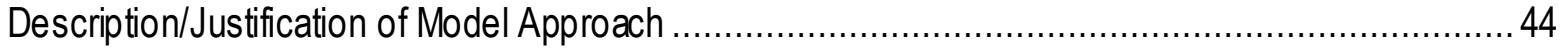

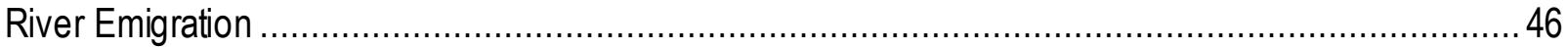

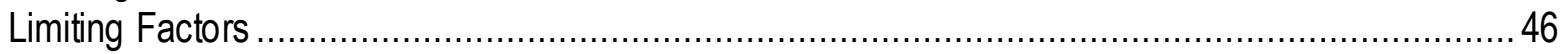

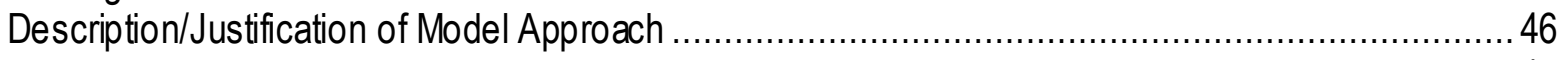

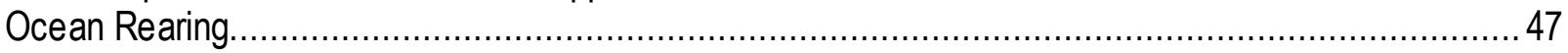

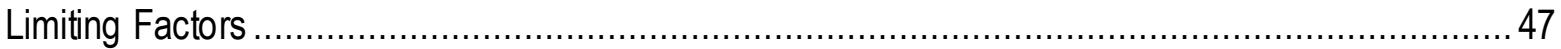

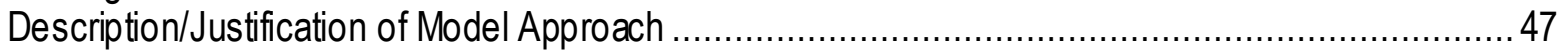

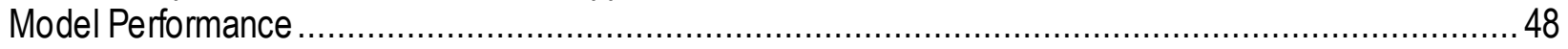

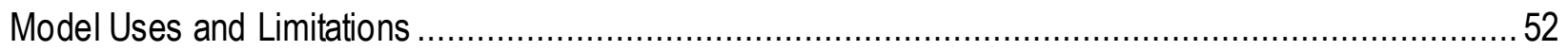

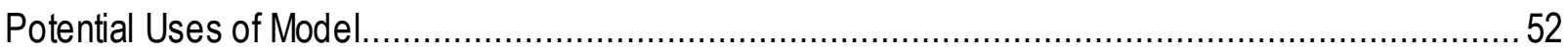

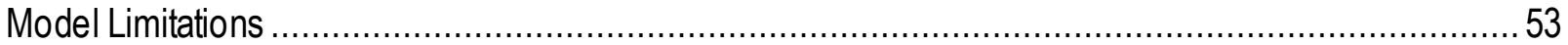

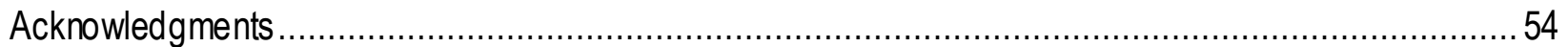

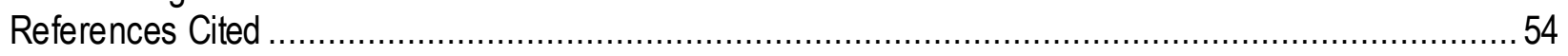

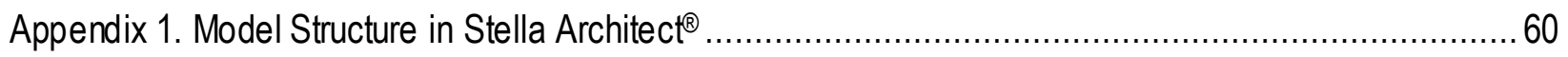

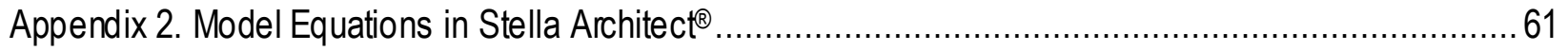




\section{Figures}

Figure 1. Map showing geography and sockeye salmon (Oncorhynchus nerka) spawning areas of Lake Ozette, northwestern Washington.

Figure 2. Conceptual model of the Lake Ozette sockeye salmon (Oncorhynchus nerka) life cycle including life stages, survival between stages, and factors that affect survival.

Figure 3. Screen capture showing first page (of three pages) of technical dashboard for Lake Ozette sockeye salmon model. .......................................................................................................

Figure 4. Screen capture of "Initial Conditions" section of dashboard for Lake Ozette sockeye salmon......8 Figure 5. Screen capture of "Output" section of dashboard for Lake Ozette sockeye salmon model..........9 Figure 6. Screen capture of "Adult River Migration" section of technical dashboard and definitions of terms for Lake Ozette sockeye salmon model.....

Figure 7. Screen capture of "Lake Holding" section of technical dashboard and definitions of terms for Lake Ozette sockeye salmon model..

Figure 8. Screen capture of "Tributary Migration" section of technical dashboard and definitions of terms for Lake Ozette sockeye salmon model.....

Figure 9. Screen capture of "Spawning - Beaches" section of technical dashboard and definitions of terms for Lake Ozette sockeye salmon model.....

Figure 10. Screen capture of "Spawning - Tributaries" section of technical dashboard and definitions of terms for Lake Ozette sockeye salmon model.

Figure 11. Screen capture of "Incubation - Beaches" section of technical dashboard and definitions of terms for Lake Ozette sockeye salmon model.....

Figure 12. Screen capture of "Incubation - Tributaries" section of technical dashboard and definitions of terms for Lake Ozette sockeye salmon model.

Figure 13. Screen capture of Fry "Dispersal - Beaches" section of technical dashboard and definition of term for Lake Ozette sockeye salmon model.....

Figure 14. Screen capture of "Fry Dispersal - Tributaries" section of technical dashboard and definitions of terms for Lake Ozette sockeye salmon model.

Figure 15. Screen capture of "Lake Rearing" section of technical dashboard and definitions of terms for Lake Ozette sockeye salmon model.

Figure 16. Screen capture of "Emigration" section of technical dashboard and definitions of terms for Lake Ozette sockeye salmon model.

Figure 17. Screen capture of "Ocean Rearing" section of technical dashboard and definitions of terms for Lake Ozette sockeye salmon model.....

Figure 18. Screen capture of "Management-Oriented Dashboard" for Lake Ozette sockeye salmon model.

Figure 19. Graphs showing function relating predation mortality to run size for migrating sockeye salmon adults in the Ozette River, northwestern Washington

Figure 20. Graph showing percentage of sockeye salmon transiting weir during daylighthours as a function of lake level in feetabove North American Vertical Datum of 1988, Lake Ozette, northwestern Washington

Figure 21. Graph showing percentage of sockeye salmon transiting the weir at a range of lake levels in feet above North American Vertical Datum of 1988, at Lake Ozette, northwestern Washington

Figure 22. Graph showing predation mortality as a function of run size for juvenile sockeye salmon rearing in Lake Ozette, northwestern Washington .....

Figure 23. Graphs showing sensitivity of Lake Ozette sockeye life cycle model results to changes in several model parameters. 


\section{Tables}

Table 1. Limiting factors for adult river migration identified in the limiting factors analysis for sockeye salmon at Ozette River and Lake Ozette, northwestern Washington.....

Table 2. Determination of default values of population exposure to predation owing to lake level.............31

Table 3. Limiting factors for lake holding identified in the limiting factors analysis for sockeye salmon at Lake Ozette, northwestern Washington

Table 4. Limiting factors for tributary migration identified in the limiting factors analysis (LFA) for sockeye salmon at Lake Ozette, northwestern Washington.

Table 5. Limiting factors for beach spawning identified in limiting factors analysis (LFA) for sockeye salmon at Lake Ozette, northwestern Washington.....

Table 6. Limiting factors for tributary spawning identified in limiting factors analysis for sockeye salmon at Lake Ozette, northwestern Washington

Table 7. Limiting factors for beach incubation identified in limiting factors analysis for sockeye salmon at Lake Ozette, northwestern Washington

Table 8. Limiting factors for tributary incubation identified in limiting factors analysis for sockeye salmon at Lake Ozette, northwestern Washington.

Table 9. Limiting factors for beach dispersal identified in limiting factors analysis for sockeye salmon at Lake Ozette, northwestern Washington

Table 10. Limiting factors for tributary dispersal identified in limiting factors analysis for sockeye salmon at Lake Ozette, northwestern Washington.

Table 11. Limiting factors for lake rearing identified in limiting factors analysis for sockeye salmon at Lake Ozette, northwestern Washington.

Table 12. Limiting factors for river emigration identified in limiting factors analysis for sockeye salmon at Lake Ozette, northwestern Washington

Table 13. Limiting factors for ocean rearing identified in limiting factors analysis for sockeye salmon at Lake Ozette, northwestern Washington.....

Table 14. Comparison between published survival-rate estimates for multiple stages of the sockeye salmon life history with Lake Ozette sockeye life cycle model results when initialized with 4,000 salmon 


\section{Conversion Factors}

U.S. customary units to International System of Units

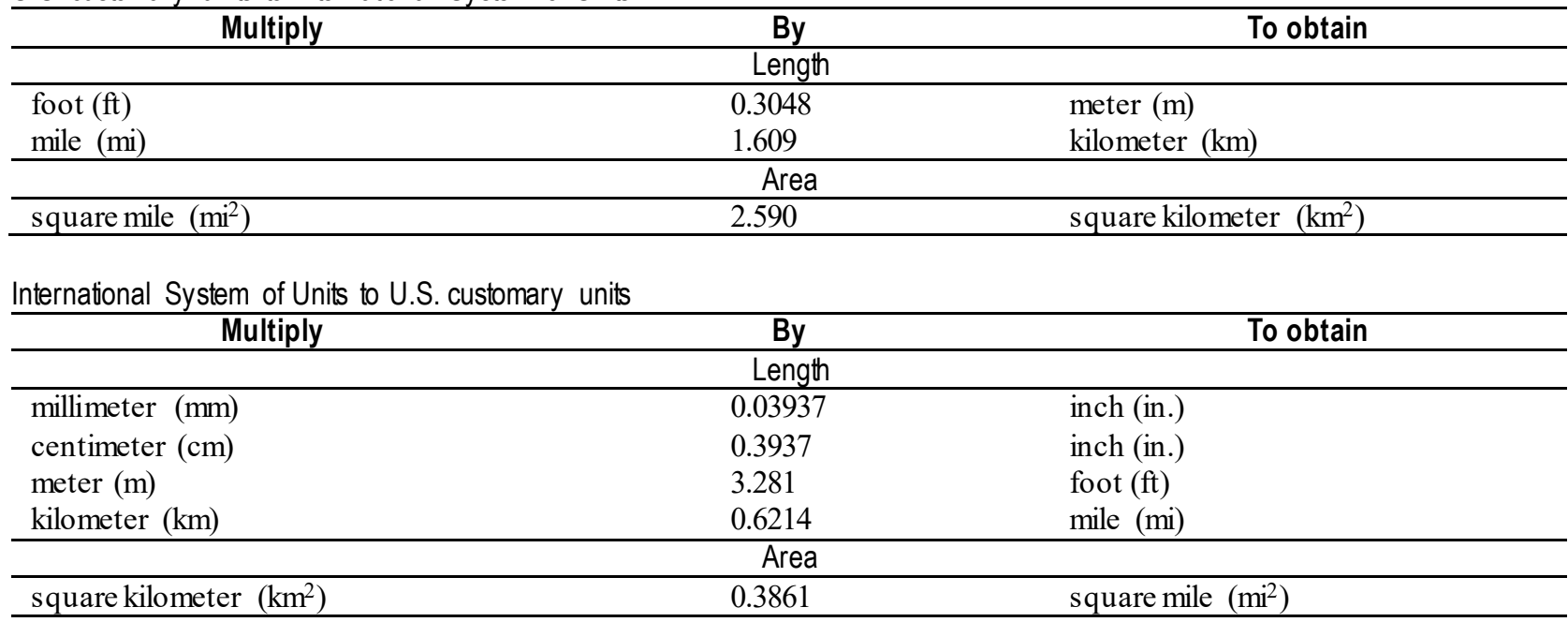

Temperature in degrees Celsius $\left({ }^{\circ} \mathrm{C}\right)$ may be converted to degrees Fahrenheit $\left({ }^{\circ} \mathrm{F}\right)$ as follows:

$$
{ }^{\circ} \mathrm{F}=\left(1.8 \times{ }^{\circ} \mathrm{C}\right)+32 \text {. }
$$

\section{Datum}

Vertical coordinate information is referenced to North American Vertical Datum of 1988 (NAVD 88).

Elevation, as used in this report, refers to distance above the vertical datum.

\section{Abbreviations}

BY brood year, defined as year when a spawning season begins

RM river mile, defined as the distance from the mouth of the river

RY run year, defined as the year when adult fish return to freshwater to spawn

LFA limiting factors analysis

LW large wood

WY Water year, defined as the 12-month period from October 1, for any given year, through September 30 , of the following year. The water year is designated by the calendar year in which it ends. 
This page intentionally left blank. 


\section{Life-History Model for Sockeye Salmon (Oncorhynchus nerka) at Lake Ozette, Northwestern Washington-Users' Guide}

By Andrea Woodward ${ }^{1}$, Mike Haggerty ${ }^{2}$, and Patrick Crain ${ }^{3}$

\section{Introduction}

Salmon populations spawning in the Lake Ozette watershed of northwestern Washington were once sufficiently abundant to support traditional Tribal fisheries, and were later harvested by settlers (Swindell, 1941; Gustafson and others, 1997). However, in 1974 and 1975, the sockeye salmon (Oncorhynchus nerka) harvest decreased to 0 from a high of more than 17,500 in 1949 (Washington Department of Fisheries, 1955), thus stimulating research into the causes of decrease, which resulted in eventual listing of the population as threatened under the Endangered Species Act in 1999 (National Oceanic and Atmospheric Administration, 1999). The listing status was upheld in 2005 (National Oceanic and Atmospheric Administration, 2005) and 2014 (National Oceanic and Atmospheric Administration, 2014) following 5-year reviews. Meanwhile, research results were compiled in a limiting factors analysis (LFA; Haggerty and others, 2009) and a recovery plan was developed (National Marine Fisheries Service, 2009). Although there has been some improvement in sockeye abundance since listing, the numbers remain too low to allow harvest and it is not yet clear which of the many potential limiting factors are most consequential.

As part of the LFA process, a population model was developed to determine values of lifehistory parameters that would enable the population to survive for 100 years. The model was based on the best available data, but data are limited for the Lake Ozette system. Results informed the qualitative assessment of the importance of limiting factors used to develop the recovery plan for Lake Ozette sockeye (National Marine Fisheries Service, 2009). The model was built in Microsoft Excel ${ }^{\circledR}$ and is difficult to use. The purpose of the model described herein is to synthesize the results of the LFA in a form that can be manipulated by resource managers and the public to create scenarios, test hypotheses, and observe sensitivities of results to changes in parameters. The goal is to provide a tool that enables research, monitoring and management to be focused on the most impactful elements and processes, including identifying the information gaps that are most critical to fill.

\footnotetext{
${ }^{1}$ U.S. Geological Survey.

${ }^{2}$ Haggerty Consulting.

3 National Park Service.
} 


\section{Background}

Lake Ozette is located on the coastal plain just inland of the Pacific Ocean in the northwestern corner of the Olympic Peninsula of Washington (fig. 1; Haggerty and others, 2009). The lake has surface area $11.8 \mathrm{mi}^{2}$, a maximum depth of $320 \mathrm{ft}$, and a surface elevation of $30.8 \mathrm{ft}$ to $41.5 \mathrm{ft}$ above the North American Vertical Datum of 1988 (NAVD 88). It has a monomictic circulation regime and an oligotrophic-to-mesotrophic nutrient supply (Beauchamp and others, 1995). The Lake Ozette watershed (88.4 $\mathrm{mi}^{2}$ ) encompasses multiple small and large tributaries, including Umbrella Creek and Big River, where two streamside hatchery rearing facilities are located. The lake drains to the Pacific Ocean through the 5.3-mi long, low-gradient, meandering Ozette River. Most of the watershed occupies gently sloping glacial deposits that fill between low hills of sedimentary rock. Larger eastern tributaries (for example, Big River) originate in steep volcanic flows and breccias.

The climate of the Olympic Peninsula is classified as temperate coastal marine, characterized by cool, relatively dry summers and mild wet winters with an average annual precipitation (1980-2010) of 100 to 120 in at Lake Ozette (PRISM Climate Group, 2019). The low-elevation terrain of the watershed means that the flow regime is rain-dominated owing to little snow storage. Vegetation resulting from the maritime climate is typified by temperate rain forest conifer and hardwood tree species with a dense understory. 


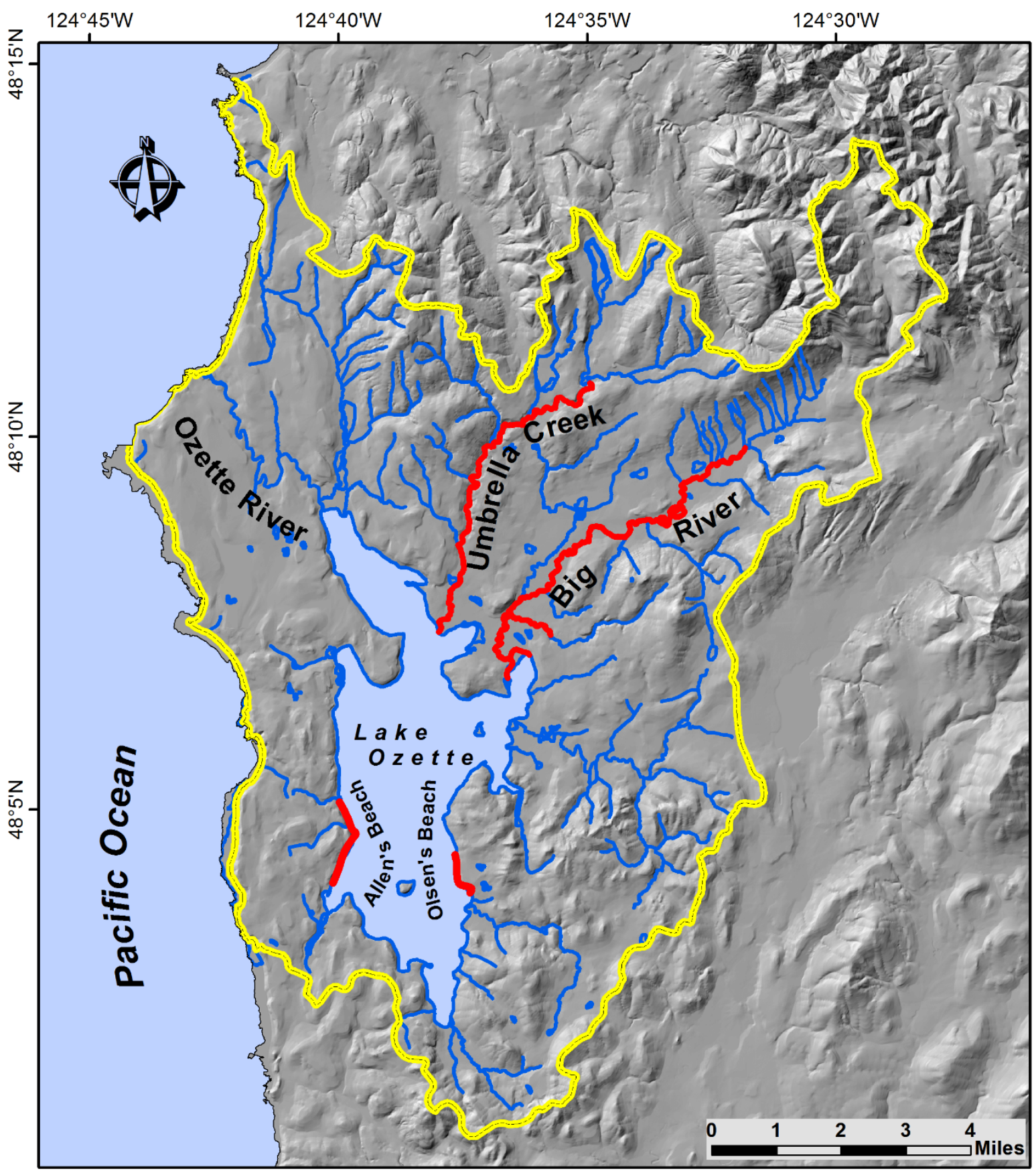

\section{Legend}
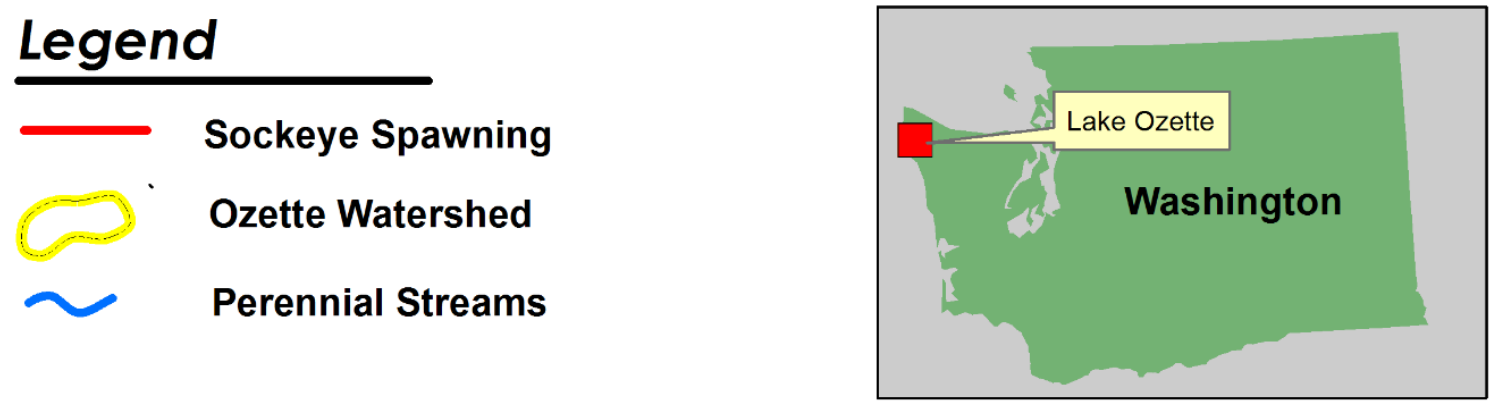

Figure 1. Map showing geography and sockeye salmon (Oncorhynchus nerka) spawning areas of Lake Ozette, northwestern Washington (Haggerty and others, 2009). 
For thousands of years, the area near Lake Ozette was populated by native peoples (Wray, 1997). They fished Lake Ozette, the Ozette River, and lake tributaries, and burned several prairies to attract game such as elk (Cervus elaphus roosevelti) and deer (Odocoileus hemionus) (Swindell, 1941). Although these activities had some environmental effect, there is no evidence of significant anthropogenic disturbance prior to European settlement, which began in the mid-1800s.

Land ownership in the Lake Ozette watershed recently (2009) was described as distributed among private (73 percent), Olympic National Park (15 percent), Washington (11 percent), and Tribal (1 percent) owners, of which 81 percent was zoned as commercial forest land and 84.6 percent was clearcut by 2003 (Haggerty and others, 2009). Although the natural disturbance regime primarily is owing to wind and hydrogeomorphic events caused by winter storms, anthropogenic disturbances now dominate the system. These disturbances include timber harvest, road construction and maintenance, residential and agricultural development, recreational activities, channelization, and direct and indirect wood clearance from waterways.

Sockeye salmon is one of 7 salmonid taxa and 26 total fish species present in the Lake Ozette system (Gustafson and others, 1997; Makah Fisheries Management, 2000). Adult sockeye immigration from the ocean peaks in mid-June, and after a short trip up the Ozette River, fish hold for about 6 months in the lake. They reside below the thermocline at depths of 30-100 ft until the lake destratifies at the onset of the wet season in October. Some fish migrate up tributaries where they spawn primarily in riffles and glides, usually in November. The present-day (2019) tributary spawning population was reestablished beginning in 1983 through artificial propagation of beach spawners. Tributary fry emerge in 100-130 days. Beginning in November, other sockeye spawn at lake beaches (specifically Olsen's Beach and Allen's Beach), where they prefer spawning in areas with upwelling groundwater that passes through small gravel and sand. Because the beach environment is slightly warmer than in the tributaries, fry emerge in 100 days with peak dispersal from late March to late April. Tributary fry disperse to the lake in mid- to late April and join beach fry in the limnetic zone (Haggerty and others 2009). Hatchery fry have been released at various times and places over the years, but release dates generally are later than the wild fry dispersal period (Makah Fisheries Management, 2015). The relative abundance of fry that are from natural tributary spawning, tributary hatchery releases, and beach spawning is thought to be 60:20:20, respectively (expert opinion based on National Marine Fisheries Service, 2015). Fry feed primarily on the zooplankton Daphnia pulicaria, and secondarily on benthic invertebrates, adult insects, and copepods for about 1 year until the spring following emergence. There are no reliable estimates of the relative abundance of lake-rearing fry by origin or their survival. Smolts then emigrate to the ocean, after which little is known about their movements. Based on other sockeye populations, it is suspected that they stay within the coastal belt during early ocean rearing, moving offshore in late autumn or winter (Hartt and Dell, 1986). Most spend 2 years at sea before returning to Lake Ozette, but some may return after 1 year and others stay in the ocean for 3 years. Lake Ozette sockeye are notable for their large smolt size (11.3-13.0 cm fork length; Blum, 1988; Jacobs and others, 1996) and relatively high ocean survival rate (15-17 percent; Haggerty and others, 2009).

Monitoring and hatchery management of Lake Ozette sockeye salmon are conducted by the Fisheries Management staff of the Makah Tribe. Returning adults were counted at a weir located near the outlet of the Lake Ozette at RM 4.8 on the Ozette River from 1977 to 2017 until the physical structure was replaced by an acoustic counting system in 2018. The emigrating smolt population is estimated using a screw trap at the same location. Production of fry occurs at the Umbrella Creek hatchery $(0.1 \mathrm{mi}$ up a tributary at RM 4.5 of Umbrella Creek) and the Stony Creek acclimation site $(0.1$ mi up a tributary at RM 7.2 of Umbrella Creek). An approximate total of 200,000 fry are annually released into Umbrella Creek and Big River. 


\section{Model Description}

\section{Overview}

The Lake Ozette sockeye life cycle model was built using a system dynamics format (Ford, 1999), which consists of three basic elements: (1) stocks, (2) flows, and (3) converters. Stocks are measurable quantities that can change over time, such as numbers of animals in populations. Flows are any processes or conditions that change the quantity in a stock over time and are expressed in the model as a rate of change. Converters are processes or conditions that change the rate of flows. Anything that influences the rate of change (such as environmental conditions, other external factors, or feedbacks from other stocks or flows) is modeled as a converter. For example, the number of fish in a population is appropriately modeled as a stock. Mortality is modeled as a flow because it is a rate of change over time that determines the number of fish in the population. The effect of predation is modeled as a converter because it influences the rate of mortality. Taken together, the flows and converters change the number (stock) of sockeye. The instructions embedded in the stocks, flows, and converters, and the linkages among them are processed by the simulation software. Unfortunately, the standard terms used for system dynamic models can be confusing when used for fisheries, where the terms "stock" and "flow" have other meanings.

The Lake Ozette sockeye model is implemented using Stella Architect ${ }^{\circledR}$ version 1.6.2 system dynamics software (http $/ / \mathrm{www}$. iseesystems.com) and is based on a conceptual model of the Lake Ozette sockeye life cycle (fig. 2) modified from that presented in the LFA. The conceptual model describes 13 life stages (stocks) with flows between pairs of them representing survival. Factors that affect survival are listed in the conceptual model and modeled in Stella Architect ${ }^{\circledR}$ as converters. These factors were based on those identified for each life stage in the LFA as described for each stage in the report sections that follow (beginning with section, "Adult River Migration"). The model includes the entire life cycle of one cohort from adults returning to spawn through their returning progeny. It does not follow the progeny through another life cycle.

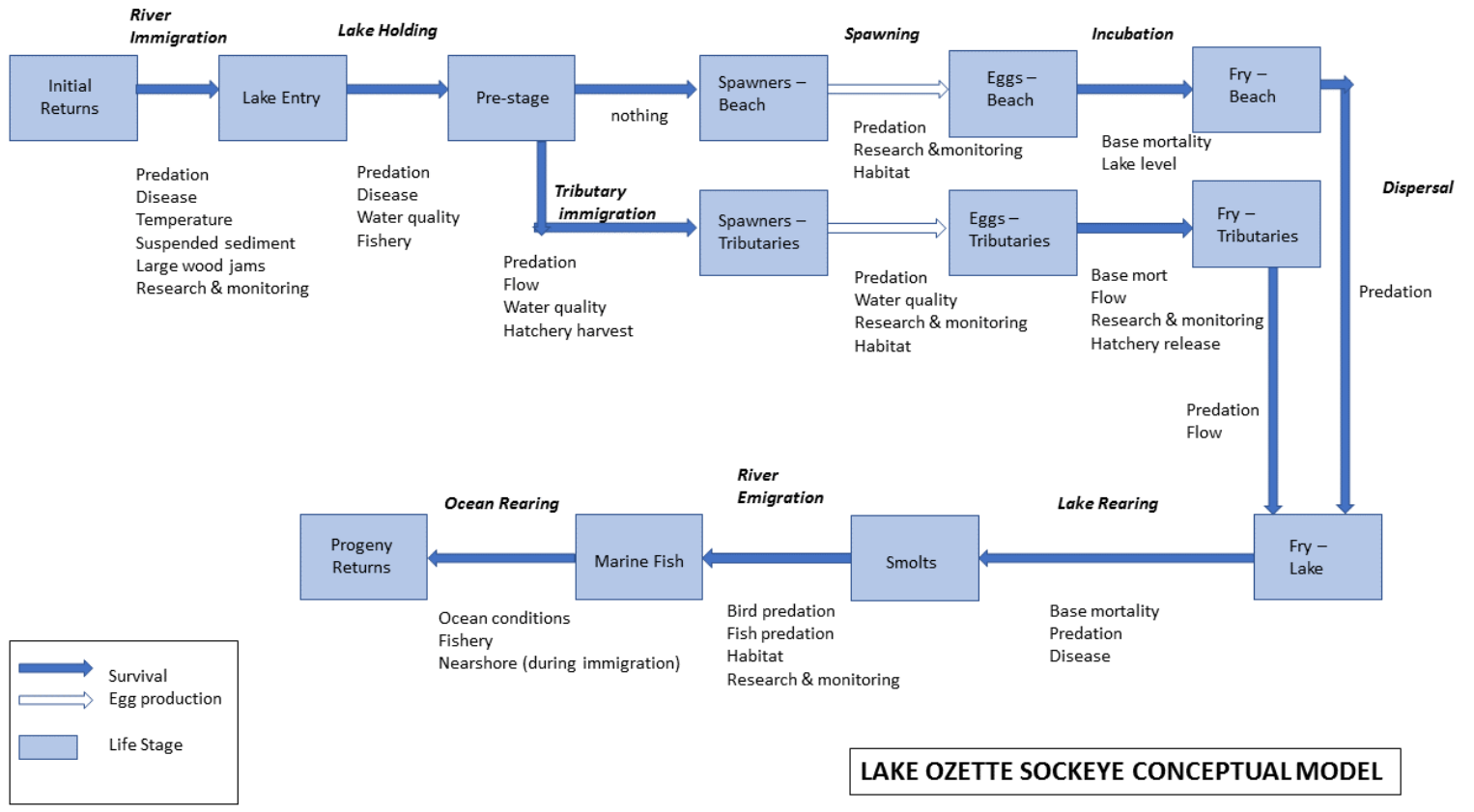

Figure 2. Conceptual model of the Lake Ozette sockeye salmon (Oncorhynchus nerka) life cycle including life stages, survival between stages, and factors that affect survival. 
The model can be accessed at https:/exchange. iseesystems.com/public/andreawoodward/lakeozette-sockeye/index.html\#page1. The web site opens to a title page (see cover of this report) with buttons that allow access to model documentation, the LFA, the conceptual model, and two model dashboards - one that is comprehensive (technical dashboard; fig. 3) and one that includes parameters considered of most interest to resource managers (management-oriented dashboard). Each page of the two dashboards (1 page for Management Dashboard; 3 pages for Technical Dashboard) allows the user to run the model and see the contents of each stock after entering the number of returning fish and changing desired parameters by entering new numbers in the "Value" fields. Default parameters can be easily reset using the "Restore" button. Output from each run is displayed on each page of the dashboard and can be downloaded to a spreadsheet using the "Export Data" button. Details of the model dashboard for each life stage follow, including a summary of modeling approach, screenshot of relevant dashboard section, and definitions of terms. A brief justification for model structure and default parameters is available in section, "Model Background/Justification." Full justification for the model structure and supporting science is available in the LFA, which can be accessed from the title page that displays upon opening the model. The full model and technical dashboard are described first, followed by a brief explanation of the management-oriented dashboard. Most factors on the dashboard are proportions (prop.), meaning a positive or negative value in the range of $0-1$. A diagram of the model structure as it appears in Stella Architect ${ }^{\circledR}$ is shown in appendix 1; model equations are shown in appendix 2.

Note to Users: Many of the factors affecting salmon mortality are set to 0 as the default value; consequently, the default version of the model may show productivity higher than what is occurring in life.

Users also should be aware that data describing environmental aspects of the Lake Ozette system generally are collected over short time periods that are not coordinated among studies. Moreover, many parameters have never been described. Additionally, fish are counted as they enter and leave the freshwater system, and nothing is known about intermediate population numbers. Therefore, the model essentially is a framework for integrating available parameter values with hypothetical numbers to determine which are most consequential for population recovery. One of the potential uses of the model is the identification of areas where more information is needed. 


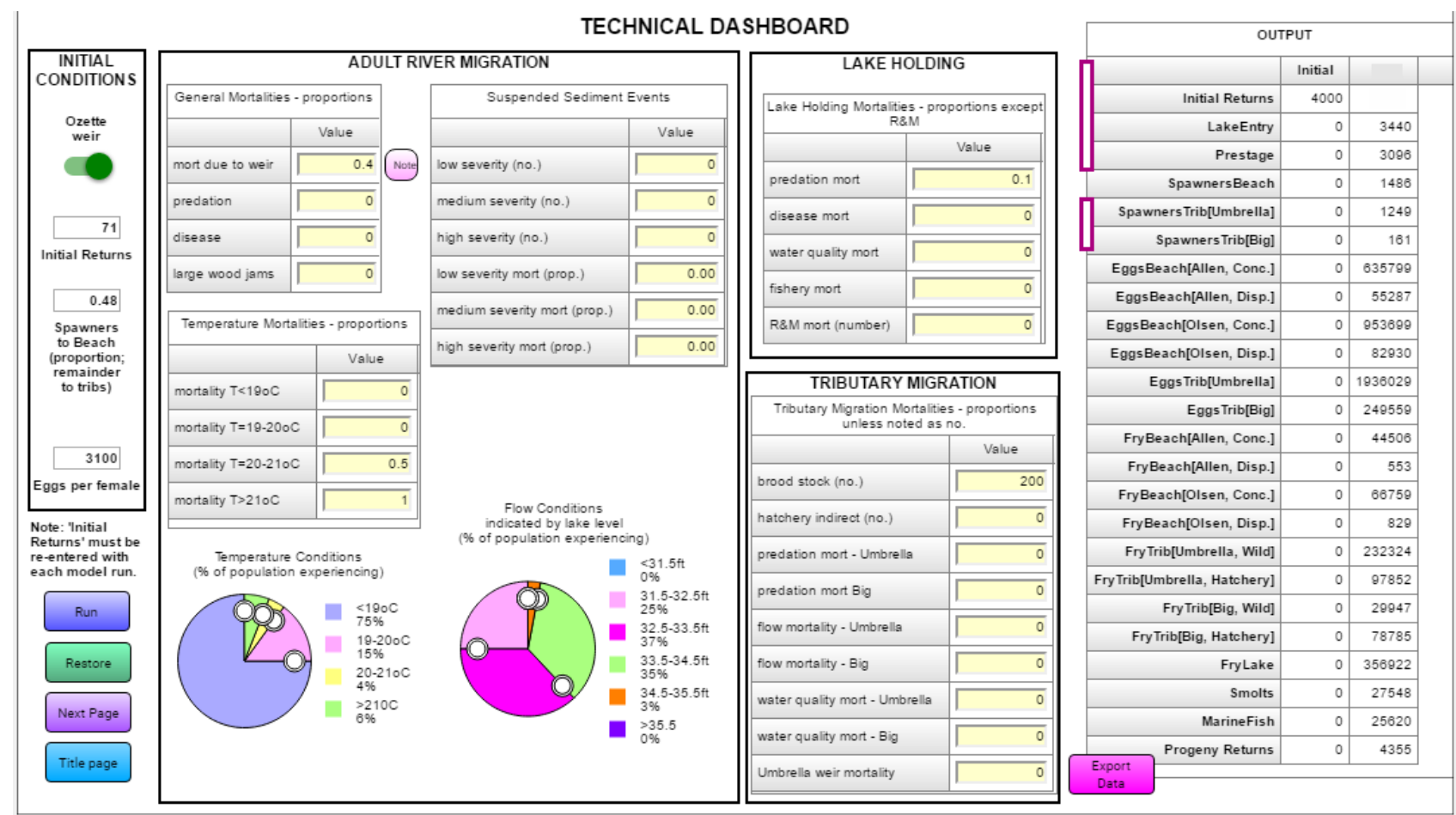

Figure 3. Screen capture showing first page (of three pages) of technical dashboard for Lake Ozette sockeye salmon model.

\section{Initial Conditions}

Before each model run, the user must enter the number of adult salmon returning to spawn to initialize the "Initial Returns" stock (fig. 4). The minimum number of returning fish is limited to 500 because the model does not attempt to simulate population dynamics at very low numbers of fish. The maximum number of returning fish allowed is 31,000 , which is the restoration goal. The user also can determine whether the weir at the lake outlet is present, the proportion of adult salmon that will spawn on beaches compared to tributaries, and the number of eggs per female. These latter values will carry from one model run to the next unless changed by the user. The default value of 20:80 for beach-totributary spawners is based roughly on run and escapement numbers presented in National Marine Fisheries Service (2015), as modified to account for differential mortality of beach compared to tributary spawners.

Throughout the model, the sex ratio is assumed to be 50:50 and mortality factors are not expected to differentiate between sexes. We have no empirical evidence to suggest this is not a reasonable assumption.

Although the Ozette River weir at the lake outlet likely has been phased out, data on productivity and mortality as a function of run size represent the situation with the weir present. The user can adjust the effect of the weir on mortality (see section, "Model Description: Adult River Migration") and remove the weir (fig. 4). Population dynamics observed in coming years can be used to evaluate the effect of the weir on productivity. 
The default value for eggs per female $(3,100)$ is based on the average fecundity of $3,097 \pm 91$ eggs per female for brood stock collected at the Umbrella Creek hatchery from 1986 to 1998 (size of fish was not reported; Makah Fisheries Management, 2000). This is slightly lower than most other estimates of sockeye fecundity, including, 3,544 for females spending 2 years in the ocean and returning to Vancouver Island (Manzer and Miki, 1986), and general sockeye fecundity of 3,500 (Groot and Margolis, 1991). However, Blum (1988) estimated effective fecundity to be 3,000 for Lake Ozette sockeye salmon.

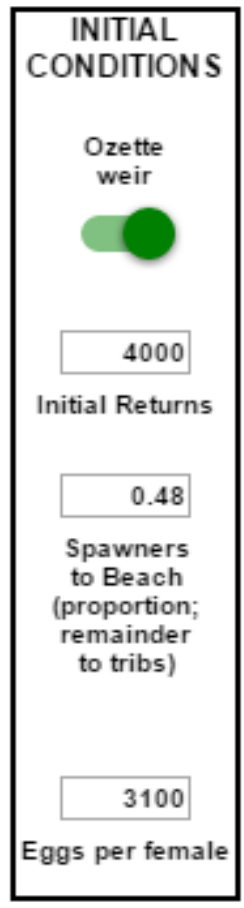

Figure 4. Screen capture of "Initial Conditions" section of dashboard for Lake Ozette sockeye salmon. tribs., tributaries. 


\section{Output}

The Output table lists all stocks calculated by the model (see fig. 2 for list) and is available on each page of the dashboards (fig. 5). Numbers of returning adults in the "Initial Returns" stock are listed on the first line of the "Initial" column, and values for all other stocks display in the adjacent column. The pink bars indicate which part of the output should be affected by parameters shown on the same page as each output table, but the numbers in the table are consistent across pages.

Results can be exported to an Excel ${ }^{\circledR}$ spreadsheet by clicking the "Export Data" button and browsing to the filename of an existing .csv file (established prior to exporting data). Open the .csv file using Excel ${ }^{\circledR}$ and the Import menu. On the first page of the menu, indicate "Delimited"; on the second page, add "Comma" to the list of delimiters; and on the third page, indicate "General". Clicking "Finish" will complete the export process. A new round of results must be exported to a different file or else new results will be written over previous results.

\begin{tabular}{|c|c|c|}
\hline \multicolumn{3}{|c|}{ OUTPUT } \\
\hline & Initial & \\
\hline Initial Returns & 4000 & \\
\hline LakeEntry & 0 & 3440 \\
\hline Prestage & 0 & 3096 \\
\hline SpawnersBeach & 0 & 1486 \\
\hline Spawners Trib[Umbrella] & 0 & 1248 \\
\hline SpawnersTrib[Big] & 0 & 161 \\
\hline EggsBeach[Allen, Conc.] & 0 & 635798 \\
\hline EggsBeach[Allen, Disp.] & 0 & 55287 \\
\hline EggsBeach[Olsen, Conc.] & 0 & 853698 \\
\hline EggsBeach[Olsen, Disp.] & 0 & 82930 \\
\hline EggsTrib[Umbrella] & 0 & 1936028 \\
\hline EggsTrib[Big] & 0 & 249558 \\
\hline FryBeach[Allen, Conc.] & 0 & 44506 \\
\hline FryBeach[Allen, Disp.] & 0 & 553 \\
\hline FryBeach[OIsen, Conc.] & 0 & 66758 \\
\hline FryBeach[Olsen, Disp.] & 0 & 828 \\
\hline FryTrib[Umbrella, Wild] & 0 & 232324 \\
\hline FryTrib[Umbrella, Hatchery] & 0 & 97852 \\
\hline FryTrib[Big, Wild] & 0 & 29947 \\
\hline FryTrib[Big, Hatchery] & 0 & 78785 \\
\hline FryLake & 0 & 356922 \\
\hline Smolts & 0 & 27548 \\
\hline MarineFish & 0 & 25620 \\
\hline Progeny Returns & 0 & 4355 \\
\hline $\begin{array}{l}\text { Export } \\
\text { Data }\end{array}$ & & \\
\hline
\end{tabular}

Figure 5. Screen capture of "Output" section of dashboard for Lake Ozette sockeye salmon model. Conc., concentrated; Disp., dispersed. 


\section{Adult River Migration}

\section{Summary of Model Approach}

The model first calculates adult migrant mortality owing to predation, which is a function of run size, weir presence, exposure to predation owing to water level, and prevailing abundance of large wood (LW) jams. The predation mortality function is thought to describe levels of predation observed over recent decades and indicates prevailing numbers of predators and exposure to predation during migration, including increased predation owing to the weir. Finally, the model adjusts mortality owing to changes in abundance of LW jams, disease, temperature, suspended sediment, and changes in predation from baseline (for example, to describe a change in the predator population; fig. 6). Clicking on "Note" button displays documentation regarding weir mortality. 


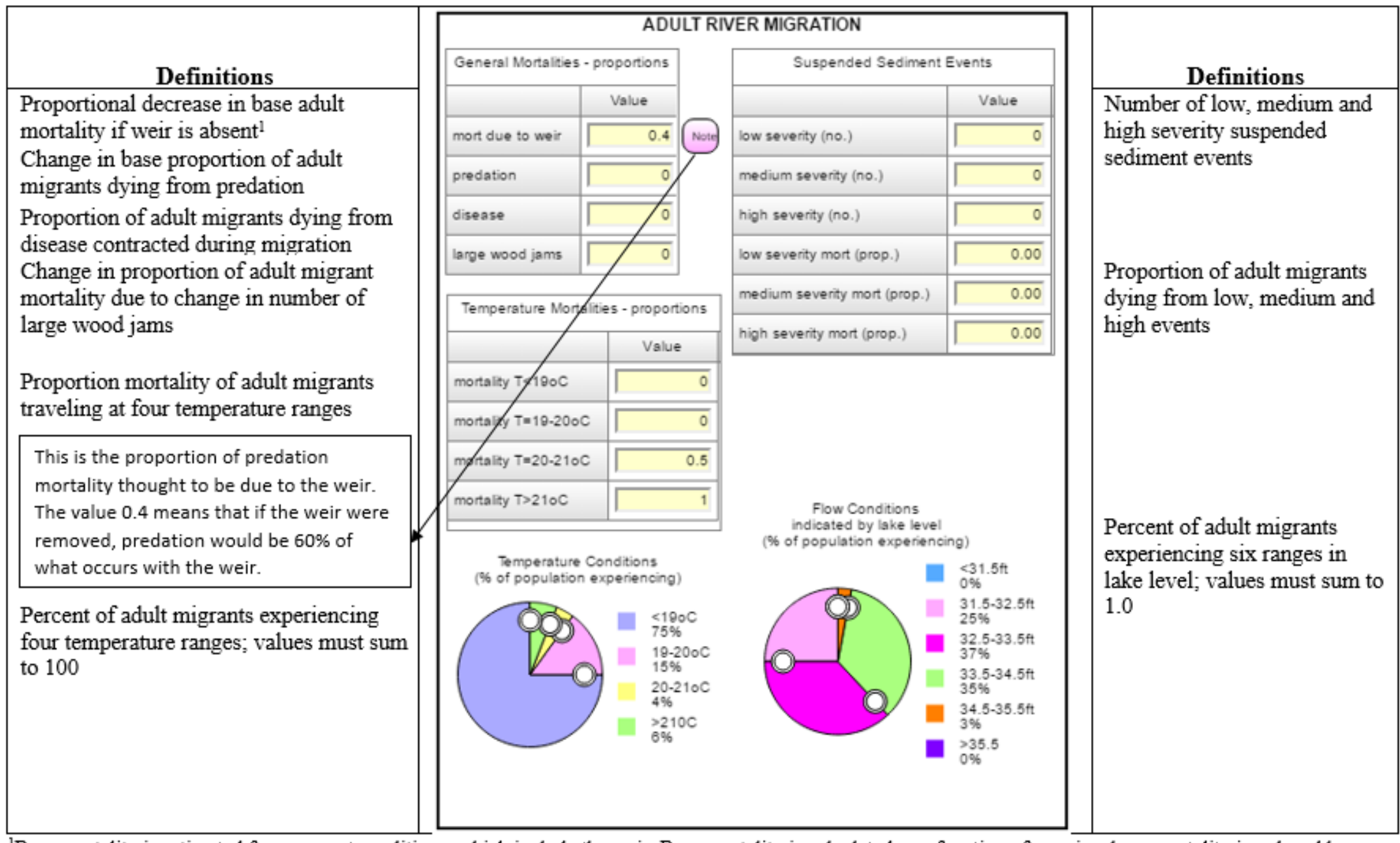

${ }^{1}$ Base mortality is estimated from current conditions, which include the weir. Base mortality is calculated as a function of run size; base mortality is reduced by a constant proportion if the weir is absent, rather than by a constant number across all run sizes.

Figure 6. Screen capture of "Adult River Migration" section of technical dashboard and definitions of terms for Lake Ozette sockeye salmon model. $\mathrm{ft}$, foot; ${ }^{\circ} \mathrm{C}$, degrees Celsius; \%, percent; <, less than. 


\section{Lake Holding}

\section{Summary of Model Approach}

The model adjusts the number of fish entering the lake by mortality rates representing predation, disease, poor water quality (that is, high water temperature), the Lake Ozette fishery, and research and monitoring activities (fig. 7). The resulting fish are segregated into the categories of beach and tributary spawners based on the proportion provided under initial conditions (fig. 4).

Model Dashboard

\begin{tabular}{|c|c|}
\hline \multicolumn{2}{|c|}{ LAKE HOLDING } \\
\hline \multicolumn{2}{|c|}{$\begin{array}{l}\text { Lake Holding Mortailies - proportions except } \\
\text { R\&M }\end{array}$} \\
\hline & Value \\
\hline predation mort & 0.1 \\
\hline disease mort & 0 \\
\hline water quality mort & 0 \\
\hline fishery mort & 0 \\
\hline R\&M mort (number) & 0 \\
\hline
\end{tabular}

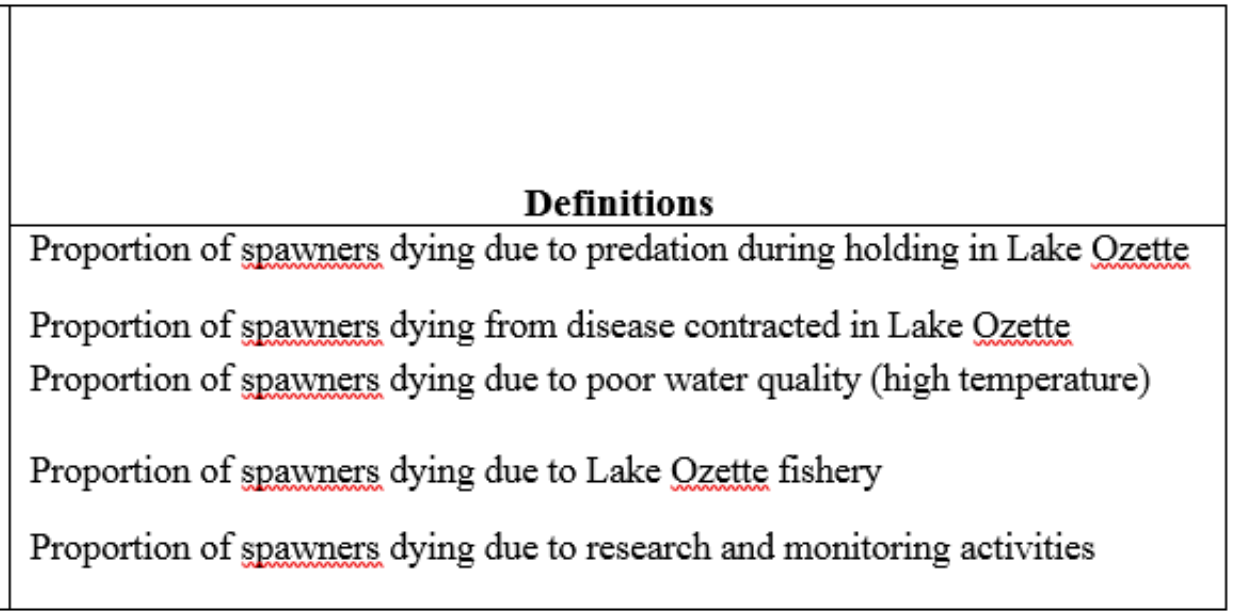

Figure 7. Screen capture of "Lake Holding" section of technical dashboard and definitions of terms for Lake Ozette sockeye salmon model. 


\section{Tributary Migration}

\section{Summary of Model Approach}

The model separately accounts for tributary spawners that migrate up Umbrella Creek compared to Big River. The model adjusts spawner numbers for the mortality rate owing to predation, streamflow, water quality (high suspended sediment concentrations), and research and monitoring (weir). Numbers of fish harvested for hatchery brood stock are subtracted (fig. 8).

Model Dashboard

\begin{tabular}{|l|r|}
\hline \multicolumn{2}{|c|}{ TRIBUTARY MIGRATION } \\
\hline \multicolumn{2}{|c|}{$\begin{array}{c}\text { Tributary Migration Mortalities - proportions } \\
\text { unless noted as no. }\end{array}$} \\
\hline \multicolumn{2}{|c|}{ Value } \\
\hline brood stock (no.) & 200 \\
\hline hatchery indirect (no.) & 0 \\
\hline predation mort - Umbrella & 0 \\
\hline predation mort Big & 0 \\
\hline flow mortality - Umbrella & \\
\hline flow mortality - Big & 0 \\
\hline water quality mort - Umbrella & \\
\hline water quality mort - Big & 0 \\
\hline Umbrella weir mortality & \\
\hline
\end{tabular}

\begin{tabular}{l} 
Definitions \\
$\begin{array}{l}\text { Number of fish harvested for hatchery brood stock } \\
\text { Number of fish killed by management activities not including harvested brood stock } \\
\text { Proportion of spawners dying from predation in Umbrella Creek } \\
\text { Proportion of spawners dying from predation in Big River } \\
\text { Proportion of spawners dying due to low flow conditions in Umbrella Creek } \\
\text { Proportion of spawners dying due to low flow conditions in Big River } \\
\text { Proportion of spawners dying due to high suspended sediment events in Umbrella Creek } \\
\text { Proportion of spawners dying due to high suspended sediment events in Big River } \\
\text { Proportion of spawners dying due to presence of weir }\end{array}$ \\
\hline
\end{tabular}

Figure 8. Screen capture of "Tributary Migration" section of technical dashboard and definitions of terms for Lake Ozette sockeye salmon model. 


\section{Spawning - Beaches}

Summary of Model Approach

The model separately accounts for spawning at concentrated compared to dispersed spawning areas at either Olsen's Beach or Allen's Beach. The model adjusts spawner numbers for the mortality rate owing to predation during staging and spawning. The model determines egg production from number of spawners, carrying capacity for redds based on area available and redd density, and expected eggs per female (set as an initial condition). Egg number is reduced by mortality owing to research and monitoring activities (fig. 9). 
Model Dashboard

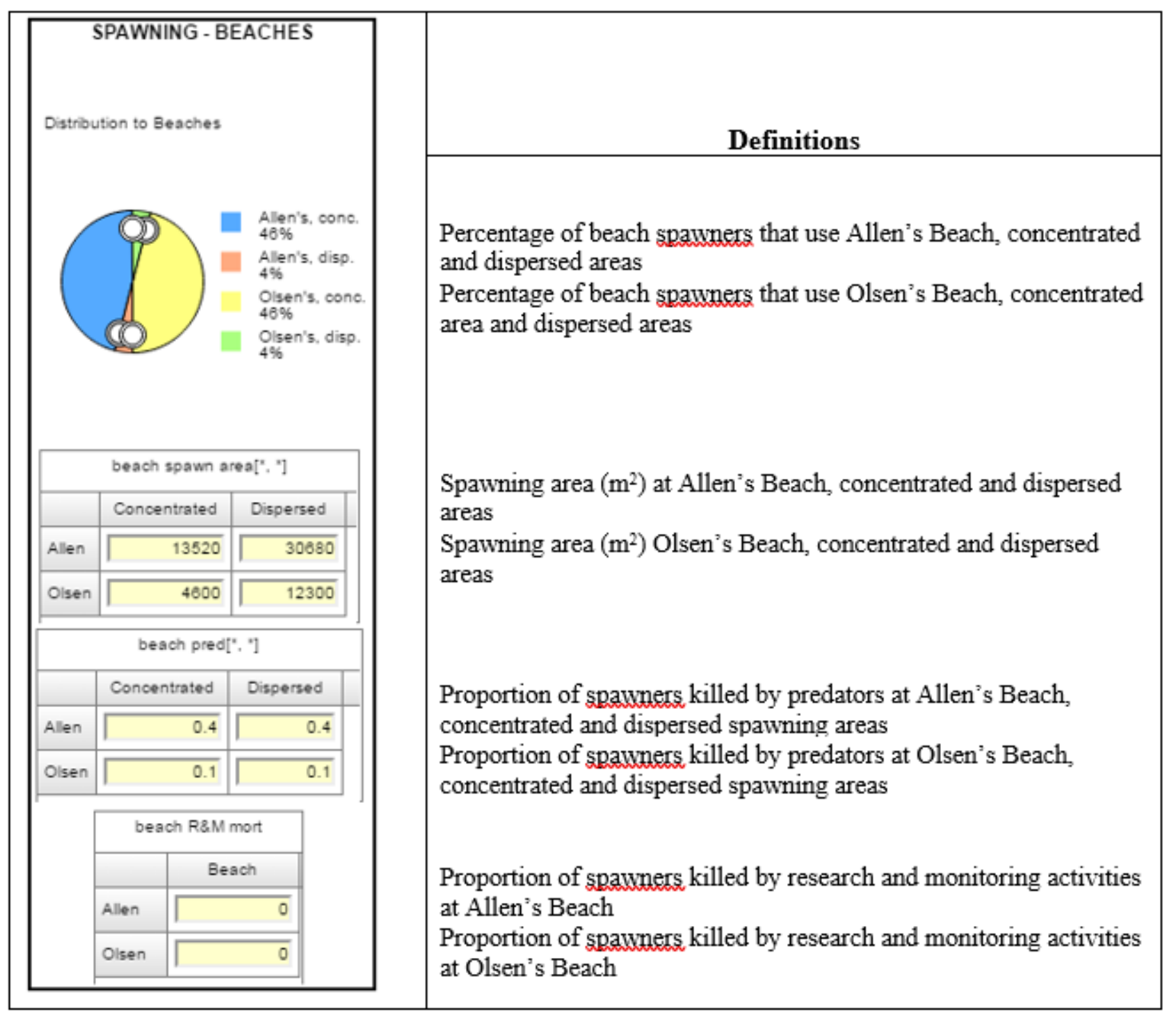

Figure 9. Screen capture of "Spawning - Beaches" section of technical dashboard and definitions of terms for Lake Ozette sockeye salmon model. $\mathrm{m}^{2}$, square meter. 


\section{Spawning - Tributaries}

\section{Summary of Model Approach}

The model separately accounts for spawning at Umbrella Creek and Big River; the user can enter the proportion of the tributary spawners that migrate up each river. The proportions must sum to 1 (see "Note"). The model determines egg production from number of spawners, carrying capacity for redds based on area available and redd density, and expected eggs per female (set in "Initial Conditions", fig. 4). Egg number is reduced by mortality factors including egg predation, water quality (elevated suspended sediment concentrations), and research and monitoring activities (fig. 10). 


\section{Model Dashboard}

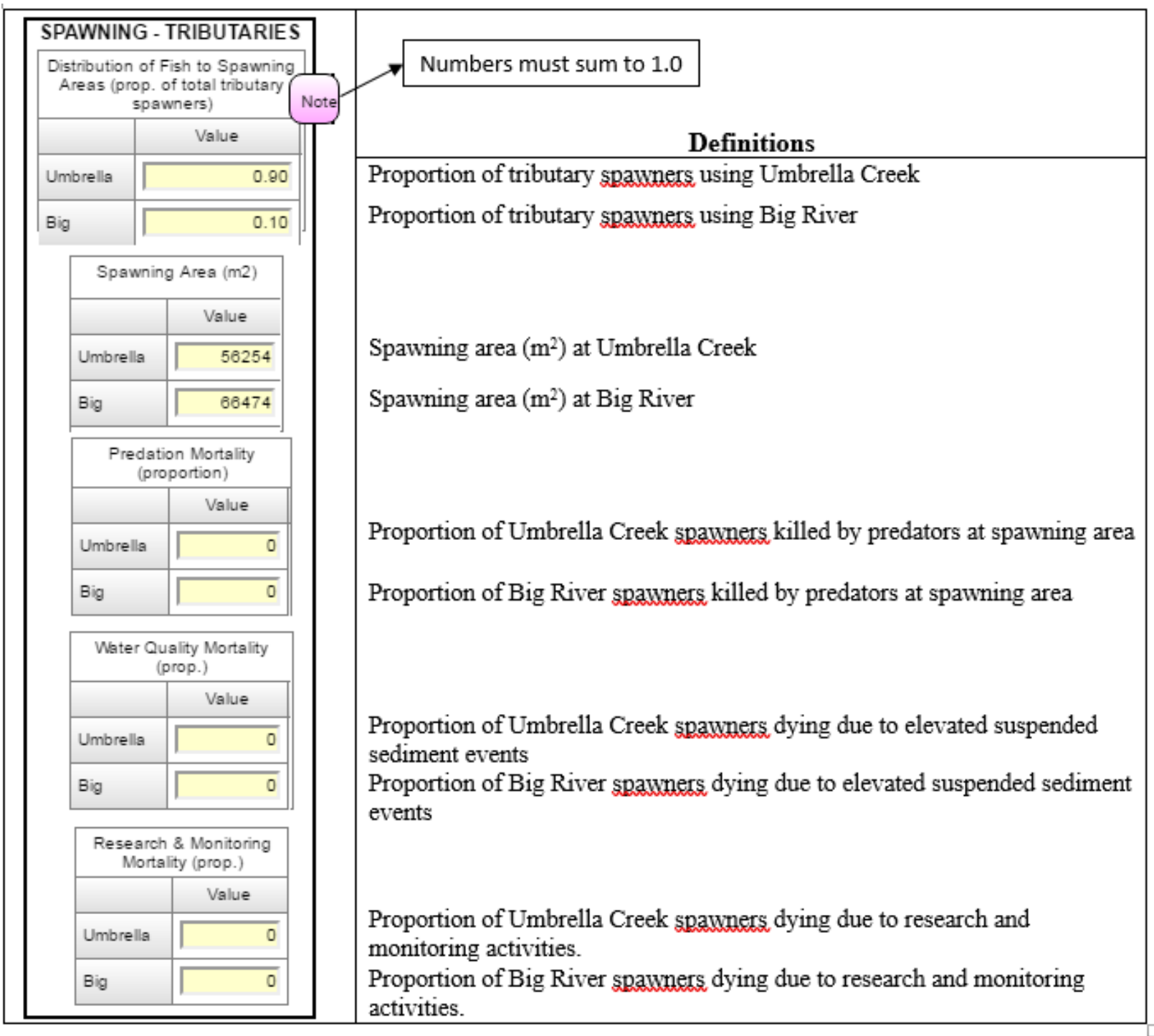

Figure 10. Screen capture of "Spawning - Tributaries" section of technical dashboard and definitions of terms for Lake Ozette sockeye salmon model. $\mathrm{m}^{2}$, square meter. 


\section{Incubation - Beaches}

Summary of Model Approach

The model determines fry production based on number of eggs adjusted for a base mortality, mortality owing to adverse lake level changes, and predation (fig. 11). 
Model Dashboard

\begin{tabular}{|c|c|c|c|}
\hline \multicolumn{3}{|c|}{ INCUBATION - BEACHES } & \multirow[b]{3}{*}{ Definitions } \\
\hline \multicolumn{3}{|c|}{ beach egg base mort[". "] } & \\
\hline & Concentrated & Dispersed & \\
\hline Allen & 0.93 & 0.98 & \multirow{4}{*}{$\begin{array}{l}\text { Proportion baseline mortality of eggs at Allen's Beach, concentrated and dispersed spawning areas } \\
\text { Proportion baseline mortality of eggs at Olsen's Beach, concentrated and dispersed spawning areas }\end{array}$} \\
\hline Olsen & 0.93 & 0.98 & \\
\hline \multicolumn{3}{|c|}{ beach egg lake level mort[". "] } & \\
\hline & Concentrated & Dispersed & \\
\hline Allen & 0 & 0 & \multirow{4}{*}{$\begin{array}{l}\text { Proportion of eggs dying due to low lake level at Allen's Beach, concentrated and dispersed areas } \\
\text { Proportion of eggs dying due to low lake level at Olsen's Beach, concentrated and dispersed areas }\end{array}$} \\
\hline Olsen & 0 & 0 & \\
\hline \multicolumn{3}{|c|}{ beach egg pred mort[", "] } & \\
\hline & Concentrated & Dispersed & \\
\hline Allen & 0 & 0 & \multirow{2}{*}{$\begin{array}{l}\text { Proportion of eggs killed by predators at Allen's Beach, concentrated and dispersed spawning areas } \\
\text { Proportion of eggs killed by predators at Olsen's Beach, concentrated and dispersed spawning areas }\end{array}$} \\
\hline Olsen & 0 & 0 & \\
\hline
\end{tabular}

Figure 11. Screen capture of "Incubation - Beaches" section of technical dashboard and definitions of terms for Lake Ozette sockeye salmon model. 


\section{Incubation - Tributaries}

\section{Summary of Model Approach}

The model determines fry production based on number of eggs adjusted for a base mortality and mortality owing to research and monitoring activities. Hatchery fry and fry produced using artificial redds are added. The user also can choose to include a scouring flow (flow equal to or greater than bank-full) event and determine the related mortality rate (fig. 12). 


\section{Model Dashboard}

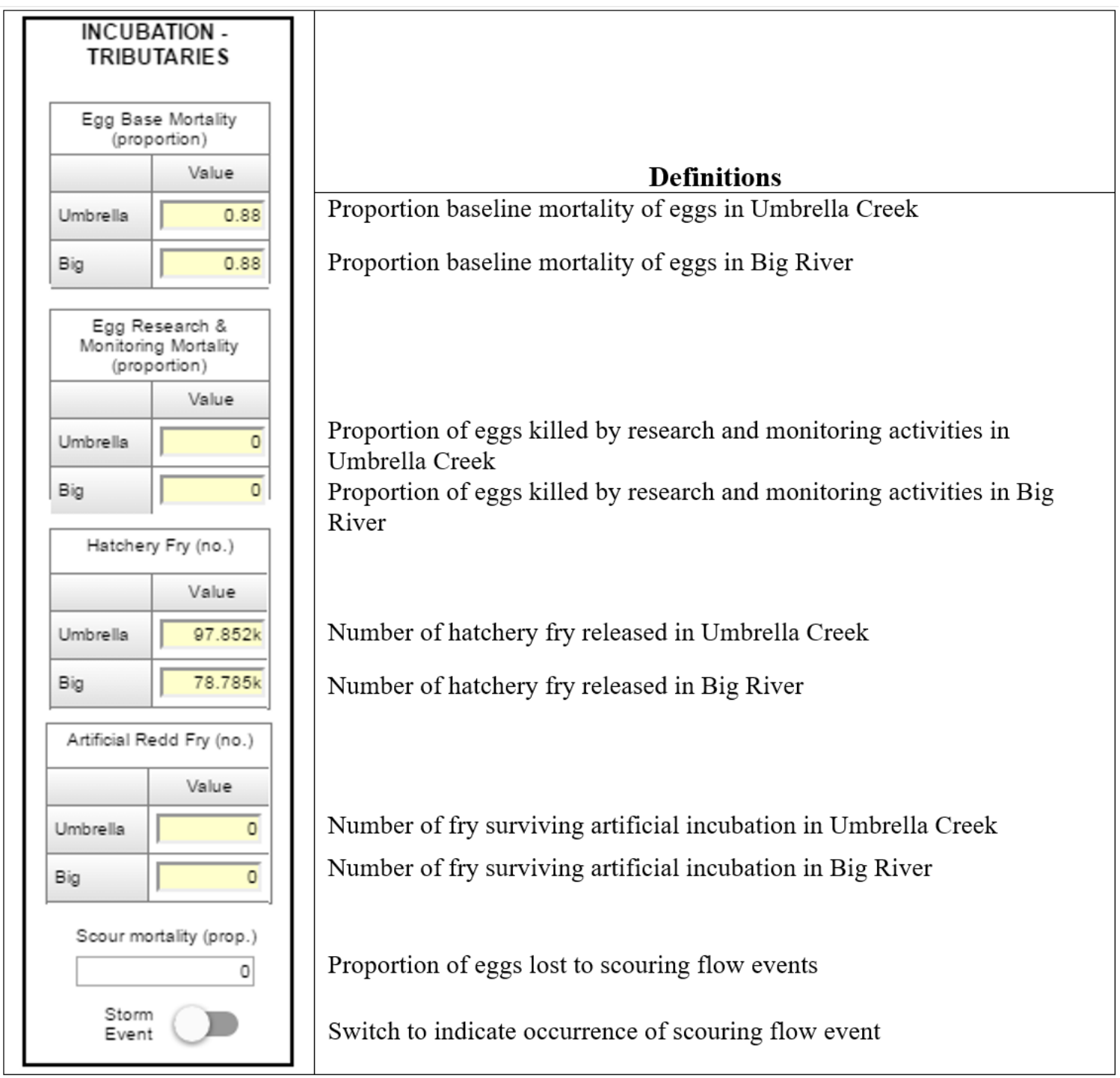

Figure 12. Screen capture of "Incubation - Tributaries" section of technical dashboard and definitions of terms for Lake Ozette sockeye salmon model. 


\section{Fry Dispersal - Beaches}

Summary of Model Approach

The model determines the number of fry entering the lake from the beaches by adjusting emergent fry for a base mortality that integrates mortality owing to predation, fine sediment, and lake-level changes (fig. 13). The effects of suspended sediment to entomb fry are covered under incubation (fig. 11).

Model Dashboard

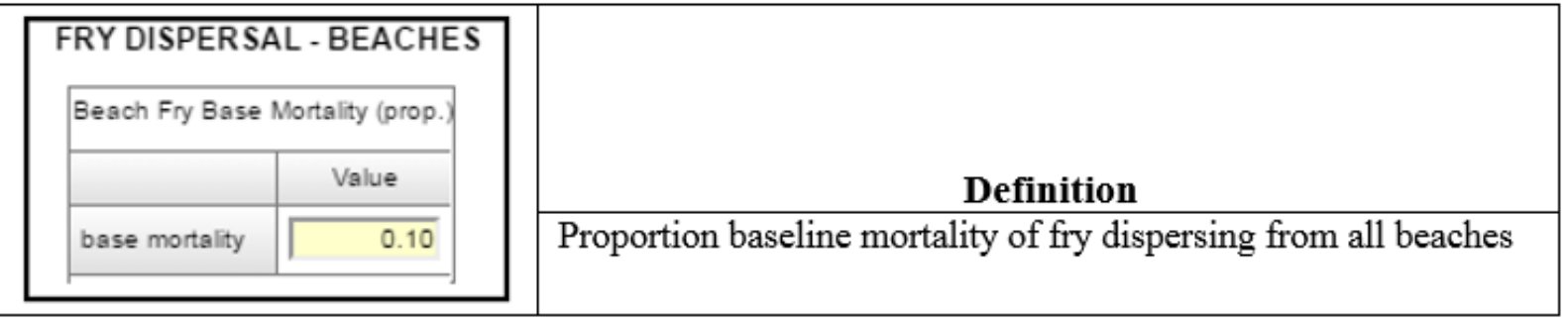

Figure 13. Screen capture of Fry "Dispersal - Beaches" section of technical dashboard and definition of term for Lake Ozette sockeye salmon model. 


\section{Fry Dispersal - Tributaries}

\section{Summary of Model Approach}

The model determines the number of fry entering the lake from the tributaries by adjusting emergent fry for the mortality rate owing to predation and low streamflow. Effects of low flow are separately determined for wild and hatchery fry originating in Umbrella Creek and Big River. Fry produced in artificial redds have the same mortality rate as wild fry and dispersal mortalities can be entered separately for hatchery fry to account for their larger size and potentially later timing of river entry (fig. 14).

\section{Model Dashboard}

\begin{tabular}{|c|c|c|c|}
\hline \multicolumn{3}{|c|}{ FRY DISPERSAL - TRIBUTARIES } & \multirow[b]{3}{*}{ Definitions } \\
\hline \multicolumn{3}{|c|}{$\begin{array}{l}\text { Tributary Fry Dispersal Predation Mortality } \\
\text { (proportion) }\end{array}$} & \\
\hline & Wild & Hatchery & \\
\hline Umbrells & 0.25 & 0.6 & \multirow{2}{*}{$\begin{array}{l}\text { Proportion of wild and hatchery fry killed by predators while dispersing from Umbrella Creek } \\
\text { Proportion of wild and hatchery fry killed by predators while dispersing from Big River }\end{array}$} \\
\hline Big & 0.25 & 0.1 & \\
\hline \multicolumn{3}{|c|}{ Tributary Fry Flow Mortality (proportion) } & \multirow{4}{*}{$\begin{array}{l}\text { Proportion of wild and hatchery fry dispersing from Umbrella Creek dying due to adverse or positive } \\
\text { flow events } \\
\text { Proportion of wild and hatchery fry dispersing from Big River dying due to adverse or positive flow } \\
\text { events }\end{array}$} \\
\hline & Wild & Hatchery & \\
\hline Umbrella & 0 & $\overline{0}$ & \\
\hline Big & 0 & 0.65 & \\
\hline
\end{tabular}

Figure 14. Screen capture of "Fry Dispersal - Tributaries" section of technical dashboard and definitions of terms for Lake Ozette sockeye salmon model. 


\section{Lake Rearing}

Summary of Model Approach

The model determines the number of fry surviving lake rearing by adjusting emigrating fry for the mortality rate owing to disease and base mortality. Predation is included as a function of run size, which primarily describes expected predator-prey dynamics. The calculated value can be overridden by entering a proportion in the dashboard (fig. 15).

\section{Model Dashboard}

\begin{tabular}{|c|c|c|}
\hline \multicolumn{2}{|c|}{ LAKE REARING } & \multirow[b]{3}{*}{ Definitions } \\
\hline \multicolumn{2}{|c|}{$\begin{array}{l}\text { Lake Juvenile Mortality Factors } \\
\text { (proportion) }\end{array}$} & \\
\hline & Value & \\
\hline base mortality & 0 & Base mortality proportion of juveniles rearing in Lake Ozette \\
\hline predation mortality & & Proportion of juveniles killed by predators during lake rearing \\
\hline disease mortality & 0 & Proportion of juveniles dying from disease during lake rearing \\
\hline
\end{tabular}

Figure 15. Screen capture of "Lake Rearing" section of technical dashboard and definitions of terms for Lake Ozette sockeye salmon model. 


\section{River Emigration}

Summary of Model Approach

The model determines the number of fish entering the ocean by adjusting the number of emigrating smolts for mortality rates owing to fish and bird predation, and research and monitoring activities (fig. 16).

\section{Model Dashboard}

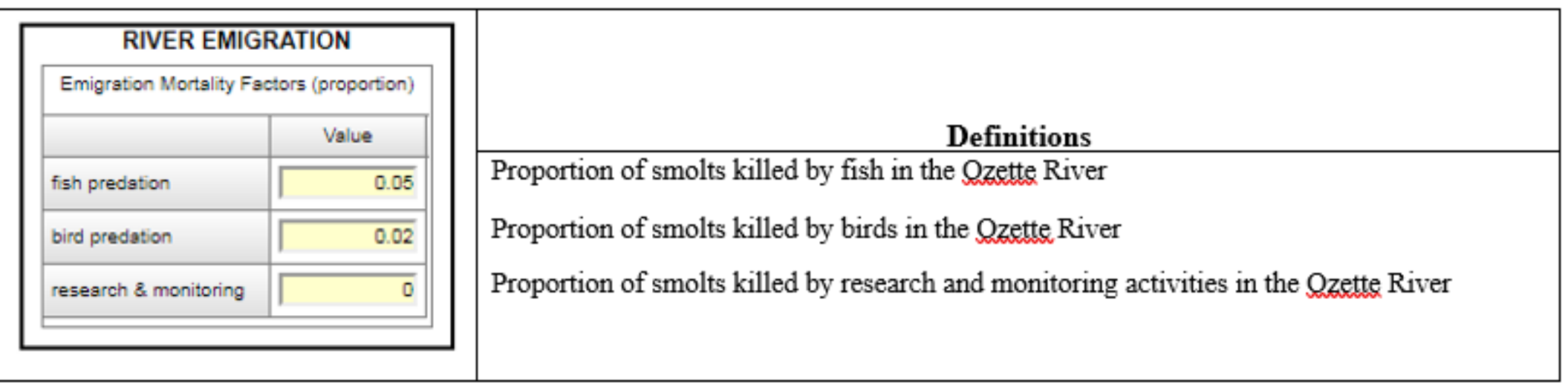

Figure 16. Screen capture of "Emigration" section of technical dashboard and definitions of terms for Lake Ozette sockeye salmon model. 


\section{Ocean Rearing}

Summary of Model Approach

The model determines the number of fish returning from ocean rearing by adjusting the number of fish entering the ocean for mortality owing to general marine conditions, nearshore conditions upon return, and both direct and indirect fishery interception. Fishery take is included so that model users can experiment with the reintroduction of harvest should the sockeye population sufficiently recover (fig. 17).

Model Dashboard

\begin{tabular}{|c|c|c|}
\hline \multicolumn{2}{|c|}{ OCEAN REARING } & \multirow[b]{3}{*}{ Definitions } \\
\hline \multicolumn{2}{|c|}{ Ocean Mortality Factors (proportion) } & \\
\hline & Value & \\
\hline nearshore conditions & 0 & Proportion of adults dying due to nearshore conditions upon return from ocean \\
\hline ocean conditions & 0.83 & Proportion of adults dying during ocean rearing due to ocean conditions \\
\hline fishery - direct & $\overline{0}$ & Proportion of adults killed directly in fisheries \\
\hline fishery - indirect & $\overline{0}$ & Proportion of adults indirectly killed by fishery activities \\
\hline
\end{tabular}

Figure 17. Screen capture of "Ocean Rearing" section of technical dashboard and definitions of terms for Lake Ozette sockeye salmon model. 


\section{Management-Oriented Dashboard}

The management-oriented dashboard (fig. 18) aggregates on one page all factors that may be of most interest to managers. These factors primarily are elements and processes that may be amenable to management interventions. Topics include (1) "Weirs", which may be removed or altered to minimize unintended effects; (2) "Hatchery Operations and Fishery", which also are under management control; and (3) "Spawning Habitat and Egg Base Mortality", both of which can be improved by restoration of spawning areas. Management actions to influence predation mortality vary by life stage and all are available to adjust on the management-oriented dashboard. The user may use this dashboard as an introduction to the model and later interact with other aspects using the technical dashboard.

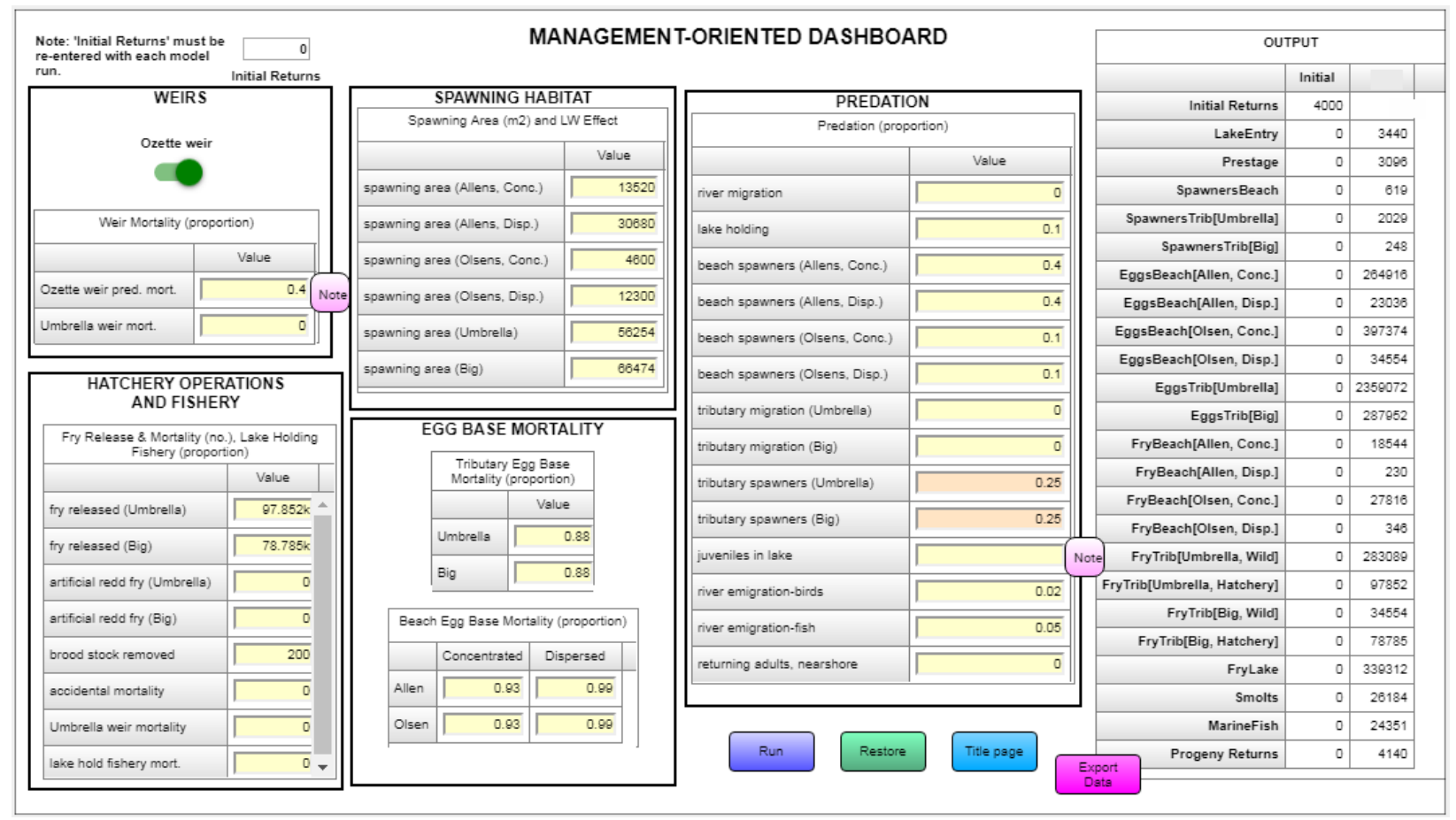

Figure 18. Screen capture of "Management-Oriented Dashboard" for Lake Ozette sockeye salmon model. 


\section{Model Background/Justification}

The rationale for model structure, default and other parameters, and documentation are presented in this report section. The model was primarily built based on information presented in the LFA (Haggerty and others, 2009). Much of the data collected to understand Lake Ozette sockeye ecology were collected by Makah Fisheries Management (MFM) or are in unpublished reports filed with MFM and are not formally published outside the LFA. Any MFM data that are reported only in the LFA are cited as Haggerty and others, 2009.

\section{Adult River Migration}

\section{Limiting Factors}

The survival of returning adults potentially is affected by several limiting factors (table 1).

Table 1. Limiting factors for adult river migration identified in the limiting factors analysis for sockeye salmon at Ozette River and Lake Ozette, northwestern Washington.

[Limiting factors, impact, and uncertainty from Haggerty and others, 2009. NA, not applicable]

\begin{tabular}{|c|c|c|c|}
\hline Factor & Impact & Certainty & Model approach \\
\hline $\begin{array}{l}\text { Mammal predation (mostly } \\
\text { river otters (Lutra } \\
\text { canadensis) }\end{array}$ & Moderate & Moderate & $\begin{array}{l}\text { Mortality is a function of run size or user can set to } \\
\text { adjust for changes in predator population from } \\
\text { baseline. See text for explanation of default. }\end{array}$ \\
\hline $\begin{array}{l}\text { River habitat } \\
\text { (large wood jams) }\end{array}$ & Low & Moderate & User can set habitat-related mortality. Default $=0$. \\
\hline $\begin{array}{l}\text { Water quality } \\
\text { (temperature) }\end{array}$ & Moderate & Moderate & $\begin{array}{l}\text { Us er can set proportion of population migrating at } \\
\text { temperature ranges and cons equent mortality. See } \\
\text { text for explanation of defaults. }\end{array}$ \\
\hline $\begin{array}{l}\text { Water quality (suspended } \\
\text { sediment) }\end{array}$ & Moderate & Moderate & $\begin{array}{l}\text { User can set number and severity of high suspended } \\
\text { sediment events, and consequent mortality. Defaults } \\
=0 \text {. }\end{array}$ \\
\hline Streamflow & Unknown & NA & $\begin{array}{l}\text { Covered in other factors (for example, exposure to } \\
\text { predation). }\end{array}$ \\
\hline Fisheries & None & High & $\begin{array}{l}\text { Not addressed; no fisheries occur during adult } \\
\text { migration. }\end{array}$ \\
\hline Dis ease & Unknown & NA & User can set disease mortality. Default $=0$ \\
\hline $\begin{array}{l}\text { Research and monitoring } \\
\text { (weir) }\end{array}$ & Low & High & $\begin{array}{l}\text { User can set proportion of predation mortality owing to } \\
\text { the weir. Default }=0.4 \text {. }\end{array}$ \\
\hline
\end{tabular}

\section{Description/Justification of Model Approach}

The most influential limiting factors affecting river migration are thought to be predation and water quality (stream temperature and suspended sediment events), with ratings of moderate impact. Impaired river habitat owing to removal of LW jams and the effects of the counting weir are thought to have a low impact, whereas summer low flow and disease have unknown severity (Haggerty and others, 2009). The model bases mortality on a relation between mortality and run size thought to describe current conditions of predation, as well as water depth (flow level), habitat quality, and presence of the weir during migration (fig. 19). Specifically, this relation describes predation dynamics between river otters (Lutra canadensis) and adult sockeye, whereby the number of predators is not dependent on the number of prey and prey killed per predator increases with the number of prey available. This mortality function can be adjusted by 
the user to indicate weir removal or changes in the flow conditions experienced by migrating fish. The user also can adjust base mortality to indicate changes from baseline in LW jam abundance, stream temperature, disease, suspended sediment concentration events, and predator abundance (example shown in fig. 19).

The Ozette River is $5.3 \mathrm{mi}$ long and adult migrants transit it in a matter of days. Residence time in the river has been estimated at about 48 hours based on observations of sockeye with sea lice at the weir (Dlugokenski and others, 1981; Makah Fisheries Management, 2000). In 2000, Gearin and others (2002) marked fish entering the river and recaptured them at the weir. Their data show that transit time averaged 65.2 hours (range: 17-154 hours). Although individual transit times are days long, the population migration period extends from mid-April to mid-August, typically peaking between late May and mid-June (Haggerty and others, 2009).

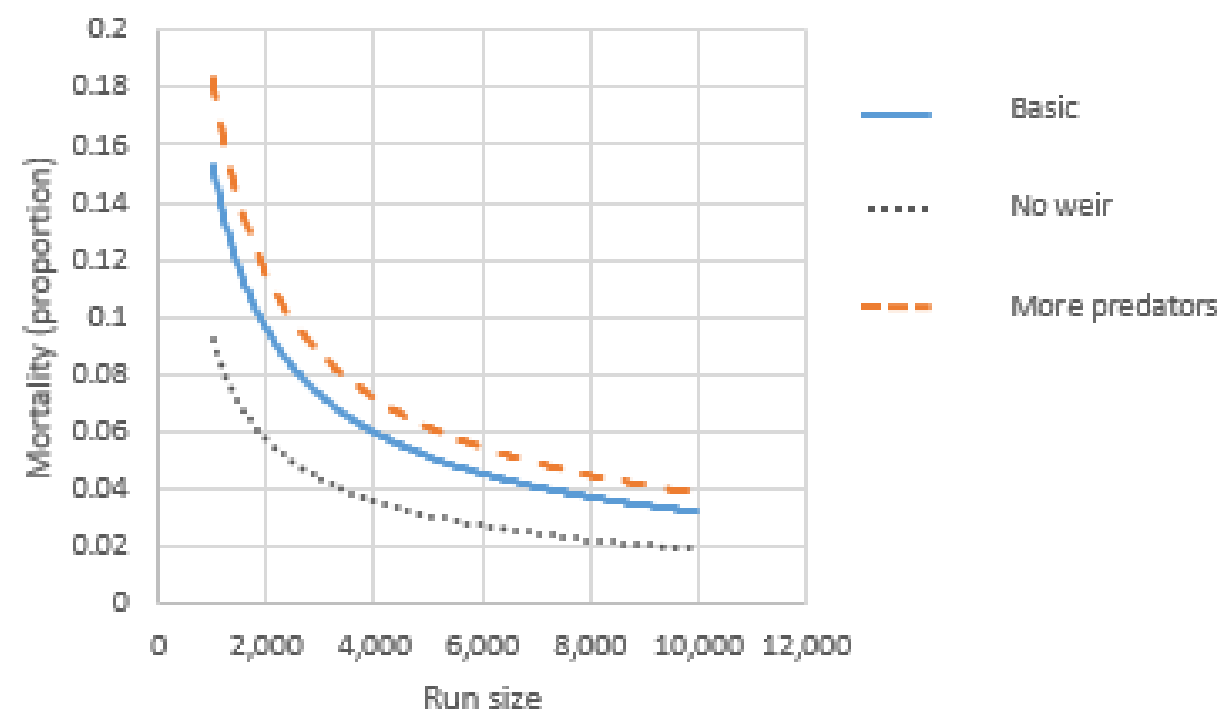

Figure 19. Graphs showing function relating predation mortality to run size for migrating sockeye salmon adults in the Ozette River, northwestern Washington.

Predators of adult sockeye migrants include river otters (Lutra canadensis) and harbor seals (Phoca vitulina). Both predator populations may be increasing because of protection from hunting afforded when the Ozette area was included in Olympic National Park in 1940 for otters and by the Marine Mammal Protection Act of 1972 (16 U.S.C. 1361-1421h) for harbor seals. Harbor seal use of the upper Ozette River was not documented until the late 1980s, persisted at least until 2004 (data from 1999 to 2004 summarized by Haggerty and others, 2009), but seems to have ended. However, harbor seals are active at the Ozette River mouth and lower Ozette River (Gearin and others, 2002; Haggerty and others, 2009). Little direct information is available to describe the effects of predators on sockeye adults and most studies examined scarring rather than mortality. One study showed the incidence of fish scarring to be 10.7 percent higher at the weir compared with the estuary (Gearin and others, 2002). This and other assessments suggest that mortality owing to predation could be high. The model accounts for baseline predation typical of recent decades in the baseline relation between run size and mortality (fig. 19), but the model user also can change the level of predation, which will proportionally adjust the baseline mortality. 
Over the last 40 years, some sort of channel-spanning weir has been placed across the Ozette River during peak adult migration to estimate the number of migrants. The effect of the weir on mortality rate is unknown, so the model user is enabled to remove the weir and adjust the default weir effect, which is 40 percent of the predicted mortality calculated from run size. This number is highly speculative and represents observations that harbor seals and river otters seem to use the weir as an aid in hunting (Haggerty and others, 2009). We are estimating that predation mortality would be reduced by nearly one-half if the weir were removed, but the user can adjust this effect. At present (2018), the weir is being replaced by acoustic monitoring that should not impede the progress of fish passing the counting area. Future data can be used to better estimate the effect of the weir on sockeye mortality.

The degree to which the weir increases susceptibility of adult sockeye to predation depends on lake level. Lake level is a surrogate for Ozette River flow and, as lake level declines, the number of fish that migrate during daylight decreases (fig. 20; data from Haggerty and others, 2009). Ninety-five percent of successful predation events have been observed during twilight or night (Haggerty and others, 2009), so predation naturally increases at low lake levels. Therefore, the proportion of the run that occurs at various lake levels influences the level of predation. These proportions are adjustable by the model user and the default values (table 2, column 2 from left) are based on the temporal distribution of run timing averaged across multiple years (fig. 21). Total exposure to predation is calculated as the sum across lake-level ranges of proportion of population migrating (table 2, column 2) times exposure at each range (table 2, column 3, based on fig. 20). Total exposure is adjusted when the user changes the proportion of the migrant population that travels during each lake-level range and is used to adjust the equation describing mortality as a function of run size (fig. 19).

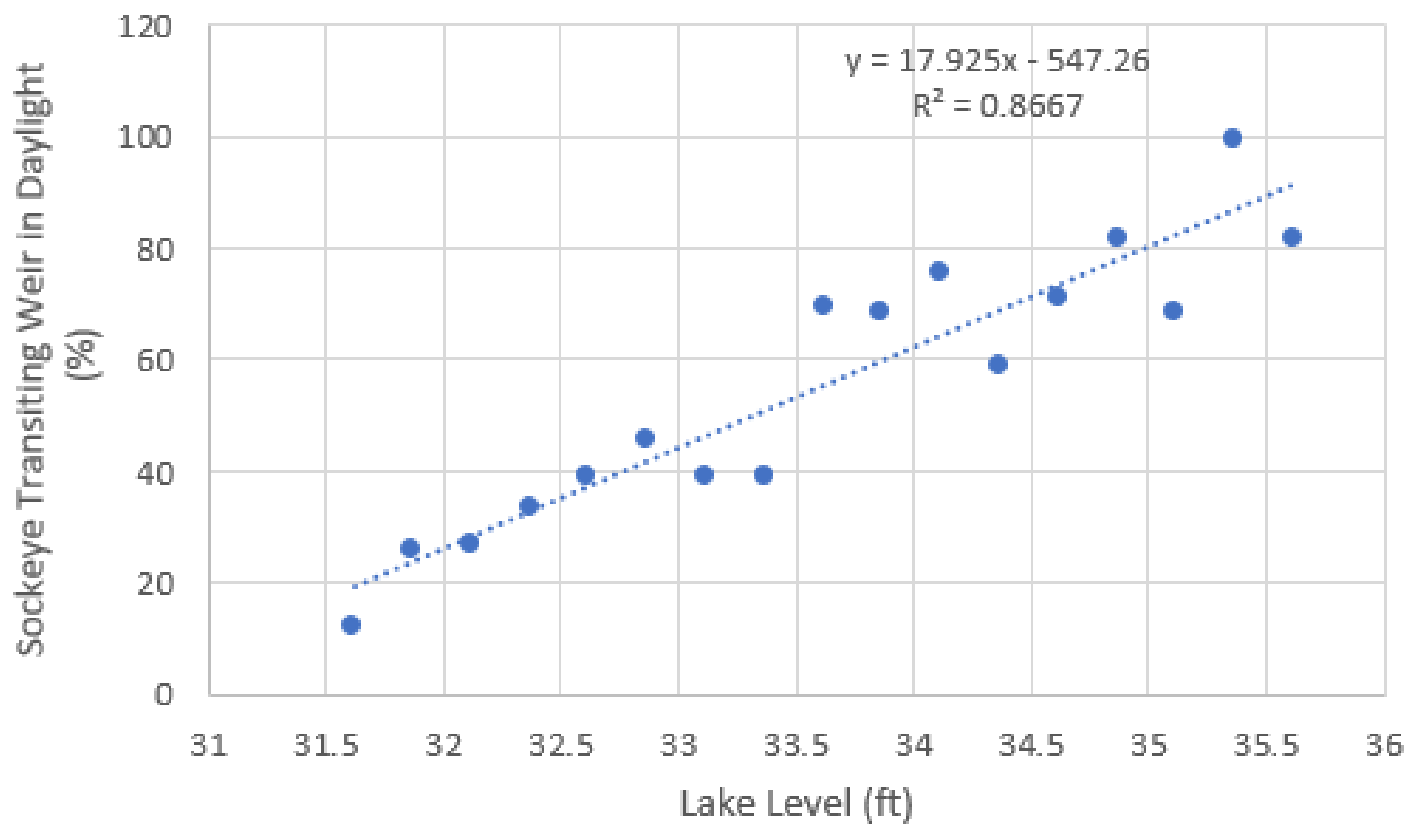

Figure 20. Graph showing percentage of sockeye salmon transiting weir during daylight hours as a function of lake level in feetabove North American Vertical Datum of 1988, Lake Ozette, northwestern Washington (data from Haggerty and others, 2009). ft, foot; \%, percentage. 


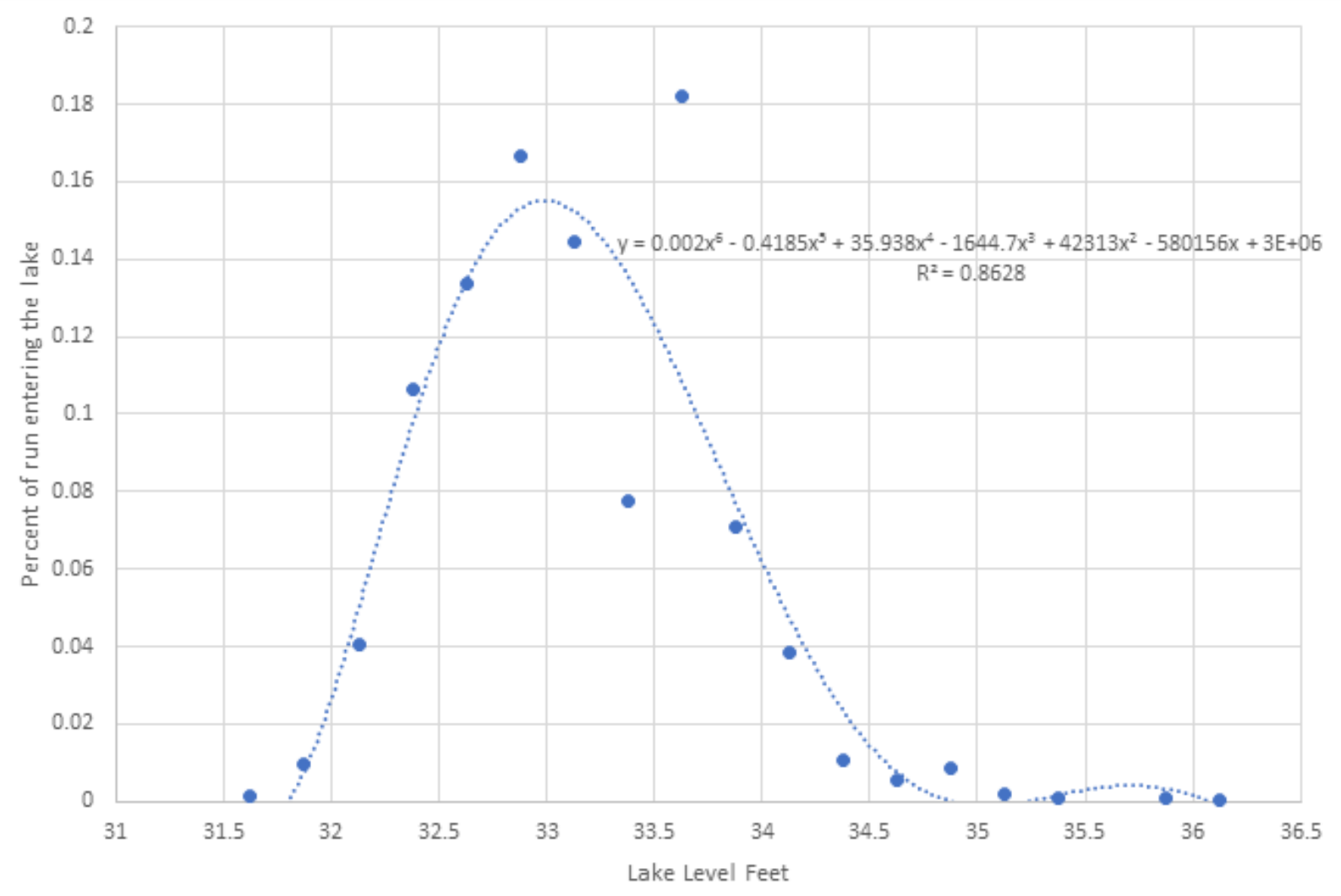

Figure 21. Graph showing percentage of sockeye salmon transiting the weir at a range of lake levels in feet above North American Vertical Datum of 1988, at Lake Ozette, northwestern Washington.

Table 2. Determination of default values of population exposure to predation owing to lake level.

[feet, feet above North American Vertical Datum of 1988; >, greater than; <, less than]

\begin{tabular}{cccc}
\hline $\begin{array}{c}\text { Lake level } \\
\text { (feet) }\end{array}$ & $\begin{array}{c}\text { Population } \\
\text { (proportion) }\end{array}$ & $\begin{array}{c}\text { Exposure } \\
\text { (proportion) }\end{array}$ & $\begin{array}{c}\text { Population exposed } \\
\text { (proportion) }\end{array}$ \\
\hline$<31.5$ & 0 & 1.00 & 0 \\
$31.5-32.5$ & .25 & .74 & .18 \\
$32.5-33.5$ & .37 & .56 & .21 \\
$33.5-34.5$ & .35 & .38 & .13 \\
$34.5-35.5$ & .03 & .20 & .01 \\
$>35.5$ & 0 & 0 & 0 \\
Total & 1.00 & & .53 \\
\hline
\end{tabular}

Removal of LW jams on the Ozette River has reduced habitat complexity for fish, and forest removal on the upper $0.4 \mathrm{mi}$ of the river has reduced LW inputs, thus delaying recovery. Haggerty and Ritchie (2004) reported that higher-quality pools (larger and more complex) were associated with LW jams. Together, the loss of LW jams and inputs reduces refuge areas for fish and increases the travel efficiency of predators, thereby increasing the success of predators. Moreover, LW removal has lowered the level of Lake Ozette, meaning that more fish migration happens at night when fish are most vulnerable to predation. Pools also may provide refuge from warm water temperatures in some systems (Berman and Quinn, 1991; Torgersen and others, 1999; Hyatt and others, 2003). However, thermal refugia seem unlikely to occur in the Ozette 
River, which is low gradient, shallow and sourced from the warm upper layer of Lake Ozette. The lack of refugia was confirmed by a snorkel survey of pool temperatures done in 2006 (data held by two of the authors). Because adult fish spend only a limited time in the river (Gearin and others, 2002), these factors may not be extremely consequential. The model user can change the rate of mortality owing to changes in LW abundance.

Disease is thought to be a minor cause of mortality for migrating sockeye; no monitoring for it has occurred (Haggerty and others, 2009). Data from run year 2000 show that fewer than 1 percent of 899 sockeye observed while transiting the weir had visible fungal growth, but several individuals had severe infections and likely did not spawn (Haggerty and others, 2009). Disease related to potentially rising water temperatures owing to a changing climate also is an emerging issue for pre-spawning mortality of sockeye in other populations (Crossin and others, 2008; Hinch and Martins, 2011). The model user can adjust mortality owing to disease.

Temperature effects on sockeye salmon are not well understood. In controlled conditions, mortality is observed at temperatures greater than $(>) 24^{\circ} \mathrm{C}$ owing to thermal stress and infection; increased infection and higher risk of death occur at $22-24{ }^{\circ} \mathrm{C}$; and no mortality occurs when fish are held at $21^{\circ} \mathrm{C}$ for 15 days (Servizi and Jensen, 1977). In more natural conditions, sockeye held at the Umbrella Creek outlet at $18{ }^{\circ} \mathrm{C}$ suffered 72 -percent mortality after 7 days (Kemmerich, 1945). Potential negative sublethal effects of high temperatures include fungal and bacterial growth, delayed migration, increased physiological stress, and decreased energy reserves for spawning. Although temperatures of $24{ }^{\circ} \mathrm{C}$ have been measured during migration (Haggerty and others, 2009), the negative effects may be mitigated by short exposure and only affect part of the population. Interannual variation in exposure also is considerable. For example, from 2002 to 2004 , the segment of the migrating population exposed to temperatures $>21{ }^{\circ} \mathrm{C}$ varied from 1.1 to 16.2 percent (data summarized in Haggerty and others, 2009). The model user can adjust the percentage of the salmon population that migrates at several stream temperature ranges and the mortality rate associated with each range. Given the higher mortality seen at lower temperatures in natural conditions, the default values for temperature-related mortality rate are 0.5 at $20-21^{\circ} \mathrm{C}, 1.0$ at greater than $21^{\circ} \mathrm{C}$ and 0 at less than $20^{\circ} \mathrm{C}$. Based on existing data (Haggerty and others, 2009), default values for the percentages of the population migrating at less than $(<) 19,19-20,20-21^{\circ} \mathrm{C}$ and $>21^{\circ} \mathrm{C}$ are $75,15,4$, and 6 percent, respectively.

High concentrations of suspended sediments can have harmful effects on fish behavior and physiology. Behavioral changes potentially include changes in avoidance, territoriality, homing, and migration, and physiological changes potentially include gill trauma and damage, reduced respiration, and changes in blood physiology (Waters, 1995; Bash and others, 2001). High precipitation events cause suspended sediment production in Coal Creek, which flows into the Ozette River. During the April-August migration period, events that happen in April are likely to be diluted by Ozette River flow. During May-August, moderately common events (310 -percent probability of occurrence by day) would result in moderate behavioral and physiologic stress on the scale developed by Newcombe and Jensen (1996). Haggerty and others (2009) estimate that over the entire migration period, 12 percent of the population is expected to have moderate stress. This likely would not cause significant mortality, but because fish with bleeding gills have been observed, the Newcombe and Jensen (1996) scale may underestimate the degree of damage in the Ozette River. The discrepancy may arise because sediment particles in the Ozette River are more angular and sharper than the test particles (Haggerty and others, 2009). The model user can determine the number, severity, and associated mortality of sediment events. Default values for number of events of different severities and associated mortalities are 0 . 


\section{Lake Holding}

\section{Limiting Factors}

The survival of adult fish during lake holding potentially is affected by several limiting factors (table 3).

Table 3. Limiting factors for lake holding identified in the limiting factors analysis for sockeye salmon at Lake Ozette, northwestern Washington.

[Limiting factors, impact, and uncertainty from Haggerty and others, 2009. NA, not applicable]

\begin{tabular}{llll}
\hline \multicolumn{1}{c}{ Factor } & Impact & Certainty & \multicolumn{1}{c}{ Model approach } \\
\hline Predation & Unknown & NA & User can set. Default $=0.1$. \\
Disease & Unknown & NA & User can set. Default $=0$. \\
Water quality (temperature) & Unknown & NA & Us er can set. Default $=0$. \\
Fisheries & Negligible & Moderate & Us er can set. Default $=0$. \\
\hline
\end{tabular}

\section{Description/Justification of Model Approach}

Very little is known about the mortality of sockeye holding in the lake owing to the volume of the lake, small sockeye population, depth of sockeye residence, and consequent difficulty in making observations. Acoustic and radio tag studies in 2000 and 2001 indicated that substantial numbers of fish die in the lake before spawning; however, causes could not be identified (Hughes and others, 2002). Potential factors include predation, disease, high water temperature, and fisheries. Although some of these factors are interrelated, the model enables the user to adjust them independently.

Predators of adult salmon present in the lake include river otters and harbor seals. Although there are some anecdotal reports of mortality caused by harbor seals (Hughes and others, 2002), most observations of aquatic mammal predation are associated with spawners near or at spawning beaches (which is addressed in the "Spawning - Beaches" section of the model technical dashboard). However, because mortality during the late stages of lake holding may be substantial and predation seems to be the most likely cause (Hughes and others, 2002), the model default for the lake holding predation mortality rate is 0.10 . The user can adjust this mortality.

Disease is thought to have a low impact on adult sockeye holding in Lake Ozette because no direct evidence of disease mortality (Haggerty and others, 2009) is available. Disease has the potential to magnify the effects of predation and elevated water temperature because injured or stressed fish are more susceptible to disease. Disease mortality that results from the river environment is calculated at the migration stage of the model even if the fish are expected to die in the lake.

Studies of Fraser River sockeye indicate that pre-spawning mortality can result from accumulated temperature units (or degree-days). Because lake temperatures are within the range preferred by sockeye (Jacobs and others, 1996; Meyer and Brenkman, 2001), warm water most likely is only present in the Ozette River during immigration. This mortality is addressed in the "Adult River Migration" section of the model technical dashboard, even if it may manifest in the lake. The option to include temperature as a source of mortality during lake holding remains in the model so the potential effects of climate change can be incorporated. 
A catch-and-release fishery is present in Lake Ozette during the adult sockeye holding period. Expert knowledge of fisher interests and behavior suggests that sockeye salmon are not targeted, and the low numbers of sockeye make it unlikely that they are incidentally caught. The factor is included in the model in case evidence becomes available that the fishery is causing mortality.

\section{Tributary Migration}

\section{Limiting Factors}

The survival of fish migrating up tributaries to spawning areas potentially is affected by several limiting factors (table 4).

Table 4. Limiting factors for tributary migration identified in the limiting factors analysis (LFA) for sockeye salmon at Lake Ozette, northwestern Washington.

[Limiting factors, impact, and uncertainty from Haggerty and others, 2009. -, no ass es sment available]

\begin{tabular}{|c|c|c|c|}
\hline Factor & Impact & Certainty & Model approach \\
\hline Predation & Low & $\begin{array}{l}\text { Moderate- } \\
\text { High }\end{array}$ & User can set. Default $=0$ \\
\hline $\begin{array}{l}\text { Holding pool quality and } \\
\text { quantity }\end{array}$ & Low & High & Not addressed. \\
\hline Streamflow & Low & Low & User can set. Default $=0$. \\
\hline Water quality (turbidity) & Low & Moderate & User can set. Default $=0$. \\
\hline $\begin{array}{l}\text { Hatchery indirect (research } \\
\text { and monitoring) }\end{array}$ & Negligible & High & User can set. Default $=0$. \\
\hline $\begin{array}{l}\text { Hatchery direct (brood stock } \\
\text { harvested) }\end{array}$ & - & - & $\begin{array}{l}\text { Not included in LFA analysis; default is } 200 \text { fish } \\
\text { harvested for brood stock. User can adjust. }\end{array}$ \\
\hline
\end{tabular}

\section{Description/Justification of Model Approach}

All potential limiting factors identified during tributary migration are thought to have a low or negligible impact (Haggerty and others, 2009). They include predation, pool quality and quantity, low autumn streamflow, turbidity/suspended sediment events, and hatchery operations. Other losses include fish trapped for use as hatchery brood stock. All factors are addressed by the model except for pool features. The model user can enter the number of brood stock taken and the number killed inadvertently in the process. The default number of brood stock is 200 in accordance with the current permit. Hatchery data show that from 2000 to 2013, brood stock harvest annually averaged 183 fish with 18 mortalities. Other factors are included as a proportion of the population lost. Because conditions can vary between Umbrella Creek and Big River, these subpopulations are separately accounted for.

Potential predators of adult sockeye in the tributaries include river otters, harbor seals and terrestrial mammals such as bears (Ursus americanus), cougars (Puma concolor) and bobcats (Lynx rufus). Harbor seals tend to stay near the mouth or in the lowest reaches of tributaries and likely only affect fish that are holding in anticipation of enough flow to migrate. Bears feed primarily on carcasses and only anecdotal sightings have been reported of fishing by cougars or bobcats frequenting the Umbrella Creek weir. Based on tagging, tracking, and genetic sampling, little evidence of predation in Umbrella Creek (Hughes and others, 2002) is available. 
Holding pools can be used by sockeye to avoid predators or by females avoiding attack by other females as they prepare to spawn (Quinn, 2005). Conditions are considered good near spawning areas in Umbrella Creek and Big River, but some reaches of Umbrella have deficient pool volume owing to lack of LW and sediment aggradation (Haggerty and Ritchie, 2004). This limiting factor is thought to have a low impact with high confidence and likely will only become an issue should sockeye numbers dramatically increase.

Low streamflow in autumn delays migration up the tributaries (Haggerty and others, 2009), thereby increasing exposure of fish to predation at the river mouth and perhaps increasing egg retention and pre-spawning mortality. However, variation in the onset of winter flows is typical and fish are expected to have considerable adaptive capacity. The river mouths also are relatively deep so that predator avoidance is more possible than at beaches. Climate and land-use changes may affect tributary hydrology in a more consequential way in the future.

Peak streamflow and turbidity events are common during sockeye migration and spawning (Haggerty and others, 2009). Although Jacobs and others (1996) reported no problems with water quality, Makah Fisheries Management (2000), Smith (2000), and Meyer and Brenkman (2001) documented frequent high-turbidity events and showed that turbidity is a good surrogate indicating elevated suspended sediment concentrations. Turbidity exceeded 100 Nephelometric Turbidity Units for 90 hours during the spawning period (1 October-15 January) and for 15 hours during the tributary emigration period (1 March-1 June) in Umbrella Creek during water year (WY) 2006 (Haggerty and others, 2009). Negative effects of suspended sediments include behavior and physiologic consequences for fish and adverse changes to habitat.

\section{Spawning - Beaches}

\section{Limiting Factors}

The production of eggs at beach spawning areas potentially is affected by several limiting factors (table 5).

Table 5. Limiting factors for beach spawning identified in limiting factors analysis (LFA) for sockeye salmon at Lake Ozette, northwestern Washington.

[Limiting factors, impact, and uncertainty from Haggerty and others, 2009. NA, not applicable; -, no assessment available]

\begin{tabular}{|c|c|c|c|}
\hline Factor & Impact & Certainty & Model approach \\
\hline Predation-staging & Low & Low & User can adjust with spawning predation. \\
\hline Predation-spawning & High & Moderate & $\begin{array}{l}\text { User can set. Default }=0.4 \text { (Allen's beach), } 0.1 \text { (Olsen's } \\
\text { beach). }\end{array}$ \\
\hline Water quality (turbidity) & Unknown & NA & Not addressed. \\
\hline Hatchery program & Negligible & High & Not addressed. \\
\hline $\begin{array}{l}\text { Research and } \\
\text { monitoring }\end{array}$ & - & - & Not in LFA; user can set. Default $=0$. \\
\hline
\end{tabular}




\section{Description/Justification of Model Approach}

Predation is the primary limiting factor thought to affect adult sockeye salmon during spawning on beaches. Other possible factors include water quality and genetic impacts that may result from breeding with straying hatchery fish (Haggerty and others, 2009). Although not mentioned in the LFA, research and monitoring activities possibly may negatively affect spawners. The model enables the user to adjust mortality owing to predation as well as research and monitoring. It also allows the user to set (1) the distribution of beach spawners to and (2) the absolute area of concentrated and dispersed spawning areas within beaches. The default distribution of spawners is 90 percent to concentrated spawning areas and 10 percent to dispersed spawning areas, based on expert opinion, and the default spawning area sizes are based on beach surveys (Haggerty and others, 2009).

Predators of adult salmon primarily are river otters and harbor seals. During spawning season 2000, more than 40 percent of spawners at Allen's Beach (Hughes and others, 2002) and 10 percent of spawners at Olsen's Beach were killed by predators (Haggerty and others, 2009); these values are used as model defaults for both dispersed and concentrated spawning areas. Based on this albeit limited information, predation of spawners may be substantial. Contributing factors may include an increase in aquatic mammal predators owing to the Marine Mammal Protection Act of 1972 such that harbor seal numbers increased 4 percent per year from 1983 to 1996 (Carretta and others, 2017). Harbor seals began appearing in the lake in the 1980s and continued to appear until at least 2004. However, seals have rarely been seen near the spawning beaches in recent years (prior to 2018), possibly owing to low numbers of beach spawners to attract them. River otters may have increased after the Ozette Village was abandoned in the 1970s and National Park Service acquired land from the western shore to the ocean (1953) and in a narrow band around the lake (1976). These events reduced the hunting and trapping pressure on river otters (Wray, 1997). An eventual fuller understanding of predator-prey dynamics at beaches will enable predation to be expressed as a function of spawner density. Model defaults likely represent a worst-case scenario that may no longer exist, but the user can adjust these values to assess their importance.

High turbidity and suspended sediment concentration events may affect the physiology and behavior of spawning salmon (Waters 1995; Bash and others, 2001). However, the remaining spawning beaches, especially Allen's Beach, are distant from potentially sedimentladen tributaries. A more substantial threat to spawning habitat may be encroaching shoreline vegetation (shrubs and herbs; Ritchie, 2005), which has been observed to capture sediment, thereby creating more habitat for further vegetation encroachment. Sediment distribution also may be influenced by beach log removal activities to protect in-holder properties.

Straying of hatchery adults from tributaries to spawning beaches may affect the genetic diversity and fitness of beach spawners. However, from RYs 2003 through 2012, <1 percent of beach spawners were hatchery-origin (National Marine Fisheries Service, 2015). Even if straying should particularly occur to Olsen's Beach, effects on genetic diversity would be limited because the hatchery stock originated from Olsen's Beach. 


\title{
Spawning - Tributaries
}

\author{
Limiting Factors
}

The production of eggs at tributary spawning areas potentially is affected by several limiting factors (table 6).

Table 6. Limiting factors for tributary spawning identified in limiting factors analysis for sockeye salmon at Lake Ozette, northwestern Washington.

[Limiting factors, impact, and uncertainty from Haggerty and others, 2009. $\mathrm{m}^{2}$, square meter]

\begin{tabular}{|c|c|c|c|}
\hline Factor & Impact & Certainty & Model approach \\
\hline Predation of spawners & Low & Moderate & Us er can set. Default $=0$ \\
\hline Holding pool quantity and quality & Negligible & Moderate & Not addressed. \\
\hline Spawning habitat quantity & Low & High & $\begin{array}{l}\text { Us er can set. Default }=56,254 \mathrm{~m}^{2} \\
\text { (Umbrella Creek), 66,474 } \mathrm{m}^{2} \text { (Big } \\
\text { River). }\end{array}$ \\
\hline Streamflow (redd placement) & Low & Moderate & Not addressed. \\
\hline Kokanee-sockeye interactions & Negligible-Low & Moderate & Not addressed. \\
\hline Water quality (suspended sediment) & Low & Moderate & User can set. Default $=0$. \\
\hline Research and monitoring & Negligible & Moderate & User can set. Default $=0$. \\
\hline
\end{tabular}

\section{Description/Justification of Model Approach}

Potential limiting factors for spawning success in tributaries include predation, holding pool quality and quantity, availability of spawning substrate, streamflow, interactions with kokanee (Oncorhynchus nerka), water quality, and research and monitoring (Haggerty and others, 2009). All factors are thought to have a negligible-to-low impact with moderate-to-high certainty. The model allows the user to adjust mortality owing to predation, water quality, and research and monitoring. The user also can set the amount of spawning area and the distribution of tributary spawners to Umbrella Creek or Big River.

Predators of spawning fish include river otter, harbor seals, and terrestrial mammals. Although there have been occasional anecdotal observations of predation events, Hughes and others (2002) reported very little evidence of predation mortality at Umbrella Creek. Their study occurred in 1 year and included tagging, tracking, genetic sampling, and spawning ground surveys. They noted that predation occurred prior to entering the tributary and, in 2000, all fish that entered Umbrella Creek spawned successfully.

Holding pool quality and quantity is most important during the holding period prior to spawning. After spawning begins, fish seem focused on protecting redds and do not use the pools (Haggerty and others, 2009).

The quality and quantity of spawning habitat in Lake Ozette tributaries has been reduced primarily because of the legacy effects of logging activities in the watersheds. Direct effects were owing to yarding and operation of equipment in and across streams. Loss of upland and riparian forests enables mobilization and delivery of sediments to stream beds, which impairs the functionality of spawning gravels. For example, Big River was described as a continuous bed of gravel for most of the length in 1953 (Kramer 1953) but as mostly sand and pebbles in the lower section by 2004 (Haggerty and Ritchie, 2004). Although gravel quality has diminished, for now (2019) there seems to be enough habitat to accommodate the current number of spawners. 
Meanwhile, activities that decreased habitat have largely ceased. Big River and Umbrella Creek once had an estimated capacity of 46,000 (Dlugokenski and others, 1981) to 60,000 (Blum, 1988) spawners, whereas spawners recently averaged 3,601 (2008-2012; Northwest Fisheries Science Center, 2015).

Changes in streamflow regime during spawning (owing to effects of legacy land-use practices or effects of climate change on overland flow and precipitation) can cause salmon to spawn too high or too low within the channel, possibly resulting in either desiccation or scouring of eggs when the flow regime returns to normal during incubation (Lapoint and others, 2000; Ames and Beecher, 2001). These potential effects on egg survival are covered elsewhere in the model.

Kokanee-sized fish (about 9.8 in fork length) are extremely rare in Big River based on observations from 1970 to 2004, but they have been observed in very small numbers spawning with sockeye in Umbrella Creek (Dlugokenski and others, 1981; Haggerty and others, 2009). Nevertheless, this is thought to be uncommon and likely does not pose more than a negligible threat to dilute the sockeye gene pool (Haggerty and others, 2009).

Turbidity and suspended sediment events potentially can decrease fitness, increase egg retention and mortality, and influence behavior of spawning sockeye (Waters, 1995; Bash and others, 2001). These events are most common in autumn and winter when spawning and incubation occur. Whether the effects are having a substantial influence on spawning success is unknown.

Spawning ground surveys are completed every 7-10 days and may disrupt spawning by causing stress to spawners. Precautions are taken to avoid interfering with spawning and years of experience indicate that sockeye salmon focus on spawning and ignore the presence of researchers.

\section{Incubation - Beaches}

\section{Limiting Factors}

Production of fry from redds at beaches potentially is affected by several limiting factors (table 7).

Table 7. Limiting factors for beach incubation identified in limiting factors analysis for sockeye salmon at Lake Ozette, northwestern Washington.

[Limiting factors, impact, and uncertainty from Haggerty and others, 2009. NA, not applicable]

\begin{tabular}{|c|c|c|c|}
\hline Factor & Impact & Certainty & Model approach \\
\hline $\begin{array}{l}\text { Spawning habitat quantity and } \\
\text { quality }\end{array}$ & High & High & $\begin{array}{l}\text { Us er can set habitat area; differential } \\
\text { survival expres ses differences in } \\
\text { quality (see section, "Model } \\
\text { Description: Spawning - Beaches"). }\end{array}$ \\
\hline Predation of eggs & Unknown & NA & $\begin{array}{l}\text { User can set base mortality. Default }= \\
0.93 \text { (concentrated) and } 0.99 \\
\text { (dispersed), both beaches. }\end{array}$ \\
\hline Seasonal lake-level changes & Low-Moderate & High & User can set. Default $=0$ \\
\hline Redd imposition & Low-Moderate & Moderate & $\begin{array}{l}\text { Addressed indirectly by setting } \\
\text { carrying capacity. Default }=0 \text {. }\end{array}$ \\
\hline Small population size & Unknown & NA & Not addressed. \\
\hline
\end{tabular}




\section{Description/Justification of Model Approach}

Limiting factors for beach incubation include habitat quality and quantity, predation, seasonal lake level, small population of sockeye, and competition for space (Haggerty and others, 2009). Effects of poor habitat quality and quantity are thought to have a high impact with high certainty. Quantity of spawning area suitable for dispersed or concentrated redd distribution is adjustable in the "Spawning - Beaches" section of the model technical dashboard. Quality of dispersed compared to concentrated areas is described by setting differential mortalities. Default values for mortality in concentrated spawning areas are set at 93 percent, which is the observed median value reported in egg basket studies during winter 2000 and 2001 (Haggerty and others, 2009); default incubation mortality is set extremely high (99 percent) for dispersed areas. These survival rates of 7 percent in concentrated areas and 1 percent in dispersed areas are lower than typical egg survival reported for sockeye (12.5 percent, Foerster, 1968; 12.7 percent, Quinn, 2005) for areas with better habitat quality. The model allows the user to specifically determine mortality owing to predation and lake level, whereas the other factors are collectively included in an adjustable base mortality factor. These factors can be set separately for concentrated and dispersed spawning areas at each beach.

Two primary factors have changed the quality and quantity of spawning beaches. First, LW removal from the Ozette River has lowered the lake level, which decreases beach area, allows establishment of shoreline vegetation and perhaps alters groundwater hydrology. Fish prefer to spawn near seeps and springs, perhaps because they afford better water circulation around eggs (Bjornn and Reiser, 1991) and the water may be warmer. Between 1953 and 2003, unvegetated shoreline around Lake Ozette decreased by 56 percent (Ritchie, 2005; Herrera Environmental Consultants, 2005, 2006). Vegetation reduces wave energy, thereby increasing sediment retention, which enables further vegetation colonization and reduces functional spawning area.

Second, past land-use practices in Lake Ozette tributary watersheds (specifically, clearcut logging) increased sediment inputs to beaches. The spawning beach at the outlet of Umbrella Creek, which is no longer used, has a fine sediment $(<0.85 \mathrm{~mm})$ content of 50 percent (Herrera Environmental Consultants, 2006) compared with about 25-percent fine sediment content at Olsen's Beach and Allen's Beach (Haggerty and others, 2009). High levels of fine sediment contribute, along with poor water circulation, to inadequate oxygen transfer from water to eggs (Bjornn and Reiser, 1991). Overall, the cumulative effects of increased sediment, changes in lake level and shoreline vegetation colonization have reduced spawning habitat area by 70 percent from historical conditions at Olsen's and Allen's beaches (Haggerty and others 2009).

Other limiting factors are intertwined with habitat condition. In addition to a chronically lower than historical lake level, the current lake level also may be more seasonally variable perhaps owing to flashier flows caused by land-use changes (Herrera Environmental Consultants, 2005, 2006). Lake-level variability may cause redds to be dewatered for some part of the incubation period (Dlugokenski and others, 1981; Haggerty and others, 2009). However, the effect is variable such that spawning surveys during 1999 to 2004 did not show high levels of dewatering while redd mapping during RY 2000 indicated that about 3 percent of redd surface area (7 redds) was dewatered by the time of emergence (Haggerty and others, 2009).

Habitat quality also may be affected by the current small population of spawners, which may be insufficient to adequately clean fine sediment from the spawning gravel, a benefit that occurs as a by-product of redd building activities (Kondolf and others, 1993; Peterson and Foote, 2000). Meanwhile, the low availability of spawning areas means that even low numbers of 
spawners are in competition for space such that in RY 2000, 90 percent of the redd surface area had been used multiple times, especially at Olsen's Beach (Haggerty and others, 2009). The aggregate effect is that some areas are used intensively, perhaps because they have the best gravel quality, whereas other areas continue to degrade with lack of use.

Egg predation by sculpins (Cottus sp.; Dlugokenski and others 1981) and aquatic insects (Haggerty and others, 2009) also may limit egg survival. No evidence of an increase compared with historical levels is available. However, the depensatory effects of predation at low prey numbers may mean that current levels of predation are having a more negative effect than historically (Haggerty and others, 2009).

\section{Incubation - Tributaries}

\section{Limiting Factors}

Production of fry from redds in tributaries potentially is affected by several limiting factors (table 8).

Table 8. Limiting factors for tributary incubation identified in limiting factors analysis for sockeye salmon at Lake Ozette, northwestern Washington.

[Limiting factors, impact, and uncertainty from Haggerty and others, 2009. NA, not applicable]

\begin{tabular}{llll}
\hline \multicolumn{1}{c}{ Factor } & \multicolumn{1}{c}{ Impact } & Certainty & \multicolumn{1}{c}{ Model approach } \\
\hline $\begin{array}{l}\text { Fine sediment } \\
\begin{array}{l}\text { Channel stability and floodplain } \\
\text { alterations }\end{array}\end{array}$ & High & Moderate & $\begin{array}{c}\text { Us er can adjust baseline mortality. } \\
\text { Default }=0.88 .\end{array}$ \\
$\begin{array}{l}\text { Streamflow } \\
\text { Water quality }\end{array}$ & Unknown & Low & Us er can adjust base mortality. \\
Redd superimposition & High & NA & Us er can adjust base mortality. \\
$\begin{array}{l}\text { Negligible- } \\
\text { Predation of eggs }\end{array}$ & Moderate & Moderate & Not directly addres sed. \\
Research and monitoring & Low & Low can adjust base mortality. & Not addressed. \\
\hline
\end{tabular}

\section{Description/Justification of Model Approach}

Quinn (2005) reported that most sockeye mortality generally occurs during incubation, and this is thought to be true at Lake Ozette (Haggerty and others, 2009). Limiting factors to survival during incubation in tributaries include fine sediment, channel stability and floodplain alterations, streamflow, water quality, competition (redd imposition), predation, and research and monitoring activities (survival much less than 10 percent; Haggerty and others 2009). Of these factors, only fine sediment and water quality are thought to have a high impact. The model subsumes all habitat-related and biological factors into an adjustable baseline mortality. The default value for baseline mortality is set at 0.88 to indicate expert opinion that egg mortality is lower in tributaries than at beaches. Research and monitoring effects are thought to be low, but research and monitoring are subject to management, so they have an independent control in the model. Hatchery fry and fry from artificial redds also are added to the fry population at this point in the model. The default numbers of hatchery fry are 97,852 (Umbrella Creek) and 78,785 (Big River), which are the averages from 2000 to 2015 . The default number of adult removals is 200 , in accordance with the permitted brood stock removals and the average of numbers collected 
from brood years 2000 to 2013 (183 harvested with 18 mortalities on average; Makah Fisheries Management, 2015, appendix). Hatchery fry are accounted for separately through the dispersal stage because the larger size of hatchery fry may give them a higher survival rate over naturally spawned fry or those produced from artificial redds.

Land-use changes including timber harvest, agricultural development, road building, and LW removal in tributary watersheds have substantially increased the input of sediment to Lake Ozette tributaries. Although the input seemed to diminish between samples taken in 1979 and 1991 (McHenry and others, 1994) perhaps owing to a decrease in logging, the current sediment production is estimated to be more than 3 times higher than prior to disturbance (Ritchie, 2005). Fine sediment $(<0.85 \mathrm{~mm})$ in spawning gravel can impede water circulation needed to deliver oxygen and remove waste products from eggs as well as entomb fry (Bjornn and Reiser, 1991), thereby decreasing egg-to-fry survival (Cederholm and others, 1981; McHenry and others 1994). The flow regime typical of the Pacific Northwest causes the risk of fine sediment events to be greatest during the incubation period (October-April).

Additionally, the consequences of land-use changes on streamflow and sediment mobility also can reduce channel stability. Relevant changes include the removal of LW from the Ozette River and consequent lower lake level leading to channel incision at the downstream end of tributaries (Herrera Environmental Consultants, 2006). Channel instability and changes in flow regime can contribute to increased frequency and depth of scour events (Lisle and others, 2000), with consequences for incubation survival (Montgomery and others 1996; Shellberg, 2002). Although observations of highly mobile streambeds in Lake Ozette tributaries have been made (Haggerty and others 2009), data are lacking to quantify the linkages among land-use change and incubation mortality. Nevertheless, the effects are likely to be important (Haggerty and others, 2009).

Effects of increased sediment and scour are aggravated by increased peak flows owing to land-use changes. Tree harvest reduces infiltration of precipitation into soils. In the winter, this means higher and more frequent peak-flow events during incubation so that both the stronger forces and the sediment load washed from hillsides can have negative effects on developing eggs. The magnitude of land-use related changes on tributary structure and function are unknown.

Competition for spawning area in Umbrella Creek leads to observations that eggs are displaced from redds as new redds are superimposed on older ones. Sockeye also may compete with kokanee and eventually with coho if the coho population outgrows the preferred spawning area. Competition is not apparent on Big River and Crooked Creek.

Potential predators of eggs include sculpin, coastal cutthroat trout (Oncorhynchus clarkii clarkii), and possibly river otters. However, predation is mostly thought to affect dislodged eggs that would not survive in any case (Foerster, 1968; Burgner 1991). Egg pumping tests in 1998 and 1999 did not indicate that predation is a factor (Haggerty and others, 2009).

Spawning ground surveys are completed every 7-10 days and may cause mortality if redds are inadvertently disturbed. However, precautions are taken to mark redds and restrict traffic to areas unsuitable for spawning so that potential impacts are minimized. 


\section{Fry Dispersal - Beaches}

\section{Limiting Factors}

The survival of fry dispersing from beaches potentially is affected by several limiting factors (table 9).

Table 9. Limiting factors for beach dispersal identified in limiting factors analysis for sockeye salmon at Lake Ozette, northwestern Washington.

[Limiting factors, impact, and uncertainty from Haggerty and others, 2009. NA, not applicable]

\begin{tabular}{llll}
\hline \multicolumn{1}{c}{ Factor } & \multicolumn{1}{c}{ Impact } & Certainty & \multicolumn{1}{c}{ Model approach } \\
\hline Predation & Unknown & NA & User can adjust base mortality. Default $=0.1$. \\
Fine sediment & Moderate & Moderate & User can adjust base mortality. \\
Seasonal lake-level changes & Low-Moderate & High & User can adjust base mortality. \\
\hline
\end{tabular}

\section{Description/Justification of Model Approach}

Limiting factors for beach dispersal include predation, fine sediment, and seasonal lakelevel changes, none of which are judged as having a high impact (Haggerty and others, 2009). The model allows the user to adjust a base mortality factor to account for all sources of mortality because little is known about them individually. Because beach fry do not disperse far to reach the lake, the default value for baseline mortality is set at 0.10 .

Potential predators include native sculpin, yearling coho salmon (Ruggerone and Rogers, 1992), and non-native fishes such as yellow perch (Perca flavescens; Haggerty and others, 2009). The magnitude of the predation effect is unknown but is possibly substantial, especially if there is a depensatory effect of predation at low sockeye abundance.

Fine sediment deposition on redds primarily seems to be a mortality factor for eggs and is described in section, "Model Backgound/Justification: Incubation - Beaches". However, fine sediment can form an impenetrable layer that may impede emergence of successfully incubated eggs (Haggerty and others, 2009).

Seasonal lake-level changes can cause mortality if a high lake level during spawning in November and December is followed by a low lake level in spring, leaving some redds to be dewatered (Dlugokenski and others, 1981; Haggerty and others, 2009). Example years when these conditions occurred include WYs 1990, 1992, and 1998 (Haggerty and others, 2009). Redd mapping at Olsen's Beach during winter 2000-01 indicated that about 3 percent of the total redd surface area (7 redds) was completely dewatered at the time of emergence (Haggerty and others, 2009). Spawning surveys during 1999-2004 do not indicate high levels of redd dewatering in Lake Ozette (Haggerty and others, 2009). Changes in the timing of storms may cause more frequent occurrences of dewatering in the future, but at present (2019) the impact is thought to be moderate. 


\section{Fry Dispersal - Tributaries}

\section{Limiting Factors}

The survival of fry dispersing from tributaries potentially is affected by several limiting factors (table 10).

Table 10. Limiting factors for tributary dispersal identified in limiting factors analysis for sockeye salmon at Lake Ozette, northwestern Washington.

[Limiting factors, impact, and uncertainty from Haggerty and others, 2009]

\begin{tabular}{|c|c|c|c|}
\hline Factor & Impact & Certainty & Model approach \\
\hline Predation & Moderate & Low & $\begin{array}{l}\text { User can set. Defaults }=0.25 \text { (wild fry, both streams), } 0.6 \\
\text { (Umbrella Creek, hatchery fry), 0.1 (Big River, hatchery } \\
\text { fry). }\end{array}$ \\
\hline Streamflow & Low & Low & $\begin{array}{l}\text { User can set. Defaults }=0.65 \text { (Big River hatchery fry), } 0 \\
\text { (others). }\end{array}$ \\
\hline $\begin{array}{l}\text { Water quality (turbidity, } \\
\text { suspended sediment) }\end{array}$ & Low & Moderate & Not addressed. \\
\hline
\end{tabular}

Description/Justification of Model Approach

Predation is thought to have a moderate impact on sockeye fry emigrating to Lake Ozette, whereas low streamflow and sediment load are considered to have a low impact. Sediment load (turbidity and suspended sediment concentration) can reduce fry fitness and cause gill abrasion, but low levels of sediment also can reduce the efficacy of predators (Lunt and Smee, 2015); however, high sediment concentration events are unlikely to occur when fry are present (MarchMay). The model allows the user to adjust mortality owing to predation and low streamflow for hatchery and wild fish on either Umbrella Creek or Big River.

Potential predators known from tributary trapping include cutthroat trout, sculpins, and coho yearlings (Gearin and others, 2002; Haggerty and others, 2009). Predators preferred sockeye fry over coho fry by a ratio of $8.3: 1$, based on the relative abundance of each species (Haggerty and others, 2009), even though coho were much more abundant than sockeye. The reason is unknown but potential explanations include the facts that sockeye are smaller and more accessible to small-bodied predators or that sockeye still have the yolk sac attached and may be less mobile than coho. Few data are available to describe predation rates in Lake Ozette tributaries. One fyke net trapping study observed that hatchery-released fry had 33-percent survival in Umbrella Creek in 1999 (Makah Fisheries Management, 2000). Burgner (1991) reviewed several studies of predation rates for sockeye fry emigrating to nursery lakes and reported that predation rates can be substantial and quite variable (for example, the range was 13-91 percent across 8 years at Karymaisky Spring, Kamchatka Peninsula, Russia). Because predation of dispersing fry is unknown but potentially important, the default mortality rate was set at 0.25 for wild fish. Predation mortality for Umbrella Creek hatchery fry was set at 0.60 to produce a ratio of 8:2 for returning wild to hatchery fish, which is the average ratio observed at Umbrella Creek (BYs 2000-2012; Makah Fisheries Management, 2015, appendix). The default predation mortality for Big River fry is set at 0.10 because most predation mortality for these fish is thought to be owing to the effects of low flows, which is covered in a separate model parameter. 
Low streamflow may enhance predation by impeding migration, thus increasing transit time. Tabor and others (1998) observed that predation is lower in areas where stream velocity is moderate to high. In Big River, flow can become so impeded that fish are stranded in pools that are disconnected from the river or become completely desiccated. These events can result in the total loss of a sockeye cohort emerging in Big River. This type of event more often is a problem for hatchery fry that are held for late release than for wild fry. Therefore, flow-related mortality can be set separately in the model for wild compared to hatchery fry on both rivers; the default is set at 0.65 for Big River fry and at 0 for all other fry.

\section{Lake Rearing}

\section{Limiting Factors}

The survival of fry rearing in Lake Ozette potentially is affected by several limiting factors (table 11).

Table 11. Limiting factors for lake rearing identified in limiting factors analysis for sockeye salmon at Lake Ozette, northwestern Washington.

[Limiting factors, impact, and uncertainty from Haggerty and others, 2009. NA, not applicable]

\begin{tabular}{llll}
\hline \multicolumn{1}{c}{ Factor } & Impact & Certainty & \multicolumn{1}{c}{ Model approach } \\
\hline Predation & High & Moderate & User can set. Default is function of run size (see text). \\
Fisheries & None & High & Not addressed. \\
Disease & Unknown & NA & User can set. Default $=0$. \\
Competition (food) & Negligible & Moderate & User can adjust base mortality. Default $=0$. \\
\hline
\end{tabular}

\section{Description/Justification of Model Approach}

Summarizing the life history of North Pacific sockeye salmon, Foerster (1968) suggested that mortality is highest and most variable during lake rearing and estimated representative survival at 8 percent, which is similar to 6.7-percent survival estimated for Lake Ozette (Beauchamp and others, 1995). McDonald (1969) estimated 13.5-percent survival of sockeye in Babine Lake, British Columbia; Quinn (2005) reported sockeye survival from fry to smolt to be about 25 percent in other lake systems; and Hansen and others (2016) observed values from 1 to 7 percent (average of 3 percent) in Lake Washington since 2001. Predation is thought to be the limiting factor with high impact during lake rearing for Lake Ozette sockeye, with disease also a potential factor (Haggerty and others, 2009). Because so little is known about what occurs in the lake, the model allows the user to enter base and disease mortality proportions. Predation mortality is calculated based on expected predator-prey dynamics and run size or can be entered as a proportion by the user. At current population levels (about 4,000 spawners), the predation mortality is close to 0.92 .

The primary predator of sockeye was determined to be cutthroat trout, with some predation by northern pikeminnow (Ptychocheilus oregonensis; Beauchamp and others, 1995). Non-native species yellow perch and largemouth bass (Micropterus salmoides) are other potential predators; however, perch did not have sockeye remains in stomach samples and largemouth bass have little spatio-temporal overlap with sockeye (Beauchamp and others, 1995). Percapita predation by northern pike minnow likely has increased substantially, as seen in Lake Washington where warmer water has forced northern pikeminnows into the thermocline during 
summer where they feed on sockeye for as many as 12 months per year (Dave Beauchamp, USGS, written communication, 12/20/2018). Predation mortality is modeled as a decreasing polynomic function of abundance, scaled to the range of sockeye juvenile numbers currently (2019) reasonable for Lake Ozette (fig. 22). The model user also can simply enter a mortality proportion on the model technical dashboard.

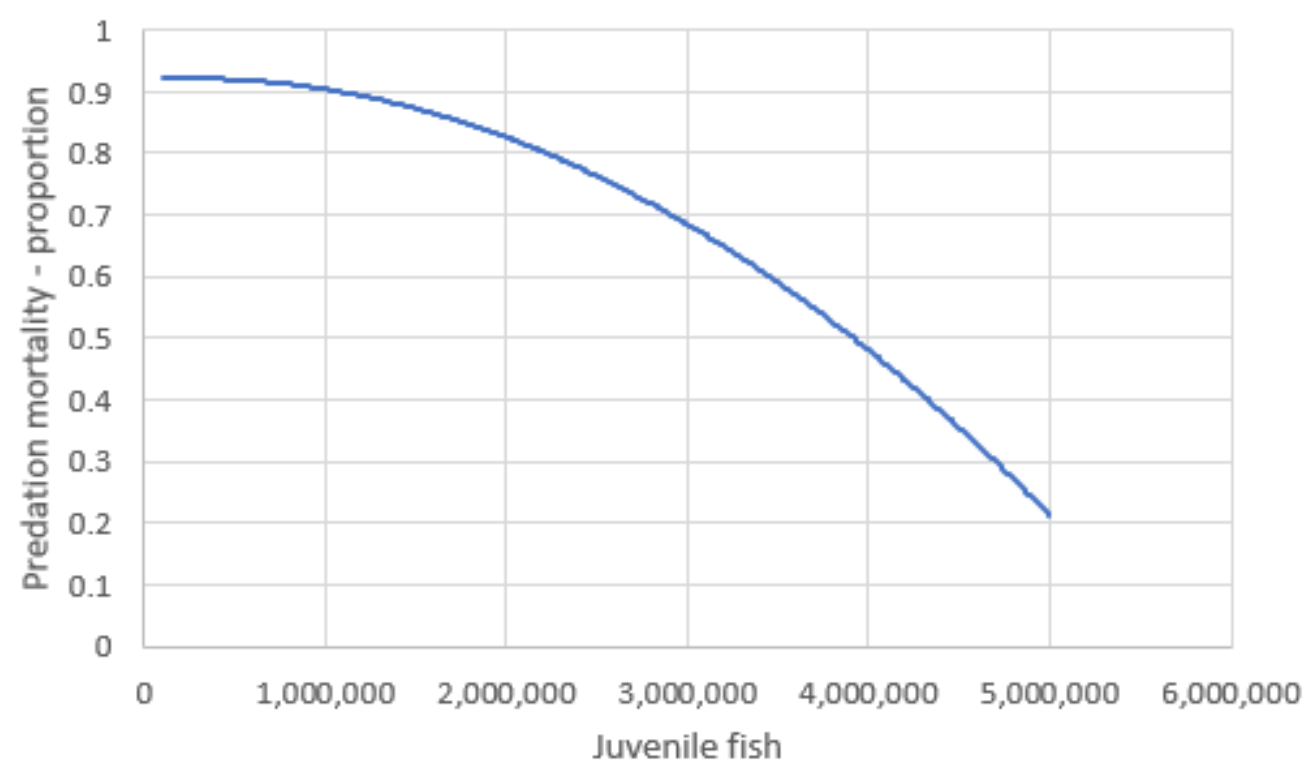

Figure 22. Graph showing predation mortality as a function of run size for juvenile sockeye salmon rearing in Lake Ozette, northwestern Washington.

With an estimated 8-percent survival for this stage of the life cycle, lake rearing represents a significant bottleneck in sockeye salmon success. Little information is available about this life stage and understanding it is a crucial need to further restoration and recovery of the population. Because predation by piscivorous fishes is thought to be the most limiting factor and predation likely is becoming more severe with warming water, the need is more urgent.

No data are available to describe the prevalence of disease in juvenile sockeye in Lake Ozette. These fish are known to be susceptible to infectious hematopoietic necrosis, a common fish pathogen in North Pacific sockeye populations (Wood, 1968), but there is no evidence that it is present at Lake Ozette.

There are no fisheries for sockeye in Lake Ozette and, given the small size of juveniles and low fishing pressure during sport fisheries for other species, it is unlikely that sockeye salmon are more than incidentally affected.

Competition for food among sockeye and Kokanee salmon potentially is a limiting factor. However, Beauchamp and others (1995) reported that sockeye consume less than 1 percent of the monthly standing stock of Daphnia pulicaria that are $>1 \mathrm{~mm}$ long. All other studies of food sources for sockeye conclude that food is not limiting (Bortleson and Dion, 1979; Dlugokenski and others, 1981; Blum, 1988; Beauchamp and others, 1995). 


\title{
River Emigration
}

\author{
Limiting Factors
}

Survival of smolts during river emigration potentially is affected by several limiting factors (table 12).

Table 12. Limiting factors for river emigration identified in limiting factors analysis for sockeye salmon at Lake Ozette, northwestern Washington.

[Limiting factors, impact, and uncertainty from Haggerty and others, 2009. NA, not applicable]

\begin{tabular}{|c|c|c|c|}
\hline Factor & Impact & Certainty & Model approach \\
\hline Predation & Moderate & Moderate & $\begin{array}{l}\text { User can set bird and fish predation. Defaults }=0.05 \text { (fish } \\
\text { predation), } 0.02 \text { (bird predation). }\end{array}$ \\
\hline Habitat conditions & Low & Moderate & $\begin{array}{l}\text { User can adjust predation mortality to indicate changes in } \\
\text { habitat. }\end{array}$ \\
\hline $\begin{array}{l}\text { Water quality (temperature, } \\
\text { turbidity) }\end{array}$ & Low & Moderate & Not addressed. \\
\hline Streamflow (flow) & Unknown & NA & Not addressed. \\
\hline $\begin{array}{l}\text { Tidal prism, estuarine } \\
\text { habitat }\end{array}$ & Unknown & NA & Not addressed. \\
\hline Fisheries & None & High & Not addressed. \\
\hline Disease & Unknown & NA & Not addressed. \\
\hline Research and monitoring & Low & High & User can set. Default $=0$. \\
\hline
\end{tabular}

\section{Description/Justification of Model Approach}

Potential limiting factors affecting sockeye survival during river emigration include predation, research and monitoring, river habitat, water quality, streamflow, estuarine habitat, fisheries, and disease (Haggerty and others, 2009). None of these factors are thought to have a high impact and only predation is thought to have a moderate impact. The model allows the user to adjust mortality owing to fish and bird predation, and research and monitoring. Other factors are not addressed because their impacts are likely to be insignificant or their effect is captured by factors that are included.

Potential predators include fish species (primarily, northern pikeminnow; Haggerty and others, 2009) and birds (for example, mergansers [Mergus merganser]). Predator fish appear to congregate near the smolt trap in the Ozette River during smolt emigration and their relative effect on the smolt population likely increases when sockeye numbers are low (Haggerty and others, 2009). Poor habitat conditions (that is, less LW) and low streamflow may increase predation. Bird and fish predation are separately adjustable in the model because managers can potentially reduce the effect of fish but not that of birds. Default predation mortality proportions are set at 0.05 from fish predators and 0.02 from bird predators.

Changes to river habitat owing to removal of LW and loss of a LW supply owing to land use have reduced cover and refuge from predators for emigrating smolts. Because smolts navigate the river very quickly (presumably in 2 to 3 days; Haggerty and others, 2009), the effects of LW likely are limited to reducing predation. Therefore, the user can include the effect of LW by adjusting the setting for mortality owing to predation.

Research and monitoring done while counting smolts using a screw trap at the upper end of the Ozette River causes almost no direct mortality but may increase predation. The user can add mortality owing to research and monitoring if desired. 
Water quality (high temperature and suspended sediment concentration) and low streamflow events are not likely to occur during the smolt emigration period (March-May). Therefore, these factors are not included in the model.

Other factors identified in the LFA as potentially limiting either have no effect (specifically, fisheries) or an unknown but likely small effect (specifically, estuary and tidal prism habitat, disease). These factors are not included in the model.

\section{Ocean Rearing}

Limiting Factors

Survival of adult fish during ocean rearing potentially is affected by several limiting factors (table 13).

Table 13. Limiting factors for ocean rearing identified in limiting factors analysis for sockeye salmon at Lake Ozette, northwestern Washington.

[Limiting factors, impact, and uncertainty from Haggerty and others, 2009]

\begin{tabular}{llll}
\hline \multicolumn{1}{c}{ Factor } & Impact & Certainty & \multicolumn{1}{c}{ Model approach } \\
\hline Fishery interception & None & High & User can set direct and indirect effects. Defaults $=0$. \\
General marine mortality & High & High & Us er can set. Default $=0.83$. \\
Nearshore conditions_-predators & Moderate & Moderate & Us er can set. Default $=0$. \\
\hline
\end{tabular}

\section{Description/Justification of Model Approach}

Potential limiting factors affecting ocean rearing include directed and non-directed fishery interceptions, general marine survival, and nearshore conditions for returning adults. General marine survival has a high impact on sockeye population numbers, whereas effects of the other factors are insignificant or unknown (Haggerty and others, 2009). Fishery effects are included in the model so that the user can experiment with catch levels should sockeye eventually recover to harvestable levels. Nearshore habitat conditions are changing, but the effects on sockeye are unknown. Predation by marine mammals is thought to have a moderate impact but quantitative data are sparse.

A directed fishery for Lake Ozette sockeye does not currently (2019) exist but may in the future if population recovery is successful. Sport catch of sockeye from 1979 to 2004 in coastal areas was observed to be insignificant (Pacific Fishery Management Council, 2005), as was bycatch in coastal commercial fisheries (Haggerty and others, 2009). Ozette sockeye return earlier than other sockeye populations (Pacific Fishery Management Council, 2005), so they are not available to commercial and sport fisheries that target other salmon populations in Alaska, British Columbia, and Washington.

Lake Ozette sockeye smolts are notable for their large size (Dlugokenski and others, 1981; Blum 1988; Jacobs and others, 1996; Haggerty and others, 2009). The average mortality of large $(>115 \mathrm{~mm})$, southern $\left(<55^{\circ} \mathrm{N}\right.$ latitude) sockeye smolts in the marine environment is 83 percent (Koenings and others, 1993) based on data collected at various times in the 20th century from sites in Canada, Russia, and Alaska. Data from the Lake Ozette population show a marine survival range of 15-27 percent based on 3 years of data (1988, 1990, and 2000; Haggerty and others, 2009), which is consistent with survival estimates for other populations of large, southern range smolts. The default value for ocean mortality is set at 0.83 based on data from Lake Ozette 
and other southern areas with large smolts. The major decrease in Lake Ozette sockeye populations occurred during 1948-78 and may have improved after a climatic regime shift in 1976-77. However, the productivity of sockeye salmon from Washington and British Columbia has not been as clearly tied to climate regimes as has been reported for Alaskan sockeye (Stachura and others, 2014).

Lake Ozette sockeye are subject to predation by marine mammals as they approach the estuary. The effect is unknown but substantial numbers of fish return to the Ozette River with scars apparently inflicted by marine mammals (Gearin, and others 2002). The system may be experiencing an increase in marine mammal predators owing to the Marine Mammal Protection Act of 1972. California sea lion (Zalophus californianus) populations increased 5 percent per year during 1975-2008 (only counted in California; Carretta and others, 2017) and harbor seal numbers increased 4 percent per year during 1983-96 (Jefferies and others, 1997; Carretta and others, 2017). Meanwhile, Steller sea lions (Eumetopias jubatus) have increased at a rate of 4.5 percent per year from Oregon to southeastern Alaska between 1989 and 2015 (National Oceanic and Atmospheric Administration, 2018). Although there are no data from the mouth of the Ozette River, it seems safe to assume there has been an increase in marine mammals in recent decades. The default value for predation is set at 0.05 to indicate the potential importance of this source of mortality.

Observed changes in the tidal prism and estuarine environment have occurred since 1950. Specifically, a spit has formed and now constricts the mouth of the river. The effect of this change on sockeye salmon, if any, is unknown (Haggerty and others, 2009).

\section{Model Performance}

Estimates of survival parameters (for example, predation rates, flow-related mortality, and others) generally are lacking for Lake Ozette sockeye salmon, and most of those available are based on a short time-series of data. Nevertheless, we have provided the model with default values for what are considered the most consequential parameters. We based the default parameter values on available data for Lake Ozette or expert opinion when data were not available. Most choices are justified in the "Model Background/Justification" section and assumptions supporting model parameters can be summarized as follows:

- One-to-one replacement of spawners by progeny occurs when the spawner population is about 4,000. This is the rounded average population level and trend observed over the last 12 years of validated data (2000-11; National Marine Fisheries Service, 2015).

- Incubation survival at beaches is lower than literature values (7-9 percent compared with 12.7 [Quinn, 2005] and 12.5 [Foerster, 1968]) based on expert opinion.

- Incubation survival is higher at tributaries than beaches based on expert opinion.

- Ocean survival for Lake Ozette sockeye is higher than for most sockeye populations, which is typical of southern populations $\left(<55^{\circ} \mathrm{N}\right.$ latitude) having large smolts $(>115$ $\mathrm{mm})$.

- Hatchery fry to smolt survival is 7.2 percent (Umbrella Creek) and 2.2 percent (Big River) based on BY 2004 data. However, the model produces only 3.2-percent survival of Umbrella Creek hatchery fry to smolt survival using default values. To produce results closer to 7.2 percent would require changing model parameters for which we have more confidence. Model results are 2.2 percent for Big River hatchery fry. 
- At Umbrella Creek, the ratio of wild-to-hatchery return is 8:2 based on 13 years of data. We assume that the only differential mortality between wild and hatchery fish occurs during fry dispersal to Lake Ozette.

- Tributary dispersal mortality is greater than beach dispersal mortality owing to exposure of tributary fish to predation and low flow during emigration to the lake.

- Predation of returning adults in the nearshore is an important source of mortality; the default value of 5-percent mortality is based on expert opinion.

- The Lake Ozette sockeye population is having a small net increase, whereas tributary populations are increasing and beach populations are decreasing (data to 2013; National Marine Fisheries Service, 2015). The recent population may be about 3,600 (2000-11). Subsequent data (2015-17) suggest that the population averages about 6,750 fish, but these data are provisional and were estimated using new methodology (acoustic system rather than the weir) and may eventually be corrected by as much as 50 percent.

We placed model results in a larger perspective by comparing model results with mortality between life-history stage reported in the sockeye salmon literature. Model results were generated using default parameters both with and without adding hatchery fry. Literature values include a thorough review of available data from the Pacific Northwest, Canada, and Alaska by Foerster (1968), who developed a representative description of survival rates for the entire life cycle. Estimates for individual stages also can be gleaned from other sources (table 14), although the numbers may not be exactly comparable. For example, egg-to-fry survival may mean survival to the swim-up fry stage to one author while meaning survival to the dispersed fry stage to another author. Results for each stage from the default version of the model for Lake Ozette agree favorably with literature estimates when the model is initialized with 4,000 returning adults. Migration survival may be lower than literature estimates because model results indicate the presence of a weir, and egg-to-smolt survival is low owing to low incubation survival at beaches. Quinn's (2005) estimate of lake rearing survival may be higher than model results because Quinn was summarizing results for healthy populations (for example, Bristol Bay) where fry numbers likely exceed predator capacity. The greatest deviation of model results from published estimates is for returns per spawner where the model results are lower than published values. However, this may be an accurate description of the Lake Ozette sockeye population, which is in poor enough condition to merit threatened species status under the Endangered Species Act. 
Table 14. Comparison between published survival-rate estimates for multiple stages of the sockeye salmon life history with Lake Ozette sockeye life cycle model results when initialized with 4,000 salmon.

\begin{tabular}{|c|c|c|}
\hline $\begin{array}{c}\text { Life-history stage } \\
\text { described in literature }\end{array}$ & Survival estimates & Model comparison \\
\hline Upriver migration & 0.95 (Foerster, 1968) & 0.86 \\
\hline \multirow[t]{3}{*}{ Egg to fry } & 0.12 (Foerster, 1968; after dispersal) & Beach (before dispersal): 0.06 \\
\hline & 0.09 (Bradford, 1995) & Beach (after dispersal): 0.06 \\
\hline & $\begin{array}{l}0.07 \text { (Williams and Amend, 1976; after } \\
\text { dispersal) }\end{array}$ & $\begin{array}{l}\text { Tributary (before dispersal): } 0.12 \\
\text { Tributary (after dispersal): } 0.09\end{array}$ \\
\hline \multirow[t]{2}{*}{ Fry to smolt (lake rearing) } & 0.08 (Foerster, 1968) & Without hatchery input: 0.06 \\
\hline & 0.25 (Quinn, 2005) & With hatchery input: 0.08 \\
\hline \multirow[t]{2}{*}{ Egg to smolt } & 0.01 (Foerster, 1968) & 0.006 \\
\hline & 0.02 (Bradford, 1995) & \\
\hline \multirow[t]{4}{*}{ Smolt to adult (ocean rearing) } & 0.10 (Foerster, 1968) & 0.17 \\
\hline & 0.06 (Bradford, 1995) & \\
\hline & 0.17 (Koenings and others, 1993) & \\
\hline & $0.01-0.23($ Henderson and Cass, 1991) & \\
\hline \multirow[t]{4}{*}{ Return/spawner } & 1.9 (Foerster, 1968) & Without hatchery input: 0.99 \\
\hline & 1.9 (Haggerty and others, 2009) & With hatchery input: 1.1 \\
\hline & 2.5 (Mueter and others, 2002) & \\
\hline & 2.5-3.6 (Hinch and others, 1995) & \\
\hline
\end{tabular}

A rudimentary assessment of model sensitivity to changes in several parameters shows that some parameters clearly have more influence on sockeye success that others (fig. 23). Each graph shows the progeny returns that result from a range of initial returns using default parameters (square symbols, solid line). Default results are compared with a 5-percent increase or decrease in the focal parameter (diamond symbol, short dashes and circle symbols, long dashes). The simple line (no symbols, solid) represents a 1:1 replacement of initial returns with progeny returns. For example, progeny returns are almost four times greater when default incubation mortality is decreased by 5 percent (round symbols, long dashes; fig. 23a) than when incubation mortality is increased by 5 percent (diamond symbols, short dashes; fig. 23a) and when there are 10,000 initial returns.

A comparison among graphs indicates that changes in mortality parameters for stages with high levels of mortality (for example, incubation, lake rearing, and ocean) are more consequential in determining returning progeny than changes in factors causing lower mortality (for example, lake holding and beach spawner predation) and distribution of spawners to beaches compared to tributaries. The model user can investigate the importance of other parameters as well as manipulate more than one parameter at a time. 
a) Incubation Mortality

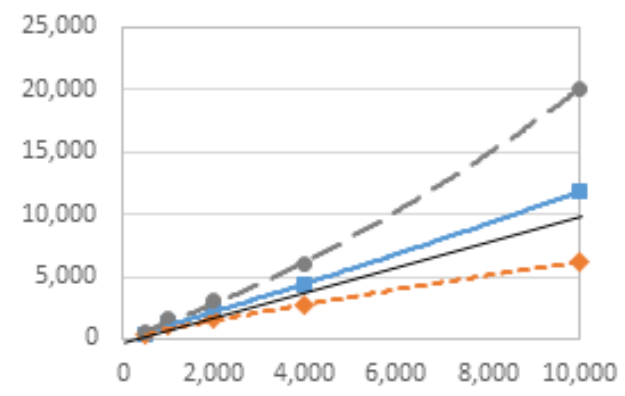

b) Lake Rearing Mortality

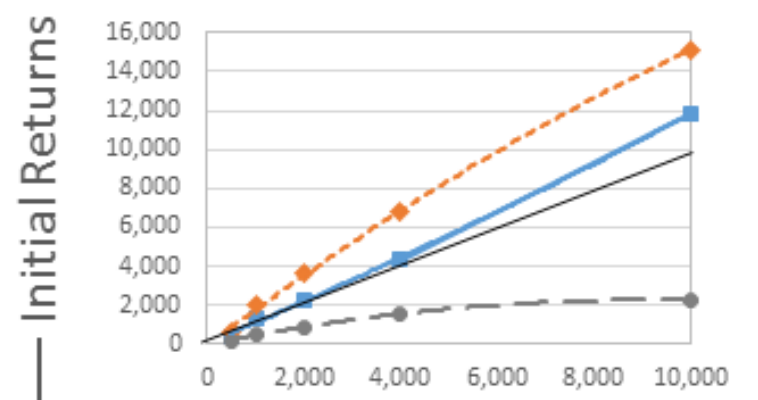

c) Ocean Mortality

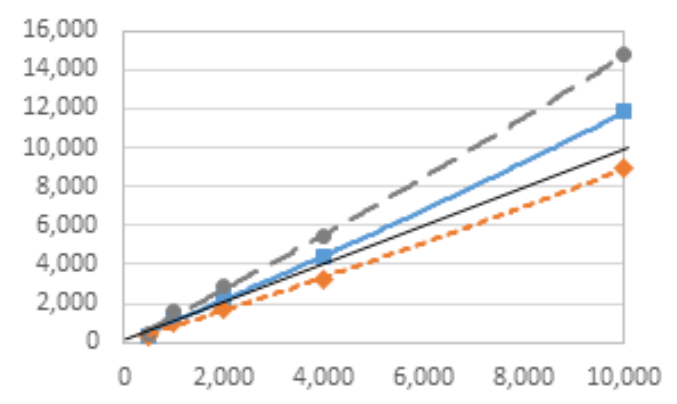

- Default (from equation)

$+5 \%$ of Default

$-5 \%$ of Default

Default $=0.93$ beachconcentrated, 0.88 tributary

$+5 \%$ of Default

$-5 \%$ of Default d) Lake Holding Predation Mortality

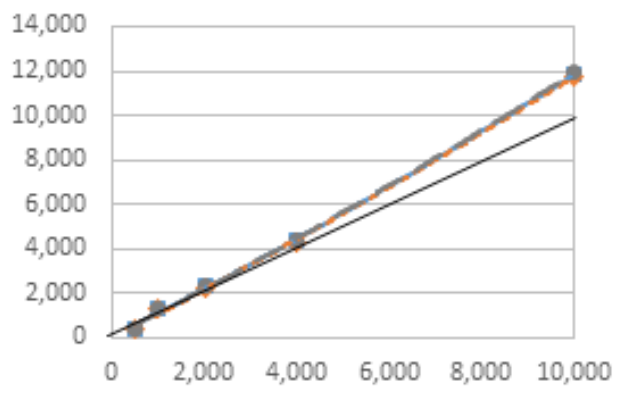

- Default $=.1$

$+5 \%$ of Default

$-5 \%$ of Default e) Beach Spawner Predation Mortality

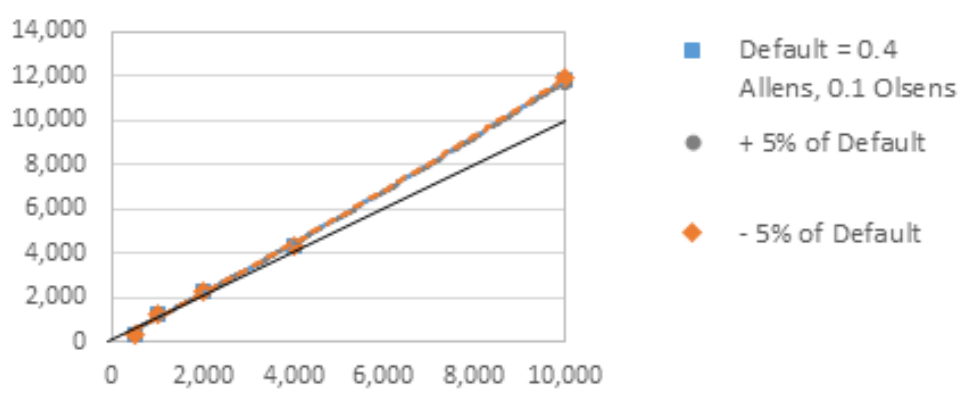

f) Beach-Tributary Spawner Distribution

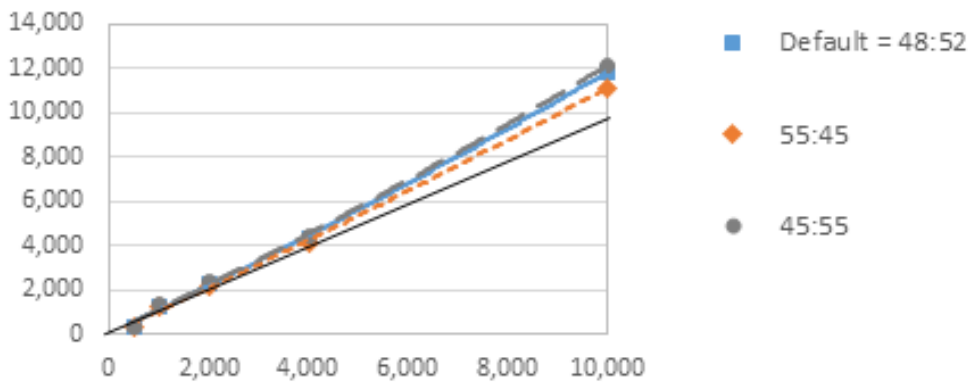

Progeny Returns

Figure 23. Graphs showing sensitivity of Lake Ozette sockeye life cycle model results to changes in several model parameters. a, incubation mortality; $b$, lake rearing mortality; c, ocean mortality; $d$, lake holding predation mortality; e, beach spawner predation mortality; and f, beach compared to tributary spawner distribution. Straight black lines indicate 1-to-1 replacement of spawners by progeny. 


\section{Model Uses and Limitations}

\section{Potential Uses of Model}

This system dynamics model of Lake Ozette sockeye salmon is a synthesis of available data and expert opinion structured to represent current hypotheses regarding interactions between Lake Ozette sockeye and their environment. It is built to be easily manipulated by resource managers of multiple agencies and Tribes as well as the general public, and could be used for the following purposes:

- Determining potential effect of management actions. Many stages of the freshwater life cycle of Lake Ozette sockeye salmon potentially are affected by management actions. Examples include predator control, LW jam manipulation, clearing encroaching vegetation from spawning beaches, and management of weirs. Any of these actions may be expensive and may have unintended consequences. Therefore, decisions should be informed by a synthetic understanding of the entire system to determine which actions are most likely to have the greatest positive effect and least negative consequences.

- Validating model with future data. As research and monitoring data continue to accumulate, better estimates may be made and greater certainty may occur regarding model parameters. Moreover, by comparing modeled survival with monitored survival, the accuracy of the model can be tested.

- Testing sensitivity of results to parameter values. Parameters in the model are based on relations primarily developed from relatively short time series of data, literature values, or expert opinion. By changing parameters and re-running the model, the user can determine the sensitivity of model outcomes. Eventually, a formal sensitivity analysis could be done to determine which parameters have the greatest influence on fish survival and should be supported with sound research.

- Outreach. The public and government agencies are keenly interested in management actions relevant to Lake Ozette sockeye. Private landowners at the edge of the lake could be affected by actions designed to change the lake level, remove encroaching vegetation, or affect sediment distribution. Several agencies (such as the National Marine Fisheries Service, U.S. Fish and Wildlife Service, and Washington Department of Fish and Wildlife) have management oversight or interest in federally listed endangered species and other protected taxa, either sockeye directly or predators of sockeye. The cultural interests and reserved treaty rights of Indian Tribes may be affected by sockeye management and recovery. Finally, the public may be interested because of a general interest in conservation and because regulations regarding recreational use of Lake Ozette (including fishing for other species) may be altered to aid sockeye recovery. The model will enable each of these parties to experiment with management actions and perhaps more easily reach consensus regarding acceptable actions.

- Improving monitoring program and restoration activities. Outcomes from model validation and tests of the sensitivity of model results to changes in parameters likely will suggest additional data needs, data that may not need to be collected, or more effective ways to collect data. The model ultimately could be used to redirect monitoring and restoration efforts and as a tool to test potential scenarios for improving growth, survival, and production of juvenile salmon. An obvious need exists to understand mortality during lake rearing and other life stages.

- Hypothesis Generation. Any surprising outcome from the model can be used to generate new hypotheses. For example, the model can be run for years when some environmental and fish numbers are known. Deviations of model results from data can be used to generate hypotheses regarding processes that might not be understood and factors that were not measured. 


\section{Model Limitations}

- All models necessarily simplify reality. Users of this model should be aware of its limitations and consider them when evaluating model outcomes:

- Limits of conceptual model. The model represents the current thinking of researchers and resource managers regarding factors limiting sockeye production. Although this conceptual model is based on direct experience and scientific evidence, the system is not perfectly understood; hence, the model may need to be modified as more information accumulates.

- Insufficient data. Most quantitative understanding of the Lake Ozette ecological system comes from short-term studies motivated by the need to inform the process of legally designating the taxon as endangered and developing a recovery plan. These studies did not include the full range and combination of possible environmental conditions. Therefore, many relations could not be described because these conditions may not have occurred during the sampled period. For example, the effect of low flow on fry dispersal in Big River is based on anecdotal observations.

- Not all the important factors were measured. Datasets were not available to describe all environmental factors and relations suspected to be important. Examples include predation by fish during lake rearing, predation by river otters on migrating and spawning adults, and the effect of smolt size on ocean survival. Some of these cases were addressed during model development using literature values (for example, estimates of survival between various life stages); however, the model would benefit from data to clarify all poorly understood relations.

- Unforeseen or unpredictable changes. A changing climate may give rise to unforeseen limiting factors resulting from novel combinations of conditions or to events that are more extreme than expected. Changes in abundance and distribution of invasive species and exotic diseases are other potential ecosystem stressors. Moreover, many assumptions may not hold in the future. For example, we do not know how fish may alter their life cycle to adapt to future environments or whether the relative importance of life-history bottlenecks will change under future hydrologic and temperature conditions.

- Simplistic representation of ocean conditions. Factors determining ocean survival are the least understood part of the sockeye life cycle, which comprises more than one-half of the length of each generation. Fish spend 24-30 months in the ocean, but little is known about which areas they use and for how long. Moreover, there are few data describing the environments they may inhabit at smaller-than-regional spatial scales. Therefore, it is difficult to develop a prediction for ocean survival based on environmental conditions.

- Deterministic model. The model does not describe the stochasticity of the real world. Therefore, it does not describe the variation in outcomes that results from the natural variation that is reduced to a simple, deterministic parameter value in the model. In other words, the user does not see the confidence interval that exists around the model prediction. 


\section{Acknowledgments}

We would like to thank the Lake Ozette Sockeye Steering Committee for encouragement and suggestions throughout the development of the model. We are grateful for sockeye data provided by the fisheries managers of the Makah Tribe. Andy Ritchie (U.S. Geological Survey [USGS]) was instrumental in developing the original population model for the limiting factors analysis and many other aspects of sockeye research at Lake Ozette while working for the Makah Tribe. Kurt Jenkins, Rebecca McCaffrey and Dave Beauchamp (all USGS) contributed helpful discussions of predator dynamics. Rich Osborne and Frank Hanson (both University of Washington) hosted a meeting at the Olympic National Resources Center so that the model could be explained in detail then tested and critiqued by people with expert knowledge of the Lake Ozette system. Participants in the meeting included representatives of the Makah Tribe, Olympic National Park, Olympic Natural Resources Center, National Oceanic and Atmospheric Administration, University of Wyoming, and the USGS. We also would like to thank Dave Beauchamp (USGS), Joseph Benjamin (USGS), and Roger Peters (U.S. Fish and Wildlife Service) for insightful reviews of the users' guide.

\section{References Cited}

Ames, J., and Beecher, H., 2001, Incorporating flood risk into controlled spawning flow regimes for Pacific salmon-An example using the Cedar River sockeye salmon: Washington Department of Fish and Wildlife Report No. FTP 01-13, 123 p.

Bash, J., Berman, C., and Bolton, S., 2001, Effects of turbidity and suspended solids on salmonids: Seattle, University of Washington, Center for Streamside Studies, 66 p. plus appendixes, https://www.wsdot.wa.gov/Research/Reports/500/526.1.htm.

Beauchamp, D.A., LaRiviere, M.G., and Thomas, G., 1995, Evaluation of competition and predation as limits to juvenile kokanee and sockeye salmon production in Lake Ozette, Washington: North American Journal of Fisheries Management, v. 15, p. 193-207.

Berman, C.H., and Quinn, T.P., 1991, Behavioural thermoregulation and homing by spring chinook salmon, Oncorhynchus tshawytscha (Walbaum), in the Yakima River: Journal of Fish Biology, v. 39, p. 301-312.

Bjornn, T.C., and Reiser, D.W., 1991, Habitat requirements of salmonids in streams, in Meehan, W.R., ed., Influences of forest and rangeland management on salmonid fishes and their habitats: American Fisheries Society Special Publication 19, p. 83-138.

Blum, J.P., 1988, Assessment of factors affecting sockeye salmon (Oncorhynchus nerka) production in Ozette Lake, WA: Seattle, University of Washington, M.S. thesis, 107 p.

Bortleson, G.C., and Dion, N.P., 1979, Preferred and observed conditions for sockeye salmon in Ozette Lake and its tributaries, Clallam County, Washington: U.S. Geological Survey Water Resources Investigations Report 78-64, 61 p.

Bradford, M.J., 1995, Comparative review of Pacific salmon survival rates: Canadian Journal of Fisheries and Aquatic Sciences, v. 52, p. 1327-1338.

Burgner, R.L., 1991, Life history of sockeye salmon Oncorhynchus nerka, in Groot, C., and Margolis, L., eds., Pacific salmon life histories: Vancouver, Canada, University of British Columbia Press, p. 1-117. 
Carretta, J.V., Forney, K.A., Oleson, E.M., Weller, D.W., Lang, A.R., Baker, J., Muto, M.M., Hanson, B., Orr, A.J., Huber, H., Lowry, M.S., Barlow, J., Moore, J.E., Lynch, D., Carswell, L., and Brownell, R.L., Jr., 2017, U.S. Pacific marine mammal stock assessments, 2016:

National Oceanic and Atmospheric Administration Technical Memorandum NMFS-SWFSC577, $407 \mathrm{p}$.

Cederholm, C.J., Reid, L.M., and Salo, E.O., 1981, Cumulative effects of logging road sediment on salmonid populations in the Clearwater River, Jefferson County, Washington, in, Conference on salmon spawning gravel-A renewable resource in the Pacific Northwest?, Seattle, Washington, October 6-7, 1980, Proceedings: Pullman, Washington State University, Water Research Center, Report 39, p. 38-74.

Crossin, G.T., Hinch, S.B., Cooke, S.J., Welch, D.W., Patterson, D.A., Jones, S.R.M., Lott, A.G., Leggat, R.A., Mathes, M.T., Shrimpton, J.M., Van Der Kraak, G., and Farrell, A., 2008, Exposure to high temperature influences the behavior, physiology, and survival of sockeye salmon during spawning migration: Canadian Journal of Zoology, v. 86, p. 127-140.

Dlugokenski, C., Bradshaw, W., and Hager, S., 1981, An investigation of the limiting factors to Lake Ozette sockeye salmon production and a plan for their restoration: U.S. Fish and Wildlife Service, Fisheries Assistance Office, 52 p. plus appendixes.

Foerster, R.E., 1968, The sockeye salmon, Oncorhynchus nerka: Ottawa, Fisheries Research Board of Canada, Bulletin 162, $422 \mathrm{p}$.

Ford, A., 1999, Modeling the environment, second edition: Washington, D.C., Island Press, $380 \mathrm{p}$.

Gearin, P.J., Hughes, K.M., Haggerty, M.J., Ritchie, A.C., Crewson, M.J., Cooke, L., Wilke, L., Dhruv, M.I., Banks, A.S., Laake, J., Delong, R.L., Griffith, J., Gosho, M.E., Orr, A.J., and Huber, H.R., 2002, Investigations of pinniped and river otter interactions with Lake Ozette sockeye salmon, Oncorhynchus nerka, 1998-2000: Neah Bay, Washington, National Oceanic and Atmospheric Administration, National Marine Mammal Laboratory, Alaska Fisheries Science Center, Makah Fisheries Management, 16 p.

Groot, C., and Margolis, L., 1991, Pacific salmon life histories: Vancouver, Canada, University of British Columbia Press, 564 p.

Gustafson, R.G., Wainwright, T.C., Winans, G.A., Waknitz, F.W., Parker, L.T., and Waples, R.S., 1997, Status review of sockeye salmon from Washington and Oregon: National Oceanic and Atmospheric Administration Technical Memorandum NMFS-NWFSC-33, 283 p.

Haggerty, M.J., and Ritchie, A.C., 2004, Lake Ozette tributary habitat conditions-A summary of Ozette watershed baseline habitat inventory data: Neah Bay, Washington, Makah Indian Tribe, $139 \mathrm{p}$.

Haggerty, M.J., Ritchie, A.C., Shellberg, J., Crewson, M., and Jalonen, J., 2009, Lake Ozette sockeye limiting factors analysis: Prepared for the Makah Indian Tribe and National Oceanic and Atmospheric Administration Fisheries in cooperation with the Lake Ozette Sockeye Steering Committee, Port Angeles, Washington, 565 p., accessed July 2018, at https://www.westcoast.fisheries.noaa.gov/publications/recovery_planning/salmon_steelhead/d omains/puget sound/lake ozette/lakeozetterecoveryplan lfa.pdf.

Hansen, A.G., Gardner, J.R., and Beauchamp, D.A., 2016, Growth, distribution, and abundance of pelagic fishes in Lake Washington-March and October 2015: Final report to Seattle Public Utilities, Washington Cooperative Fish and Wildlife Research Unit Report \#WACFRU-16-01, $30 \mathrm{p}$. 
Hartt, A.C., and Dell, M.B., 1986, Early oceanic migrations and growth of juvenile Pacific salmon and steelhead trout: Bulletin-International North Pacific Fisheries Commission, v. 46, p. 1-105.

Henderson, M.A., and Cass, A.J., 1991, Effect of smolt size on smolt-to-adult survival for Chilko Lake sockeye salmon (Oncorhynchus nerka): Canadian Journal of Fisheries and Aquatic Sciences, v. 48, p. 988-994.

Herrera Environmental Consultants, 2005, Hydraulic and geomorphic evaluation-Analysis of wood loading in the Ozette River and its effect on water levels in Lake Ozette, Clallam County, Washington: Unpublished report prepared for Makah Fisheries Management, Neah Bay, Washington, 134 p. plus appendixes.

Herrera Environmental Consultants, 2006, Reconnaissance study of geomorphic conditionsLake Ozette watershed: Unpublished report prepared for Olympic National Park, Port Angeles, Washington, $154 \mathrm{p}$. plus appendixes.

Hinch, S.G., Healey, M.C., Diewert, R.E., Henderson, M.A., Thomson, K.A., Hourston, R., and Juanes, F., 1995, Potential effects of climate change on marine growth and survival of Fraser River sockeye salmon: Canadian Journal of Fisheries and Aquatic Sciences, v. 52, p. 26512659.

Hinch, S.G., and Martins, E.G., 2011, A review of potential climate change effects on survival of Fraser River sockeye salmon and an analysis of interannual trends in en route loss and prespawn mortality: Vancouver, British Columbia, Cohen Commission Technical Report 9, 134 p. Hughes, K.M., Crewson, M.J., and Ritchie, A.C., 2002, FY-2001 hatchery reform phase II telemetry study of Lake Ozette sockeye: Neah Bay, Washington, Makah Fisheries Management, $6 \mathrm{p}$.

Hyatt, K.D., Stockwell, M.M., and Rankin, D.P, 2003, Impact and adaptation responses of Okanogan River sockeye salmon (Oncorhynchus nerka) to climate variation and change effects during firewater migration-Stock restoration and fisheries management implications: Canadian Water Resources Journal, v. 28, p. 689-713.

Jacobs, R., Larson, G., Meyer, J., Currence, N., Hinton, J., Adkison, M., and Burgner, R., 1996, The sockeye salmon Oncorhynchus nerka populations in Lake Ozette, Washington, USA: National Park Service, Technical Report NPS/CCSOSU/NRTR-96/04, 140 p.

Jefferies, S. J., Brown, R. F., Huber, H.R., and DeLong, R. L., 1997, Assessment of harbor seals in Washington and Oregon, 1996, in Hill, P. S., and DeMaster, D.P., eds., MMPA and ESA implementation program, 1996: Seattle, Washington, National Marine Fisheries Laboratory, AFSC Processed Report 97-10, p. 83-94.

Kemmerich, J., 1945, A review of the artificial propagation and transplantation of the sockeye salmon of the Puget Sound area in the State of Washington conducted by the Federal Government from 1896 to 1945: U.S. Fish and Wildlife Service, 114 p.

Koenings, J.P., Geiger, H.J., and Hasbrouck, J.J., 1993, Smolt-to-adult survival patterns of sockeye salmon -Effects of smolt length and geographic latitude when entering the sea:

Canadian Journal of Fisheries and Aquatic Sciences, v. 49, p. 600-611.

Kondolf, G.M., Sale, M.J., and Wolman, M.G., 1993, Modification of fluvial gravel size by spawning salmonids: Water Resources Research, v. 29, p. 2265-2274.

Kramer, R., 1953, Completion report by stream clearance unit on Ozette and Big Rivers: Olympia, Washington, Washington Department of Fisheries, Stream Improvement Division, $11 \mathrm{p}$. 
Lapointe, M., Eaton, B., Driscoll, S., and Latulippe, C., 2000, Modeling the probability of salmonid egg pocket scour due to floods: Canadian Journal of Fisheries and Aquatic Sciences, v. 57, p. 1120-1130.

Lisle, T.E., Nelson, J.M., Pitlick, J., Madej, M.A., and Barkett, B.L., 2000, Variability of bed mobility in natural, gravel-bed channels and adjustments to sediment load at local and reach scales: Water Resources Research, v. 36, p. 3743-3755.

Lunt, J., and Smee, D.L., 2015, Turbidity interferes with foraging success of visual but not chemosensory predators: PeerJ-The Journal of Life and Environmental Sciences, v. 3, p. e1212.

Makah Fisheries Management, 2000, Lake Ozette sockeye hatchery and genetic management plan-Biological assessment, Section 7 consultation, October 23, 2000: Prepared by Makah Fisheries Management, Neah Bay, Washington, for Bureau of Indian Affairs, 219 p.

Makah Fisheries Management, 2015, Appendix Lake Ozette Sockeye Hatchery Genetics Management Plan Extension Request supporting tables. Prepared by Joseph Hinton, Makah Fisheries Hatchery Manager. Makah Fisheries Management, Neah Bay, Washington, 14 p.

Manzer, J.I., and Miki, I., 1986, Fecundity and egg retention of some sockeye salmon (Oncorhynchus nerka) stocks in British Columbia: Canadian Journal of Fisheries and Aquatic Sciences, v. 34, p. 1643-1655.

McDonald, J.G., 1969, Distribution, growth, and survival of sockeye fry (Oncorhynchus nerka) produced in natural and artificial stream environments: Journal of the Fisheries Research Board of Canada, v. 26, p. 229-267.

McHenry, M.L., Morrill, D.C., and Currence, E., 1994, Spawning gravel quality, watershed characteristics and early life history survival of coho salmon and steelhead in five north Olympic Peninsula watersheds: Lower Elwha S'Klallam Tribe, Port Angeles, Washington, and Makah Tribe, Neah Bay, Washington, 59 p.

Meyer, J., and Brenkman, S., 2001, Water quality conditions in the Lake Ozette Basin, Washington and potential impacts to salmonids: Olympic National Park, Port Angeles, Washington, $81 \mathrm{p}$.

Montgomery, D.R., Buffington, J.M., Peterson, N.P., Schuett-Hames, D., and Quinn, T.P., 1996, Stream-bed scour, egg burial depths, and the influence of salmonid spawning on bed surface mobility and embryo survival: Canadian Journal of Fisheries and Aquatic Sciences, v. 53, p. 1061-1070.

Mueter, F.J., Peterman, R.M., and Pyper, B.J., 2002, Opposite effects of ocean temperature on survival rates of 120 stocks of Pacific salmon (Oncorhynchus spp.) in northern and southern areas: Canadian Journal of Fisheries and Aquatic Sciences, v. 59, p. 456-463.

National Marine Fisheries Service, 2009, Recovery plan for Lake Ozette sockeye salmon (Oncorhynchus nerka): National Marine Fisheries Service, Northwest Regional Office, Seattle, Washington. 394 p.

National Marine Fisheries Service, 2015, An Endangered Species Act (ESA) Section 7 Biological Opinion and Magnuson-Stevens Fishery Conservation and Management Act essential fish habitat (EFH) consultation-WCR-2015-2484: National Marine Fisheries Service West Coast Region, Sustainable Fisheries Division, Seattle, Washington, 45 p. National Oceanic and Atmospheric Administration, 1999, Endangered and threatened speciesThreatened status for Ozette Lake sockeye salmon in Washington: Federal Register, v. 64, no. 57, p. 14528-14536, accessed October 20, 2018, at https:/www.govinfo.go v/content/pkg/FR1999-03-25/pdf/99-6813.pdf. 
National Oceanic and Atmospheric Administration, 2005a, Endangered and threatened speciesFinal listing determinations for 16 ESUs of West Coast salmon, and final 4(d) protective regulations for threatened salmonid ESUs: Federal Register, v. 70, no. 123, p. 37160-37204, accessed September 15, 2018, at https://www.govinfo.gov/content/pkg/FR-2005-06-28/pdf/0512351.pdf.

National Oceanic and Atmospheric Administration, 2014, Endangered and threatened wildlifeFinal rule to revise the Code of Federal Regulations for species under the jurisdiction of the National Marine Fisheries Service: Federal Register, v. 79, no. 71, p. 20802-20817, accessed September 10, 2018, at https:/www. westcoast. fisheries.noaa.gov/publications/frn/2014/79fr20802.pdf.

National Oceanic and Atmospheric Administration, 2018, Steller sea lion: National Oceanic and Atmospheric Administration Fisheries web page, accessed September 15, 2018, at https:/www. fis heries.noaa.go v/species/steller-sea-lion.

Newcombe, C.P., and Jensen, J.O.T., 1996, Channel suspended sediment and fisheries: a synthesis for quantitative assessment of risk and impact: North American Journal of Fisheries Management, v. 16, p. 693-727.

Northwest Fisheries Science Center, 2015, Status review update for Pacific salmon and steelhead listed under the Endangered Species Act: National Oceanic and Atmospheric Administration Fisheries, Pacific Northwest, Seattle, Washington. 356 p.

Pacific Fishery Management Council, 2005, Stock assessment and fishery evaluation documents-Review of 2004 ocean salmon fisheries: Portland, Oregon, Pacific Fishery Management Council, 309 p., https://www.pcouncil.org/salmon/stock-assessment-and-fisheryevalutaion-safe-documents/review-of-2004-ocean-salmon-fisheries.

Peterson, D.P., and Foote, C.J., 2000, Disturbance of small-stream habitat by spawning sockeye salmon in Alaska: Transactions of the American Fisheries Society, v. 129, p. 924-934.

PRISM Climate Group, 2018, 30-yr normal: PRISM climate group web page, accessed March 8, 2019, at http://www.prism/ore gonstate.edu/normals.

Quinn, T.P., 2005, The behavior and ecology of pacific salmon and trout: Bethesda, Maryland, American Fisheries Society, $378 \mathrm{p}$.

Ritchie, A.C., 2005, Lake Ozette shoreline morphology-1953-2003: Unpublished progress report submitted to Olympic National Park, Port Angeles, Washington, 9 p.

Ruggerone, G.T., and Rogers, D.E., 1992, Predation on sockeye salmon fry by juvenile coho salmon in the Chignik Lakes, Alaska-Implications for salmon management: North American Journal of Fisheries Management, v. 12, p. 87-102.

Servizi, J.A., and Jensen, J.O.T., 1977, Resistance of adult sockeye salmon to acute thermal shock: International Pacific Salmon Commission Progress Report No. 34, 11 p.

Shellberg, J.G., 2002, Hydrologic, geomorphic, and biologic influences on redd scour in bull char (Salvelinus confluentus) spawning streams: Seattle, University of Washington, M.S. thesis, $224 \mathrm{p}$.

Smith, C., 2000, Salmon and steelhead habitat limiting factors Water Resource Inventory Area 20-North coastal streams: Olympia, Washington, Washington State Conservation Commission.

Stachura, M.M., Mantua, N.J., and Scheuerell, M.D., 2014, Oceanographic influences on patterns in North Pacific salmon abundance: Canadian Journal of Fisheries and Aquatic Sciences, v. 71, p. 226-235. 
Swindell, E.G., 1941, Transcript of minutes of a meeting between Mr. E.G. Swindell, Jr. (U.S. Attorney Office, representing Taholah Indian Agency) and Makah Indians, discussing traditional fishing locations: Neah Bay, Washington, Makah Museum.

Tabor, R., Chan, J., and Hager, S., 1998, Predation of sockeye salmon fry by cottids and other predatory fishes in the Cedar River and southern Lake Washington: Lacey, Washington, U.S. Fish and Wildlife Service, unpublished report, $54 \mathrm{p}$.

Torgersen, C.E., Price, D.M., Li, H.W., and McIntosh, B.A., 1999, Multiscale thermal refugia and stream habitat associations of Chinook salmon in northeastern Oregon: Ecological Applications, v. 9, p. 301-319.

Washington Department of Fisheries, 1955, Salmon fisheries of Washington coastal rivers and harbors: Olympia, Washington Department of Fisheries, 70 p.

Waters, T.F., 1995, Sediment in streams: Bethesda, Maryland, American Fisheries Society Monograph No. 7.

Williams, I.V., and Amend, D.F., 1976, A natural epizootic of infectious hematopoietic necrosis in fry of sockeye salmon (Oncorhynchus nerka) at Chilko Lake, British Columbia: Journal of the Fisheries Research Board of Canada, v. 33, p. 1564-1567.

Wood, J.W., 1968, Disease of Pacific salmon-Their prevention and treatment: Olympia, Washington Department of Fisheries, Hatchery Division, $82 \mathrm{p}$.

Wray, J., 1997, Olympic National Park ethnographic overview and assessment: Prepared for, Olympic National Park, Port Angeles, Washington, 252 p. 


\section{Appendix 1. Model Structure in Stella Architect ${ }^{\circledR}$}

This screen capture of the life-history model for sockeye salmon (Oncorhynchus nerka) at Ozette Lake, Northwestern Washington, as structured in Stella Architect ${ }^{\circledR}$ (fig. 1.1), shows how model parameters relate to each other. Equations defining those relations are shown in appendix 2. Elements in green enable the outputs from stocks to be displayed in one column and can be ignored for most purposes.

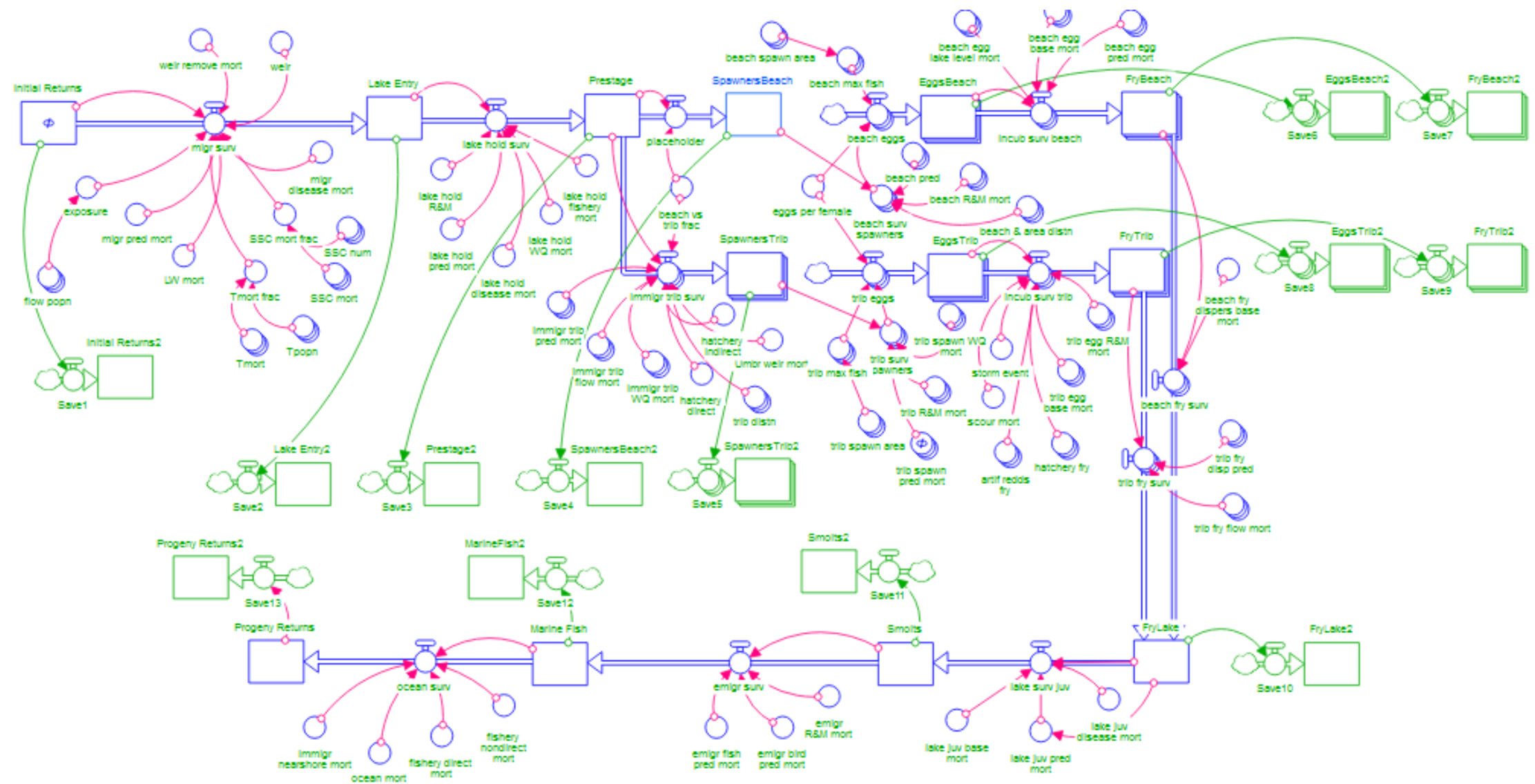

Figure 1.1. Screen capture of model structure as displayed in Stella Architect巴 Version 1.6.2 system dynamics software. 


\section{Appendix 2. Model Equations in Stella Architect ${ }^{\circledR}$}

The following equations are used by Stella Architect $^{\circledR}$ to calculate each of the elements of the lifehistory model for sockeye salmon (Oncorhynchus nerka) at Ozette Lake, Northwestern Washington. The intial values of stocks are indicated by 'INIT". Documentation found in the model to describe model elements is found following "DOCUMENT".

Top-Level Model:

EggsBeach[Allen, Concentrated] $(\mathrm{t})=$ EggsBeach[Allen, Concentrated] $(\mathrm{t}-\mathrm{dt})+($ beach_eggs[Allen, Concentrated] - incub_surv_beach[Allen, Concentrated] $) * \mathrm{dt}\{$ NON-NEGATIVE $\}$

INIT EggsBeach[A $\overline{l l}$ en, Concentrated] $=0$

DOCUMENT: Eggs deposited in dispersed and concentrated spawning areas of each beach.

EggsBeach[Allen, Dispersed] $(\mathrm{t})=$ EggsBeach[Allen, Dispersed] $(\mathrm{t}-\mathrm{dt})+($ beach_eggs[Allen, Dispersed]

- incub_surv_beach[Allen, Dispersed] $*$ dt $\{$ NON-NEGATIVE\}

INIT EggsBeach[Allen, Dispersed] $=0$

DOCUMENT: Eggs deposited in dispersed and concentrated spawning areas of each beach.

EggsBeach[Olsen, Concentrated] $(\mathrm{t})=$ EggsBeach[Olsen, Concentrated] $(\mathrm{t}-\mathrm{dt})+($ beach_eggs[Olsen, Concentrated] - incub_surv_beach[Olsen, Concentrated]) *dt $\{$ NON-NEGATIVE\}

INIT EggsBeach[Olsen, Concentrated] $=0$

DOCUMENT: Eggs deposited in dispersed and concentrated spawning areas of each beach.

EggsBeach[Olsen, Dispersed] $(\mathrm{t})=$ EggsBeach[O lsen, Dispersed] $(\mathrm{t}-\mathrm{dt})+($ beach_eggs[Olsen,

Dispersed] - incub_surv_beach[Olsen, Dispersed] $) * d t$ NON-NEGATIVE $\}$

INIT EggsBeach[Olsen, Dispersed] $=0$

DOCUMENT: Eggs deposited in dispersed and concentrated spawning areas of each beach.

DOCUMENT: Eggs deposited in dispersed and concentrated spawning areas of each beach.

INFLOWS:

beach_eggs[Allen, Concentrated] $=$ IF(beach_surv_spawners[Allen,

Concentrated]<beach_max_fish[Allen, Concentrated]) THEN beach_surv_spawners[Allen,

Concentrated] $/ 2 *$ eggs_per_female ELSE beach_max_fish[Allen, Concentrated] $/ 2 *$ eggs_per_female

$\{$ UNIFLOW\}

DOCUMENT: This flow generates eggs depending on number of surviving female spawners and eggs per redd.

beach_eggs[Allen, Dispersed] = IF (beach_surv_spawners[Allen, Dispersed] $<$

beach_max_fish[Allen, Dispersed]) THEN beach_surv_spawners[Allen, Dispersed]/2 * eggs_per_female ELSE beach_max_fish[Allen, Dispersed] $/ 2 *$ eggs_per_female \{UNIFLOW\}

DOCUMENT: This flow generates eggs depending on number of surviving female spawners and eggs per redd.

beach_eggs[Olsen, Concentrated] = IF (beach_surv_spawners[O1sen, Concentrated] $<$ beach_max_fish[Olsen, Concentrated]) THEN beach_surv_spawners[Olsen, Concentrated] $/ 2$ *eggs_per_female ELSE beach_max_fish[Olsen, Concentrated] $/ 2 *$ eggs_per_female $\{$ UNIFLOW $\}$

DOCUMENT: This flow generates eggs depending on number of surviving female spawners and eggs per redd.

beach_eggs[Olsen, Dispersed] = IF (beach_surv_spawners[Olsen, Dispersed] $<$

beach_max_fish[Olsen, Dispersed]) THEN beach_surv_spawners[Olsen, Dispersed]/2* eggs_per_female ELSE beach_max_fish[Olsen, Dispersed] $/ 2 *$ eggs_per_female $\{$ UNIFLOW\} 
DOCUMENT: This flow generates eggs depending on number of surviving female spawners and eggs per redd.

DOCUMENT: This flow generates eggs depending on number of surviving female spawners and eggs per redd.

OUTFLOWS:

incub_surv_beach[Allen, Concentrated] $=$ EggsBeach[Allen,Concentrated $]^{*}(1-$

(beach_egg_lake_level_mort[Allen,Concentrated]+beach_egg_base_mort[Allen,Concentrated]+beach egg pred_mort[Ällen,Concentrated])) \{UNIFLOW\}

DOCUMENT: Number of fish transferred from EggsBeach stock to FryBeach stock to represent eggs that survive incubation to become fry at each spawning area and beach.

incub_surv_beach[Allen, Dispersed] $=$ EggsBeach[Allen, Dispersed] $*(1-$

(beach_egg_lake_level_mort[Allen, Dispersed]+beach_egg_base_mort[Allen, Dispersed]+beach_egg_pred_mort[Allen, Dispersed])) $\{$ UNIFLOW

DOCUMENT: Number of fish transferred from EggsBeach stock to FryBeach stock to represent eggs that survive incubation to become fry at each spawning area and beach.

incub_surv_beach [Olsen, Concentrated] $=$ EggsBeach[Olsen,Concentrated $]^{*}(1-$ (beach_egg_lake_level_mort[Olsen,Concentrated]+beach_egg_base_mort[Olsen,Concentrated]+beach_ egg_pred_mort[Ölsen,Concentrated])) \{UNIFLOW

DOCUMENT: Number of fish transferred from EggsBeach stock to FryBeach stock to represent eggs that survive incubation to become fry at each spawning area and beach.

incub_surv_beach[Olsen, Dispersed] $=$ EggsBeach[Olsen, Dispersed $]^{*}(1-$ (beach_egg_lake_level_mort[Olsen, Dispersed]+beach_egg_base_mort[Olsen, Dispersed]+beach_egg_pred_mort[Olsen, Dispersed])) $\{$ UNIFLOW

DOCUMENT: Number of fish transferred from EggsBeach stock to FryBeach stock to represent eggs that survive incubation to become fry at each spawning area and beach.

DOCUMENT: Number of fish transferred from EggsBeach stock to FryBeach stock to represent eggs that survive incubation to become fry at each spawning area and beach.

EggsBeach2[Beach, Redd_Density](t) = EggsBeach2[Beach, Redd_Density](t - dt) $+($ Save6[Beach, Redd_Density] $) * \mathrm{dt}\{$ NON-NEGATIVE $\}$

INIT EggsBeach2[Beach, Redd_Density] $=0$

DOCUMENT: First calculated value of FryBeach

INFLOWS:

Save6[Beach, Redd_Density] $=$ IF EggsBeach $>0$ AND $($ HISTORY (EggsBeach, TIME-1) $=0)$ THEN EggsBeach ELSE 0 \{UNIFLOW\}

DOCUMENT: Saves first calculated value of EggsBeach

EggsTrib[Umbrella] $(\mathrm{t})=$ EggsTrib[Umbrella] $(\mathrm{t}-\mathrm{dt})+($ trib_eggs[Umbrella] -

incub_surv_trib[Umbrella, Wild] - incub_surv_trib[Umbrella, Hatchery]) $*$ dt \{NON-NEGATIVE\}

INIT EggsTrib[Umbrella] $=0$

DOCUMENT: Eggs deposited at each tributary.

EggsTrib[Big](t) = EggsTrib[Big](t - dt) + (trib_eggs[Big] - incub_surv_trib[Big, Wild] incub_surv_trib[Big, Hatchery] $*$ dt $\{$ NON-NEGATIVE\}

INIT EggsTrib[Big] $=0$

DOCUMENT: Eggs deposited at each tributary.

DOCUMENT: Eggs deposited at each tributary.

INFLOWS:

trib_eggs[Umbrella] $=$ IF trib_surv_spawners[Umbrella] $>$ trib_max_fish[Umbrella] THEN trib_max_fish[Umbrella] $/ 2 *$ eggs_per_female ELSE trib_surv_spawners[Umbrella] $/ 2 *$ eggs_per_female $\{\mathrm{UN} \mathrm{N} F \overline{\mathrm{O}} \mathrm{W}\}$ 
DOCUMENT: This flow generates eggs depending on number of surviving female spawners and eggs per redd.

trib_eggs[Big] = IF trib_surv_spawners[Big]>trib_max_fish[Big] THEN

trib_max_fish[Big] $/ 2 *$ eggs_per_female ELSE trib_surv_spawners[Big]/2*eggs_per_female $\{\mathrm{UNIFLOW}\}$

DOCUMENT: This flow generates eggs depending on number of surviving female spawners and eggs per redd.

DOCUMENT: This flow generates eggs depending on number of surviving female spawners and eggs per redd.

OUTFLOWS:

incub_surv_trib[Umbrella, Wild] $=$ EggsTrib[Umbrella] $*(1-$

(trib_egg_R\&M_mort[Umbrella]+trib_egg_base_mort[Umbrella]+ (IF (storm_event $=1)$ THEN

scour_mort ELSE 0)) $)+($ IF EggsTrib[Ümbrella] $>0$ THEN artif_redds_fry[Umb-ella] ELSE 0)

$\{$ UNIFLOW\}

incub_surv_trib[Umbrella, Hatchery] $=$ IF (EggsTrib[Umbrella] $>0)$ THEN hatchery_fry[Umbrella] ELSE 0 \{UNIFLOW\}

incub_surv_trib [Big, Wild] $=$ EggsTrib $[\mathrm{Big}]^{*}(1-$

(trib_egg_base_mort[Big]+trib_egg_R\&M_mort[Big] + (IF(storm_event $=1)$ THEN scour_mort ELSE

$0)))+($ IF EggsTrib[Big] $>0$ THEN artif_redds_fry[Big] ELSE 0) \{UNIFLOW\}

incub_surv_trib[Big, Hatchery] $=$ IF (EggsTrib[Big]>0) THEN hatchery_fry[Big] ELSE 0 $\{\mathrm{UNIFLOW}\}$

EggsTrib2[Tributary] $(\mathrm{t})=$ EggsTrib2[Tributary] $(\mathrm{t}-\mathrm{dt})+($ Save8[Tributary] $) * \mathrm{dt}\{$ NON-NEGATIVE $\}$

INIT EggsTrib2[Tributary] $=0$

DOCUMENT: Saves initial value of EggsTrib

INFLOWS:

Save8[Tributary] = IF EggsTrib >0 AND (HISTORY(EggsTrib, TIME-1) $=0)$ THEN EggsTrib ELSE 0 \{UNIFLOW\}

DOCUMENT: Saves first calculated value of EggsTrib

FryBeach[Allen, Concentrated] $(\mathrm{t})=$ FryBeach[Allen, Concentrated] $(\mathrm{t}-\mathrm{dt})+($ incub_surv_beach[Allen, Concentrated] - beach_fry_surv[Allen, Concentrated] $) *$ dt $\{$ NON-NEGATIVE $\}$

INIT FryBeach[Allen, Concentrated] $=0$

DOCUMENT: Number of fry emerging from dispersed and concentrated spawning areas of each beach.

FryBeach[Allen, Dispersed] $(\mathrm{t})=$ FryBeach[Allen, Dispersed] $(\mathrm{t}-\mathrm{dt})+($ incub_surv_beach[Allen,

Dispersed] - beach_fry_surv[Allen, Dispersed] $) * \mathrm{dt}\{$ NON-NEGATIVE\}

INIT FryBeach[Ällen, Dispersed] $=0$

DOCUMENT: Number of fry emerging from dispersed and concentrated spawning areas of each beach.

FryBeach[Olsen, Concentrated $](t)=$ FryBeach[Olsen, Concentrated $](t-d t)+($ incub_surv_beach[Olsen, Concentrated] - beach_fry_surv[Olsen, Concentrated] $) *$ dt $\{$ NON-NEGATIVE\}

INIT FryBeach[Olsen, Concentrated] $=0$

DOCUMENT: Number of fry emerging from dispersed and concentrated spawning areas of each beach.

FryBeach[Olsen, Dispersed $](t)=$ FryBeach[Olsen, Dispersed $](t-d t)+($ incub_surv_beach[Olsen,

Dispersed] - beach_fry_surv[Olsen, Dispersed] $) * \mathrm{dt}\{$ NON-NEGATIVE\}

INIT FryBeach[Olsen, Dispersed] $=0$

DOCUMENT: Number of fry emerging from dispersed and concentrated spawning areas of each beach. 
DOCUMENT: Number of fry emerging from dispersed and concentrated spawning areas of each beach.

INFLOWS:

incub_surv_beach[Allen, Concentrated] $=$ EggsBeach[Allen,Concentrated] $*(1-$ (beach_egg_lake_level_mort[Allen,Concentrated]+beach_egg_base_mort[Allen,Concentrated]+beach_ egg_pred_mort[Āllen, $\bar{C}$ oncentrated])) \{UNIFLOW $\}$

DOCUMENT: Number of fish transferred from EggsBeach stock to FryBeach stock to represent eggs that survive incubation to become fry at each spawning area and beach.

incub_surv_beach[Allen, Dispersed] $=$ EggsBeach[Allen, Dispersed]* ${ }^{*} 1$ (beach_egg_lake_level_mort[Allen, Dispersed]+beach_egg_base_mort[Allen, Dispersed]+beach_egg_pred_mort[Allen, Dispersed])) $\{$ UNIFLOW\}

DOCUMENT: Number of fish transferred from EggsBeach stock to FryBeach stock to represent eggs that survive incubation to become fry at each spawning area and beach.

incub_surv_beach[Olsen, Concentrated $]=$ EggsBeach[Olsen,Concentrated $]^{*}(1-$

(beach_egg_lake_level_mort[Olsen,Concentrated]+beach_egg_base_mort[Olsen,Concentrated]+beach_ egg_pred_mort[Ōlsen, $\bar{C}$ Concentrated])) \{UNIFLOW\}

DOCUMENT: Number of fish transferred from EggsBeach stock to FryBeach stock to represent eggs that survive incubation to become fry at each spawning area and beach.

incub_surv_beach[Olsen, Dispersed] = EggsBeach[Olsen, Dispersed]*(1(beach_egg_lake_level_mort[Olsen, Dispersed]+beach_egg_base_mort[Olsen, Dispersed]+beach_egg_pred_mort[Olsen, Dispersed])) \{UNIFLOW\}

DOCUMENT: Number of fish transferred from EggsBeach stock to FryBeach stock to represent eggs that survive incubation to become fry at each spawning area and beach.

DOCUMENT: Number of fish transferred from EggsBeach stock to FryBeach stock to represent eggs that survive incubation to become fry at each spawning area and beach.

OUTFLOWS:

beach_fry_surv[Beach, Redd_Density] =FryBeach*(1-beach_fry_dispers_base_mort) $\{$ UNIFLOW $\}$

DOCUMENT: Number of fish transferred from FryBeach stock to FryLake stock representing fry surviving dispersal from beaches to lake. Predation is the only mortality factor and it is applied equally to fry from both redd density areas and both beaches.

FryBeach2[Beach, Redd_Density](t) = FryBeach2[Beach, Redd_Density](t - dt) + (Save7[Beach, Redd_Density $]$ * dt $\{$ NON-NEGATIVE $\}$

INIT FryBeach2[Beach, Redd_Density] $=0$

DOCUMENT: First calculated value of FryBeach

INFLOWS:

Save7[Beach, Redd_Density] $=$ IF FryBeach $>0$ AND (HISTORY(FryBeach, TIME -1$)=0)$ THEN FryBeach ELSE $0\{$ UNIFLOW $\}$

DOCUMENT: Saves first calculated value of FryBeach

FryLake $(\mathrm{t})=$ FryLake $(\mathrm{t}-\mathrm{dt})+($ trib_fry_surv[Umbrella, Wild] + trib_fry_surv[Umbrella, Hatchery] + trib_fry_surv[Big, Wild] + trib_fry_surv[Big, Hatchery] + beach_fry_surv[Allen, Concentrated] + beach_fry_surv[Allen, Dispersed] + beach_fry_surv[Olsen, Concentrated] + beach_fry_surv[Olsen, Dispersed] - lake_surv_juv) *dt $\{$ NON-NEGATTIVE $\}$

INIT FryLake $=0$

DOCUMENT: Fry surviving to enter Lake Ozette.

INFLOWS:

trib_fry_surv[Umbrella, Wild] $=$ FryTrib[Umbrella,Wild]*(1-trib_fry_disp_pred[Umbrella,Wild]trib_fry_flow_mort[Umbrella,Wild]) \{UNIFLOW 
DOCUMENT: Number of fish transferred from FryTrib stock to FryLake stock to represent survival of fry traveling from tributaries to lake. A switch is available to the user to indicate an extreme low flow event on Big River, which results in all fish being consumed by predators.

trib fry surv[Umbrella, Hatchery] = FryTrib[Umbrella,Hatchery] ${ }^{*}(1-$

trib_fry_disp_pred[Umbrella,Hatchery]-trib_fry_flow_mort[Umbrella,Hatchery]) \{UNIFLOW

DOCUMENT: Number of fish transferred from FryTrib stock to FryLake stock to represent survival of fry traveling from tributaries to lake. A switch is available to the user to indicate an extreme low flow event on Big River, which results in all fish being consumed by predators.

trib_fry_surv[Big, Wild] = FryTrib[Big,Wild]*(1-trib_fry_disp_pred[Big,Wild]trib_fry_flow_mort[Big,Wild]) \{UNIFLOW $\}$

DOCŪMENT: Number of fish transferred from FryTrib stock to FryLake stock to represent survival of fry traveling from tributaries to lake. A switch is available to the user to indicate an extreme low flow event on Big River, which results in all fish being consumed by predators.

trib_fry_surv[Big, Hatchery] = FryTrib[Big,Hatchery]*(1-trib_fry_disp_pred[Big,Hatchery]trib_fry_flow_mort[Big, Hatchery]) \{UNIFLOW

DOCŪMENT: Number of fish transferred from FryTrib stock to FryLake stock to represent survival of fry traveling from tributaries to lake. A switch is available to the user to indicate an extreme low flow event on Big River, which results in all fish being consumed by predators.

beach_fry_surv[Allen, Concentrated] = FryBeach*(1-beach_fry_dispers_base_mort) $\{$ UNIFLOW

DOCUMENT: Number of fish transferred from FryBeach stock to FryLake stock representing fry surviving dispersal from beaches to lake. Predation is the only mortality factor and it is applied equally to fry from both redd density areas and both beaches.

beach_fry_surv[Allen, Dispersed] $=$ FryBeach*(1-beach_fry_dispers_base_mort) $\{$ UNIFLOW

DOCUMENT: Number of fish transferred from FryBeach stock to FryLake stock representing fry surviving dispersal from beaches to lake. Predation is the only mortality factor and it is applied equally to fry from both redd density areas and both beaches.

beach_fry_surv[Olsen, Concentrated] = FryBeach*(1-beach_fry_dispers_base_mort) \{UNIFLOW

DOCUMENT: Number of fish transferred from FryBeach stock to FryLake stock representing fry surviving dispersal from beaches to lake. Predation is the only mortality factor and it is applied equally to fry from both redd density areas and both beaches.

beach_fry_surv[Olsen, Dispersed] $=$ FryBeach*(1-beach_fry_dispers_base_mort) \{UNIFLOW\}

DOCUMENT: Number of fish transferred from FryBeach stock to FryLake stock representing fry surviving dispersal from beaches to lake. Predation is the only mortality factor and it is applied equally to fry from both redd density areas and both beaches.

OUTFLOWS:

lake_surv_juv $=$ FryLake $*(1-($ lake_juv_pred_mort

+lake_juv_disease_mort+lake_juv_base_mort)) \{UNIFLOW

DOCUMENT: Number of fish transferred from FryLake stock to Smolts stock to represent survival of fish during juvenile rearing in lake.

FryLake2 $(\mathrm{t})=$ FryLake2 $(\mathrm{t}-\mathrm{dt})+($ Save 10$) * \mathrm{dt}$ (NON-NEGATIVE $\}$

INIT FryLake2 $=0$

DOCUMENT: First calculated value of FryLake

INFLOWS:

Save10 $=$ IF FryLake $>0$ AND $($ HISTORY $($ FryLake, TIME- 1$)=0)$ THEN FryLake ELSE 0 $\{$ UNIFLOW\}

DOCUMENT: Saves first calculated value of FryLake

FryTrib[Umbrella, Wild](t) = FryTrib[Umbrella, Wild](t - dt) + (incub_surv_trib[Umbrella, Wild] trib_fry_surv[Umbrella, Wild] $* \mathrm{dt}\{\mathrm{NON}-\mathrm{NEGATIVE}\}$ 
INIT FryTrib[Umbrella, Wild] $=0$

DOCUMENT: Number of fry emerging from each tributary spawning area.

FryTrib[Umbrella, Hatchery](t) = FryTrib[Umbrella, Hatchery] $(\mathrm{t}-\mathrm{dt})+($ incub_surv_trib[Umbrella, Hatchery] - trib_fry_surv[Umbrella, Hatchery] $*$ dt $\{$ NON-NEGATIVE\}

INIT FryTrib[Umbrella, Hatchery] $=0$

DOCUMENT: Number of fry emerging from each tributary spawning area.

FryTrib[Big, Wild](t) = FryTrib[Big, Wild](t - dt) + (incub_surv_trib[Big, Wild] - trib_fry_surv[Big, Wild] $) *$ dt $\{$ NON-NEGATIVE $\}$

INIT FryTrib[Big, Wild] $=0$

DOCUMENT: Number of fry emerging from each tributary spawning area.

FryTrib[Big, Hatchery](t) = FryTrib[Big, Hatchery](t - dt) + (incub_surv_trib[Big, Hatchery] trib_fry_surv[Big, Hatchery]) $*$ dt $\{$ NON-NEGATIVE $\}$

INIT FryTrib[Big, Hatchery] $=0$

DOCUMENT: Number of fry emerging from each tributary spawning area.

DOCUMENT: Number of fry emerging from each tributary spawning area.

INFLOWS:

incub_surv_trib[Umbrella, Wild] $=$ EggsTrib[Umbrella] $*(1-$

(trib_egg_R $\& M$ - mort[Umbrella]+trib_egg_base_mort[Umbrella]+ (IF (storm_event $=1)$ THEN

scour_mort ELSE 0)) $)+($ IF EggsTrib[Umbrella] $>0$ THEN artif_redds_fry[Umbrella] ELSE 0)

$\{\mathrm{UNIFLOW}\}$

incub_surv_trib[Umbrella, Hatchery] $=$ IF (EggsTrib[Umbrella] $>0)$ THEN hatchery_fry[Umbrella]

ELSE 0 \{UNIFLOW\}

incub_surv_trib[Big, Wild] $=$ EggsTrib[Big] ${ }^{*}(1-$

(trib_egg_base_mort[Big]+trib_egg_R\&M_mort[Big] +(IF(storm_event $=1)$ THEN scour_mort ELSE

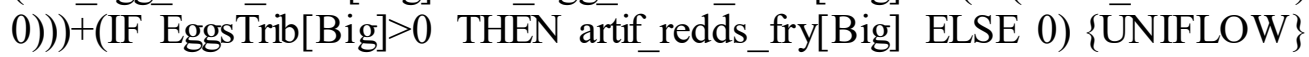

incub_surv_trib[Big, Hatchery] = IF (EggsTrib[Big] $>0)$ THEN hatchery_fry[Big] ELSE 0

$\{$ UNIFLOW

OUTFLOWS:

trib_fry_surv[Umbrella, Wild] $=$ FryTrib[Umbrella,Wild]*(1-trib_fry_disp_pred[Umbrella,Wild]trib_fry_flow_mort[Umbrella,Wild]) \{UNIFLOW

DOCUMENT: Number of fish transferred from FryTrib stock to FryLake stock to represent survival of fry traveling from tributaries to lake. A switch is available to the user to indicate an extreme low flow event on Big River, which results in all fish being consumed by predators.

trib_fry_surv[Umbrella, Hatchery] = FryTrib[Umbrella,Hatchery] ${ }^{*}(1-$

trib_fry_disp_pred[Umbrella,Hatchery]-trib_fry_flow_mort[Umbrella,Hatchery]) \{UNIFLOW\}

DOCUMENT: Number of fish transferred from FryTrib stock to FryLake stock to represent

survival of fry traveling from tributaries to lake. A switch is available to the user to indicate an extreme low flow event on Big River, which results in all fish being consumed by predators.

trib_fry_surv[Big, Wild] $=$ FryTrib[Big,Wild]*(1-trib_fry_disp_pred[Big,Wild]-

trib_fry_flow_mort[Big,Wild]) \{UNIFLOW

DOCUMMNT: Number of fish transferred from FryTrib stock to FryLake stock to represent

survival of fry traveling from tributaries to lake. A switch is available to the user to indicate an extreme low flow event on Big River, which results in all fish being consumed by predators.

trib_fry_surv[Big, Hatchery] = FryTrib[Big,Hatchery]*(1-trib_fry_disp_pred[Big,Hatchery]trib_fry_flow_mort[Big, Hatchery]) \{UNIFLOW

DOCUMENT: Number of fish transferred from FryTrib stock to FryLake stock to represent survival of fry traveling from tributaries to lake. A switch is available to the user to indicate an extreme low flow event on Big River, which results in all fish being consumed by predators. 
DOCUMENT: Number of fish transferred from FryTrib stock to FryLake stock to represent survival of fry traveling from tributaries to lake. A switch is available to the user to indicate an extreme low flow event on Big River, which results in all fish being consumed by predators.

FryTrib2[Tributary, Source] $(\mathrm{t})=$ FryTrib2[Tributary, Source] $(\mathrm{t}-\mathrm{dt})+($ Save9[Tributary, Source]) $* \mathrm{dt}$ $\{$ NON-NEGATIVE $\}$

INIT FryTrib2[Tributary, Source] $=0$

DOCUMENT: First calculated value of FryTrib

INFLOWS:

Save9[Tributary, Source] $=$ IF FryTrib $>0$ AND $($ HISTORY $($ FryTrib, TIME-1) $=0)$ THEN FryTrib ELSE 0 \{UNIFLOW\}

Initial_Returns $(\mathrm{t})=$ Initial_Returns $(\mathrm{t}-\mathrm{dt})+(-$ migr_surv $) * \mathrm{dt}\{\mathrm{NON}-\mathrm{NEGATIVE}\}$

INIT Initial_Returns $=4000$

DOCUMENT: Number of spawners entering Ozette River. Value can be set by user in interface.

OUTFLOWS:

migr_surv $=\left(\left(1-\left(16.39 *\left(\right.\right.\right.\right.$ Initial_Returns $\left.{ }^{\wedge}-.6765\right) *($ IF weir=1 THEN 1 ELSE $(1-$

weir_remove_mort) $))^{*} .531$ /exposure $)^{*}$ Initial_Returns) -

(Initial_Returns* $(\mathrm{LW}$ _mort+migr_pred_mort+migr_disease_mort+Tmort_frac + SSC_mort_frac $)$ ) $\{$ UNIFLOW

DOCUMENT: Number of fish transferred from Escapement stock to Lake Entry stock to reflect river immigration mortality. Mortality is based on baseline (current conditions, thought to mainly be due to predation and including effect of weir) and is a function of runsize (mortality as a proportion of population decreases as a negative exponential function of runsize). Mortality due to disease, SSC events, high stream temperature, number of LWD jams and changes in predation that is not determined by runsize (e.g., change in number of predators) that differ from baseline are also incorporated. Baseline mortality also reflects the proportion of the population that migrates at night, and is therefore more subject to predation. It is also lowered by a proportion that can be adjusted by user (weir mort) if the weir is removed.

Initial_Returns $2(\mathrm{t})=$ Initial_Returns $2(\mathrm{t}-\mathrm{dt})+($ Save 1$) * \mathrm{dt}\{\mathrm{NON}-\mathrm{NEGATIVE}\}$

INIT Initial_Returns $2=0$

DOCUMENTT: Initial value of Initial Returns

INFLOWS:

Save1 $=$ IF $($ TIME $<1)$ THEN Initial Returns ELSE $0\{$ UNIFLOW

DOCUMENT: Saves initial value of Initial Returns

Lake_Entry $(\mathrm{t})=$ Lake_Entry $(\mathrm{t}-\mathrm{dt})+($ migr_surv - lake_hold_surv $) * \mathrm{dt}\{\mathrm{NON}-\mathrm{NEGATIVE}\}$

INIT Lake_Entry $=0$

DOCUMENT: Number of sockeye spawners immigrating to Lake Ozette.

INFLOWS:

migr_surv $=\left(\left(1-\left(16.39 *\left(\right.\right.\right.\right.$ Initial_Returns $\left.{ }^{\wedge}-.6765\right) *(I F$ weir=1 THEN 1 ELSE $(1-$ weir_remove_mort) $))^{*} .531$ /exposure)*Initial_Returns) -

(Initial_Returns* $(\mathrm{LW}$ _mort+migr_pred_mort+migr_disease_mort+Tmort_frac + SSC_mort_frac $)$ ) $\{$ UNIFLOW $\}$

DOCUMENT: Number of fish transferred from Escapement stock to Lake Entry stock to reflect river immigration mortality. Mortality is based on baseline (current conditions, thought to mainly be due to predation and including effect of weir) and is a function of runsize (mortality as a proportion of population decreases as a negative exponential function of runsize). Mortality due to disease, SSC events, high stream temperature, number of LWD jams and changes in predation that is not determined by runsize (e.g., change in number of predators) that differ from baseline are also incorporated. Baseline mortality also reflects the proportion of the population that migrates at night, and is therefore more 
subject to predation. It is also lowered by a proportion that can be adjusted by user (weir mort) if the weir is removed.

OUTFLOWS:

lake_hold_surv $=$ Lake_Entry*(1-lake_hold_fishery_mort-lake_hold_WQ_mortlake_hold_disease_mort-lake_hold_pred_mort)- $\overline{\text { lake_hold_R\&M }\{\bar{U} N I F L O W}\}$

DOCCUMENT: Number of fish transferred from Lake Entry stock to Prestage stock to represent mortality during lake holding. Mortality as a proportion of population due to predation, disease, lake water quality, and the lake fishery are set by the user. Most are currently thought to be low.

Lake_Entry2 $(\mathrm{t})=$ Lake_Entry $2(\mathrm{t}-\mathrm{dt})+($ Save 2$) * \mathrm{dt}\{$ NON-NEGATIVE $\}$

INIT Lake_Entry2 =0

DOCUMENT: First calculated value of Lake Entry

INFLOWS:

Save $2=$ IF Lake_Entry $>0$ AND $($ HISTORY(Lake_Entry, TIME-1)=0) THEN Lake_Entry ELSE

$0\{$ UNIFLOW $\}$

DOCUMENT: Saves first calculated value of Lake Entry

Marine_Fish $(\mathrm{t})=$ Marine_Fish $(\mathrm{t}-\mathrm{dt})+($ emigr_surv - ocean_surv $) * \mathrm{dt}\{$ NON-NEGATIVE $\}$

INIT Marine_Fish $=0$

DOCUMENT: Fish that have emigrated down the Ozette River and leave the nearshore to rear in the ocean.

INFLOWS:

emigr_surv $=($ Smolts-emigr_R\&M_mort)*(1-emigr_fish_pred_mort-emigr_bird_pred_mort $)$ $\{$ UNIFLOW $\}$

DOCUMENT: Number of fish transferred from Smolts stock to Marine Fish stock to represent survival of emigration from Lake Ozette to the mouth of the Ozette River.

OUTFLOWS:

ocean_surv $=$ Marine_Fish*(1-ocean_mort-immigr_nearshore_mort-fishery_direct_mortfishery_nondirect_mort) $\{$ UNIFLOW

DOCUMENT: Number of fish transferred from Marine Fish stock to Returns stock to represent survival during marine rearing and nearshore approach to the Ozette River. Mike Haggerty suggests that they do not spend much time in the nearshore upon initial entry to marine water. (ref?)

MarineFish2 $(\mathrm{t})=$ MarineFish2 $(\mathrm{t}-\mathrm{dt})+($ Save12 $) * \mathrm{dt}\{$ NON-NEGATIVE $\}$

INIT MarineFish2 $=0$

DOCUMENT: First calculated value of MarineFish

INFLOWS:

Save12 $=$ IF Marine_Fish $>0$ AND (HISTORY(Marine_Fish, TIME-1) $=0$ ) THEN Marine_Fish ELSE 0 \{UNIFLOW\}

DOCUMENT: Saves first calculated value of MarineFish

Prestage $(\mathrm{t})=$ Prestage $(\mathrm{t}-\mathrm{dt})+($ lake_hold_surv - placeholder - immigr_trib_surv[Umbrella] immigr_trib_surv[Big] $) * \mathrm{dt}\{$ NON-NEGATIVE $\}$

INIT Prestage $=0$

DOCUMENT: Sockeye spawners that survive the lake holding stage.

INFLOWS:

lake_hold_surv $=$ Lake_Entry*(1-lake_hold_fishery_mort-lake_hold_WQ_mortlake_hold_disease_mort-lake_hold_pred_mort)- lake_hold_R\&M \{UNNIFLOW

DOCUMENT: Number of fish transferred from Lake Entry stock to Prestage stock to represent mortality during lake holding. Mortality as a proportion of population due to predation, disease, lake water quality, and the lake fishery are set by the user. Most are currently thought to be low.

OUTFLOWS: 
placeholder $=$ Prestage*beach_vs_trib_frac $\{$ UNIFLOW $\}$

DOCUMENT: Number of fish transferred from Prestage stock to SpawnersBeach stock. This flow exists so that beach and tributary events stay synchronized.

immigr_trib_surv[Umbrella] $=(1-$

(immigr_trib_pred_mort[Umbrella]+immigr_trib_flow_mort[Umbrella]+immigr_trib_WQ_mort[Umbr ella]+Umbr_weir_mort))*Prestage*(1-beach_vs_trib_frac)*trib_distn[Umbrella] -

(hatchery_direct+hatchery_indirect) $\{$ UNIFLOW $\}$

DOCUMENT: Number of fish transferred from Prestage stock to SpawnersTrib stock to

represent proportion of population and survival of spawners that migrate up tributaries. Mortality factors include predation, flow, water quality and hatchery harvest.

immigr_trib_surv[Big] $=(1-$

(immigr_trib_pred_mort[Big]+immigr_trib_flow_mort[Big]+immigr_trib_WQ_mort[Big]))*Prestage*( 1-beach_vs_trib_frac)*trib_distn[Big] $\{$ UNIFLOW $\}$

DOCUMENT: Number of fish transferred from Prestage stock to SpawnersTrib stock to

represent proportion of population and survival of spawners that migrate up tributaries. Mortality factors include predation, flow, water quality and hatchery harvest.

Prestage2 $(\mathrm{t})=$ Prestage $2(\mathrm{t}-\mathrm{dt})+($ Save 3$) * \mathrm{dt}\{$ NON-NEGATIVE $\}$

INIT Prestage $2=0$

DOCUMENT: First calculated value of Prestage

INFLOWS:

Save3 $=$ IF Prestage $>0$ AND (HISTORY(Prestage, TIME-1) $=0$ ) THEN Prestage ELSE 0 $\{$ UNIFLOW\}

DOCUMENT: Saves first calculated value of Prestage

Progeny_Returns $(\mathrm{t})=$ Progeny_Returns $(\mathrm{t}-\mathrm{dt})+($ ocean_surv $) * \mathrm{dt}\{\mathrm{NON}-\mathrm{NEGATIVE}\}$

INIT Progeny_Returns $=0$

DOCUMENT: Fish successfully returning to the river after surviving the ocean and nearshore environment.

INFLOWS:

ocean_surv $=$ Marine_Fish*(1-ocean_mort-immigr_nearshore_mort-fishery_direct_mortfishery_nondirect_mort) $\{$ UNIFLOW

DOCUME $\bar{E}$ T: Number of fish transferred from Marine Fish stock to Returns stock to represent survival during marine rearing and nearshore approach to the Ozette River. Mike Haggerty suggests that they do not spend much time in the nearshore upon initial entry to marine water. (ref?)

Progeny_Returns $2(\mathrm{t})=$ Progeny_Returns $2(\mathrm{t}-\mathrm{d} t)+($ Save 13$) * \mathrm{dt}\{$ NON-NEGATIVE $\}$

INIT Progeny_Returns $2=0$

INFLOWS:

Save13 $=$ IF Progeny_Returns $>0$ AND(HISTORY(Progeny_Returns, TIME-1)=0) THEN Progeny_Returns ELSE $0\{$ UNIFLOW\}

Smolts $(\mathrm{t})=$ Smolts $(\mathrm{t}-\mathrm{dt})+($ lake_surv_juv - emigr_surv $) * \mathrm{dt}\{$ NON-NEGATIVE $\}$

INIT Smolts $=0$

DOCUMENT: Number of fish surviving juvenile rearing in lake as fry and emigrating down the river as smolts.

INFLOWS:

lake_surv_juv $=$ FryLake $*(1-($ lake_juv_pred_mort

+lake_juv_disease_mort+lake_juv_base_mort)) \{(UNNIFLOW

DŌCUMENT: Number of fish transferred from FryLake stock to Smolts stock to represent survival of fish during juvenile rearing in lake.

OUTFLOWS: 


\section{emigr_surv $=($ Smolts-emigr_R\&M_mort $) *\left(1-e m i g r \_f i s h \_p r e d \_m o r t-e m i g r \_b i r d \_p r e d \_m o r t\right)$ $\{$ UNIFLOW $\}$}

DOCUMENT: Number of fish transferred from Smolts stock to Marine Fish stock to represent survival of emigration from Lake Ozette to the mouth of the Ozette River.

Smolts $2(\mathrm{t})=\operatorname{Smolts} 2(\mathrm{t}-\mathrm{dt})+($ Save 11$) * \mathrm{dt}\{$ NON-NEGATIVE $\}$

INIT Smolts2 $=0$

DOCUMENT: First calculated value of Smolts

INFLOWS:

Save11 $=$ IF Smolts $>0$ AND $($ HISTORY $($ Smolts, TIME-1) $=0)$ THEN Smolts ELSE 0 $\{$ UNIFLOW $\}$

DOCUMENT: Saves first calculated value of Smolts

SpawnersBeach $(\mathrm{t})=$ SpawnersBeach $(\mathrm{t}-\mathrm{dt})+($ placeholder $) * \mathrm{dt}\{$ NON-NEGATIVE $\}$

INIT SpawnersBeach $=0$

DOCUMENT: Spawners going to beaches (total across beaches).

INFLOWS:

placeholder $=$ Prestage* $*$ beach_vs_trib_frac $\{$ UNIFLOW $\}$

DOCUMENT: Number of fish transferred from Prestage stock to SpawnersBeach stock. This flow exists so that beach and tributary events stay synchronized.

SpawnersBeach2 $(\mathrm{t})=$ SpawnersBeach2 $(\mathrm{t}-\mathrm{dt})+($ Save4 $) * \mathrm{dt}\{\mathrm{NON}-\mathrm{NEGATIVE}\}$

INIT SpawnersBeach2 $=0$

DOCUMENT: First calculated value of SpawnersBeach

INFLOWS:

Save4 $=$ IF SpawnersBeach $>0$ AND (HISTORY(SpawnersBeach， TIME-1)=0) THEN SpawnersBeach ELSE 0 \{UNIFLOW\}

DOCUMENT: Saves first calculated value of SpawnersBeach

SpawnersTrib[Tributary] $(\mathrm{t})=$ SpawnersTrib[Tributary] $(\mathrm{t}-\mathrm{dt})+($ immigr_trib_surv[Tributary] $) * \mathrm{dt}$ $\{$ NON-NEGATIVE\}

INIT SpawnersTrib[Tributary] $=0$

DOCUMENT: Spawners going to tributaries (total across tributaries).

INFLOWS:

immigr_trib_surv[Umbrella] $=(1-$

(immigr_trib_pred_mort[Umbrella]+immigr_trib_flow_mort[Umbrella]+immigr_trib_WQ_mort[Umbr ella]+Umbr weir mort))*Prestage*(1-beach vs trib frac)*trib distn[Umbrella] (hatchery direct+hatchery indirect) $\{\mathrm{UNIFLO} \overline{\mathrm{W}}\}$

DOCUMENT: Number of fish transferred from Prestage stock to SpawnersTrib stock to represent proportion of population and survival of spawners that migrate up tributaries. Mortality factors include predation, flow, water quality and hatchery harvest.

immigr_trib_surv[Big] $=(1-$

(immigr_trib_pred_mort[Big]+immigr_trib_flow_mort[Big]+immigr_trib_WQ_mort[Big]))*Prestage*( 1-beach_vs_trib_frac)*trib_distn[Big] \{UNIFLOW\}

DOCUMENT: Number of fish transferred from Prestage stock to SpawnersTrib stock to represent proportion of population and survival of spawners that migrate up tributaries. Mortality factors include predation, flow, water quality and hatchery harvest.

DOCUMENT: Number of fish transferred from Prestage stock to SpawnersTrib stock to represent proportion of population and survival of spawners that migrate up tributaries. Mortality factors include predation, flow, water quality and hatchery harvest.

SpawnersTrib2[Tributary] $(\mathrm{t})=$ SpawnersTrib2[Tributary] $(\mathrm{t}-\mathrm{dt})+($ Save5[Tributary] $) * \mathrm{dt}\{\mathrm{NON}-$ NEGATIVE\} 
INIT SpawnersTrib2[Tributary] $=0$

DOCUMENT: First calculated value of SpawnersTrib

INFLOWS:

Save5[Tributary] $=$ IF SpawnersTrib $>0$ AND $($ HISTORY $($ SpawnersTrib, TIME-1) $=0)$ THEN SpawnersTrib ELSE $0\{$ UNIFLOW\}

DOCUMENT: Saves first calculated value of SpawnersTrib

artif_redds_fry[Umbrella] $=0$

artif_redds_fry[Big] $=0$

beach_\&_area_distn[Allen, Concentrated] $=46$

DOCUMENT: Proportion of total beach spawners that go to each beach concentrated or dispersed spawning area (LFA Figures 3.11 and 3.12 for proportion going to each beach; Mike Haggerty data for proportion going to area within beach). Numbers are adjustable by user. (This will likely need to be a function that incorporates capacity of favored areas.) User can adjust.

beach \& area distn[Allen, Dispersed] $=4$

DOCUMENT: Proportion of total beach spawners that go to each beach concentrated or dispersed spawning area (LFA Figures 3.11 and 3.12 for proportion going to each beach; Mike Haggerty data for proportion going to area within beach). Numbers are adjustable by user. (This will likely need to be a function that incorporates capacity of favored areas.) User can adjust.

beach_\&_area_distn[Olsen, Concentrated] $=46$

DOCUMENT: Proportion of total beach spawners that go to each beach concentrated or dispersed spawning area (LFA Figures 3.11 and 3.12 for proportion going to each beach; Mike Haggerty data for proportion going to area within beach). Numbers are adjustable by user. (This will likely need to be a function that incorporates capacity of favored areas.) User can adjust.

beach_\&_area_distn[Olsen, Dispersed] $=4$

DOCUMENT: Proportion of total beach spawners that go to each beach concentrated or dispersed spawning area (LFA Figures 3.11 and 3.12 for proportion going to each beach; Mike Haggerty data for proportion going to area within beach). Numbers are adjustable by user. (This will likely need to be a function that incorporates capacity of favored areas.) User can adjust.

DOCUMENT: Proportion of total beach spawners that go to each beach concentrated or dispersed spawning area (LFA Figures 3.11 and 3.12 for proportion going to each beach; Mike Haggerty data for proportion going to area within beach). Numbers are adjustable by user. (This will likely need to be a function that incorporates capacity of favored areas.) User can adjust.

beach_egg_base_mort[Allen, Concentrated] $=.93$

DOCUMENT: Baseline mortality of eggs during incubation period. Source for default of $12.7 \%$ survival is Quinn (XXXX). User can adjust. beach_egg_base_mort[Allen, Dispersed] $=.99$

DOCUMENT: Baseline mortality of eggs during incubation period. Source for default of $12.7 \%$ survival is Quinn (XXXX). User can adjust.

beach_egg_base_mort[Olsen, Concentrated] $=.93$

DOCUMENT: Baseline mortality of eggs during incubation period. Source for default of $12.7 \%$ survival is Quinn $(\mathrm{XXXX)}$. User can adjust.

beach_egg_base_mort[Olsen, Dispersed] $=.99$

DOCUMENT: Baseline mortality of eggs during incubation period. Source for default of $12.7 \%$ survival is Quinn (XXXX). User can adjust.

DOCUMENT: Baseline mortality of eggs during incubation period. Source for default of $12.7 \%$ survival is Quinn (XXXX). User can adjust.

beach_egg_lake_level_mort[Beach, Redd_Density] $=0$

DOCUMENT: Mortality due to low lake level. User defines. 
beach_egg_pred_mort[Beach, Redd_Density] $=0$

beach_fry_dispers_base_mort $=.10$

DOCUMENT: Predation during dispersal from beach to lake. There is a function in the LFA model, but it was decided to let the user define the level of predation from the interface.

beach_max_fish[Allen, Concentrated] = beach_spawn_area[Allen,Concentrated] $/ 3 * 2$

DOCUMENT: Maximum capacity of each beach and beach area (concentrated and dispersed) for spawners if all available area is used. Number assumes a redd has an area of $3 \mathrm{~m} 2$ in concentrated areas, $9 \mathrm{~m} 2$ in dispersed areas, and two fish are associated with each redd.

beach_max_fish[Allen, Dispersed] = beach_spawn_area[Allen,Dispersed] $/ 9 * 2$

DOCUMENT: Maximum capacity of each beach and beach area (concentrated and dispersed) for spawners if all available area is used. Number assumes a redd has an area of $3 \mathrm{~m} 2$ in concentrated areas, $9 \mathrm{~m} 2$ in dispersed areas, and two fish are associated with each redd.

beach_max_fish[Olsen, Concentrated] = beach_spawn_area[Olsen,Concentrated] $/ 3 * 2$

DOCUMENT: Maximum capacity of each beach and beach area (concentrated and dispersed) for spawners if all available area is used. Number assumes a redd has an area of $3 \mathrm{~m} 2$ in concentrated areas, $9 \mathrm{~m} 2$ in dispersed areas, and two fish are associated with each redd.

beach_max_fish[Olsen, Dispersed] = beach_spawn_area[Olsen,Dispersed] $/ 9 * 2$

DOCUMENT: Maximum capacity of each beach and beach area (concentrated and dispersed) for spawners if all available area is used. Number assumes a redd has an area of $3 \mathrm{~m} 2$ in concentrated areas, $9 \mathrm{~m} 2$ in dispersed areas, and two fish are associated with each redd.

DOCUMENT: Maximum capacity of each beach and beach area (concentrated and dispersed) for

spawners if all available area is used. Number assumes a redd has an area of $3 \mathrm{~m} 2$ in concentrated areas, $9 \mathrm{~m} 2$ in dispersed areas, and two fish are associated with each redd.

beach pred[Allen, Concentrated] $=.4$

DOCUMENT: Proportion of spawners killed by predators at each beach (ref, at the moment it is expert opinion). User can adjust.

beach $\_$pred[Allen, Dispersed] $=.4$

DOCUMENT: Proportion of spawners killed by predators at each beach (ref; at the moment it is expert opinion). User can adjust.

beach_pred[Olsen, Concentrated] $=.1$

DOCUMENT: Proportion of spawners killed by predators at each beach (ref; at the moment it is expert opinion). User can adjust.

beach _pred[Olsen, Dispersed] $=.1$

DOCUMENT: Proportion of spawners killed by predators at each beach (ref; at the moment it is expert opinion). User can adjust.

DOCUMENT: Proportion of spawners killed by predators at each beach (ref; at the moment it is expert opinion). User can adjust.

beach_R\&M_mort[Allen] $=0$

DOCUMENT: Proportion of spawning population killed by research and monitoring activities. This is thought to be very low at present. Number can be adjusted by user.

beach_R\&M_mort[Olsen] $=0$

DOCUMENT: Proportion of spawning population killed by research and monitoring activities. This is thought to be very low at present. Number can be adjusted by user.

DOCUMENT: Proportion of spawning population killed by research and monitoring activities. This is thought to be very low at present. Number can be adjusted by user.

beach_spawn_area[Allen, Concentrated] $=13520$

DOCUMENT: Beach area $(\mathrm{m} 2)$ where concentrated and dispersed spawning occurs for both beaches. User can adjust. 
beach_spawn_area[Allen, Dispersed] $=30680$

DOCUMENT: Beach area $(\mathrm{m} 2)$ where concentrated and dispersed spawning occurs for both beaches. User can adjust.

beach_spawn_area[Olsen, Concentrated] $=4600$

DOCUMENT: Beach area $(\mathrm{m} 2)$ where concentrated and dispersed spawning occurs for both beaches. User can adjust.

beach_spawn_area[Olsen, Dispersed] $=12300$

DOCUMENT: Beach area $(\mathrm{m} 2)$ where concentrated and dispersed spawning occurs for both beaches. User can adjust.

DOCUMENT: Beach area $(\mathrm{m} 2)$ where concentrated and dispersed spawning occurs for both beaches. User can adjust.

beach_surv_spawners[Allen, Concentrated] $=$ SpawnersBeach*beach_\&_area_distn[Allen, Concentrated] $/ 100 *(1$-beach_pred[Allen, Concentrated]-beach_R\&M_mort[A1len])

DOCUMENT: Number of spawners that migrate to each beach and survive predation and research/monitoring mortality to spawn.

beach_surv_spawners[Allen, Dispersed] = SpawnersBeach*beach_\&_area_distn[Allen, Dispersed] $/ 100 *$ (1-beach pred[Allen, Dispersed] + beach_R\&M_mort[Allen])

DOCUMENT: Number of spawners that migrate to each beach and survive predation and research/monitoring mortality to spawn.

beach_surv_spawners[Olsen, Concentrated] = SpawnersBeach *beach_\&_area_distn[Olsen, Concentrated $] / 100 *$ (1-beach_pred[Olsen, Concentrated] - beach_R\&M_mort[Ō

DOCUMENT: Number of spawners that migrate to each beach and survive predation and research/monitoring mortality to spawn.

beach_surv_spawners[Olsen, Dispersed] = SpawnersBeach*beach_\&_area_distn[Olsen, Dispersed] $/ 100 *$ (1-beach_pred[Olsen, Dispersed] +beach_R\&M_mort[Olsen])

DOCUMENT: Number of spawners that migrate to each beach and survive predation and research/monitoring mortality to spawn.

DOCUMENT: Number of spawners that migrate to each beach and survive predation and research/monitoring mortality to spawn.

beach_vs_trib_frac $=.20$

DOCUMENTT: Fraction of fish going to beaches versus tributaries. Default value of $48 \%$ of fish surviving lake holding go to beaches versus tributaries based on Table 2 of HGMP Extension Request appendix. This proportion can be adjusted by user.

eggs_per_female $=3100$

DOCUMENT: Typical number of eggs per sockeye redd (3100, rounded from 3097; MFM 2000). Number can be adjusted by user.

emigr_bird_pred_mort $=.02$

DOCUMENT: Emigration mortality due to birds, primarily mergansers. Setting the level of predation includes consideration of SSC events, stream temperature and streamflow, as they can be beneficial or detrimental to predation. Predation is thought to be a function of the number of fish typically eaten by a bird times the number of birds, so predation is expressed as number of fish rather than proportion of population. Value must be set by user.

emigr fish pred mort $=.05$

DOCUMENT: Emigration mortality due to fish (primarily northern pike minnow). Setting the level of predation includes consideration of SSC events, stream temperature and streamflow, as they can be beneficial or detrimental to predation. Predator swamping dynamics are thought to be appropriate so mortality is expressed as a percentage of the sockeye population. Value must be set by user.

emigr_R\&M_mort $=0$ 
DOCUMENT: Regulations authorize the number of fish that can be handled and the allowable proportion that can die directly or indirectly due to smolt trapping. What is this number? User can adjust the value.

exposure $=$

flow_popn[lakelt315]/100+flow_popn[lake315 to325]/100*.74+flow_popn[lake325to335]/100*.56+flo

w_popn[lake335to345]/100*.38+flow_popn[lake345 to355]/100*.2+flow_popn[lakegt355]/100*0

DOCUMENT: Calculates proportion of population most vulnerable to predation because it transits the weir at night. The equation sums the percent of the population immigrating during each flow range multiplied by the exposure during that flow range. Flow is indicated by ranges in lake level: $35.5 \mathrm{ft}$. Exposure is calculated for the mid-point of each flow range based on a linear regression of sockeye transiting the weir in daylight against lake level (LFA). The user can adjust the proportion of the population migrating under the various flow conditions using 'flow popn'.

fishery_direct_mort $=0$

DOCUMENT: Mortality due to directed fishery. At the moment this is 0 but harvest may be allowed if the population recovers. User can adjust.

fishery_nondirect_mort $=0$

DOCUMENT: Mortality in ocean due to by-catch of other fisheries and illegal harvest. User can adjust.

flow_popn[lakelt315] $=0$

DOCUMENT: Proportion of population entering river at a range of flows indicated by ranges in lake level: $35.5 \mathrm{ft}$. Values must sum to 1.0 .

Default values represent the typical situation based on area under the curve showing percent of run entering the lake as a function of lake level using data from XXXX to XXXX (Haggerty, unpublished). User can adjust.

flow_popn[lake315to325] $=25$

DOCUMENT: Proportion of population entering river at a range of flows indicated by ranges in lake level: $35.5 \mathrm{ft}$. Values must sum to 1.0 .

Default values represent the typical situation based on area under the curve showing percent of run entering the lake as a function of lake level using data from XXXX to XXXX (Haggerty, unpublished). User can adjust.

flow popn[lake325 to335] $=37$

DOCUMENT: Proportion of population entering river at a range of flows indicated by ranges in lake level: $35.5 \mathrm{ft}$. Values must sum to 1.0 .

Default values represent the typical situation based on area under the curve showing percent of run entering the lake as a function of lake level using data from XXXX to XXXX (Haggerty, unpublished). User can adjust.

flow_popn[lake335to345] $=35$

DOCUMENT: Proportion of population entering river at a range of flows indicated by ranges in lake level: $35.5 \mathrm{ft}$. Values must sum to 1.0 .

Default values represent the typical situation based on area under the curve showing percent of run entering the lake as a function of lake level using data from XXXX to XXXX (Haggerty, unpublished). User can adjust.

flow_popn[lake345 to355] $=3$ 
DOCUMENT: Proportion of population entering river at a range of flows indicated by ranges in lake level: $35.5 \mathrm{ft}$. Values must sum to 1.0 .

Default values represent the typical situation based on area under the curve showing percent of run entering the lake as a function of lake level using data from XXXX to XXXX (Haggerty, unpublished). User can adjust.

flow_popn[lakegt355] $=0$

DOCUMENT: Proportion of population entering river at a range of flows indicated by ranges in lake level: $35.5 \mathrm{ft}$. Values must sum to 1.0 .

Default values represent the typical situation based on area under the curve showing percent of run entering the lake as a function of lake level using data from XXXX to XXXX (Haggerty, unpublished). User can adjust.

DOCUMENT: Proportion of population entering river at a range of flows indicated by ranges in lake level: $35.5 \mathrm{ft}$. Values must sum to 1.0 .

Default values represent the typical situation based on area under the curve showing percent of run entering the lake as a function of lake level using data from XXXX to XXXX (Haggerty, unpublished). User can adjust.

hatchery_direct $=200$

DOCUMENT: Number of fish harvested by hatchery for brood stock. hatchery_fry[Umbrella] $=97852$

DOCUMENT: Number of fry released into Umbrella Creek and Big River based on average releases 2000-2013. User can adjust. hatchery_fry[Big] $=78785$

DOCUMMNT: Number of fry released into Umbrella Creek and Big River based on average releases 2000-2013. User can adjust.

DOCUMENT: Number of fry released into Umbrella Creek and Big River based on average releases 2000-2013. User can adjust.

hatchery_indirect $=0$

DOCŪMENT: Number of fish harvested lost due to hatchery operations. User can adjust. immigr_nearshore_mort $=0$

DOCUMENT: Mortality experienced in the nearshore, prior to entry into Ozette River, primarily thought to be due to marine mammal predation. Level can be set by user. There are no data to indicate a default value.

immigr_trib_flow_mort[Tributary] $=0$

DOCUMENT: Proportion of population that dies during tributary immigration due to poor flow conditions. User can adjust. immigr_trib_pred_mort[Tributary] $=0$

DOCUMENT: Proportion of population subject to predation during tributary immigration. User can adjust.

immigr_trib_WQ_mort[Tributary] $=0$

DOCUMENT: Proportion of population that dies during tributary migration due to poor water quality conditions. User can adjust.

lake_hold_disease_mort $=0$

DOCUMENT: Proportion of spawner population that dies during holding from disease in Lake Ozette. User can adjust.

lake_hold_fishery_mort $=0$ 
DOCUMENT: Proportion of spawner population that dies during holding as a result of the Lake Ozette fishery. This is not considered to be an issue at present. User can adjust. lake_hold_pred_mort $=.1$

DOCUMENT: Proportion of spawner population subject to predation during holding in Lake Ozette. User can adjust.

lake hold R\&M $=0$

DOCUMENT: Proportion of population dying due to research and monitoring activites while holding in Lake Ozette. User can adjust.

lake hold WQ mort $=0$

DOCUMENT: Proportion of spawner population that dies due to poor water quality during holding in Lake Ozette. Not thought to be a problem at present. User can adjust.

lake juv base mort $=0$

DOCUMMENT: Base mortality during lake residence of juveniles. It could be due to factors such as high density or climate change, which may cause water temperature and fish metabolism to be so high that they cannot consume enough food to support it. User can adjust.

lake_juv_disease_mort $=0$

DOCUMENT: Mortality due to disease during juvenile residence in lake. User defines level. lake juv pred mort $=-.00000000000003 *$ FryLake*FryLake $+.00000002 *$ FryLake +.9195

DOCUMENT: Survival estimated by Foerster (1968) to 8\%; Beauchamp et al. (1995) estimates 6.7\%; McDonald (1969) estimates 13.5\%.

LW_mort $=0$

DOCUMENT: Proportion change in mortality due to gain or loss of LW jams from baseline. migr_disease_mort $=0$

DOCUMENT: Proportion of population experiencing immigration mortality due to disease. Baseline conditions are that it is rare. User can adjust.

migr_pred_mort $=0$

DOCUMENT: Increase or decrease in baseline mortality due to a change in predator abundance from baseline (typical current conditions). No attempt is made to describe predator-prey dynamics. Rather, the user simply determines what change in mortality is achieved by predator management. How that amount is achieved is not addressed by the model. User can adjust mortality.

ocean mort $=.83$

DOCUMENT: Mortality during ocean rearing. The default value $(83 \%)$ is based on the average survival observed by Jacobs et al. (1996) in BY1988 and BY1990 cited in the LFA. Level can be adjusted by user. This includes nearshore (emigration) as well as open ocean mortality. Use can adjust. scour_mort $=0$

$\mathrm{SSC}$ mort$[\mathrm{SSC}]=0$

DOCCUMENT: Proportion of population dying due to a high, medium or low severity SSC event during immigration. User can adjust.

SSC_mort_frac $=$

SSC_num[Low]*SSC_mort[Low]+SSC_num[Med]*SSC_mort[Med]+SSC_num[High]*SSC_mort[Hig $\mathrm{h}]$

DOCUMENT: Calculates mortality due to SSC events by summing number events of each severity level times the effect of each.

$\mathrm{SSC}$ num $[\mathrm{SSC}]=0$

DŌCUMENT: Number of low, medium and high severity SSC events occurring during immigration. Baseline conditions assume no SSC events during immigration. User can adjust.

storm_event $=0$

Tmort[Tlt19] $=0$ 
DOCUMENT: Proportion of population transiting the river under water temperature conditions $21 \mathrm{oC}$ that die due to temperature conditions. User can adjust.

Tmort[T1920] $=0$

DOCUMENT: Proportion of population transiting the river under water temperature conditions $21 \mathrm{oC}$ that die due to temperature conditions. User can adjust.

Tmort[T2021] $=.50$

DOCUMENT: Proportion of population transiting the river under water temperature conditions $21 \mathrm{oC}$ that die due to temperature conditions. User can adjust.

Tmort[Tgt21] $=1.00$

DOCUMENT: Proportion of population transiting the river under water temperature conditions $21 \mathrm{oC}$ that die due to temperature conditions. User can adjust.

DOCUMENT: Proportion of population transiting the river under water temperature conditions 21 oC that die due to temperature conditions. User can adjust.

Tmort frac $=$

(Tpopn[Tlt19]/100*Tmort[Tlt19])+(Tpopn[T1920]/100*Tmort[T1920])+(Tpopn[T2021]/100*Tmort[T 2021])+(Tpopn[Tgt21]/100*Tmort[Tgt21])

DOCUMENT: Sum of mortality due to subpopulations of fish migrating at ranges of water temperatures determined in Tpopn. Baseline conditions assume no negative temperature conditions. Tpopn[Tlt19] $=75$

DOCUMENT: Proportion of population transiting river when water temperature is $21 \mathrm{oC}$. User can adjust.

Tpopn[T1920] $=15$

DOCUMENT: Proportion of population transiting river when water temperature is $21 \mathrm{oC}$. User can adjust.

Tpopn[T2021] $=4$

DOCUMENT: Proportion of population transiting river when water temperature is $21 \mathrm{oC}$. User can adjust.

Tpopn[Tgt21] $=6$

DOCUMENT: Proportion of population transiting river when water temperature is $21 \mathrm{oC}$. User can adjust.

DOCUMENT: Proportion of population transiting river when water temperature is $21 \mathrm{oC}$. User can adjust.

trib_distn[Umbrella] $=.90$

DOCUMENT: Fraction of tributary spawners that go to each tributary (Umbrella or Big River, Crooked River is not included). Source. User can adjust.

trib_distn[Big] $=.10$

DOCUMENT: Fraction of tributary spawners that go to each tributary (Umbrella or Big River, Crooked River is not included). Source. User can adjust.

DOCUMENT: Fraction of tributary spawners that go to each tributary (Umbrella or Big River, Crooked River is not included). Source. User can adjust.

trib_egg_base_mort[Umbrella] $=.88$

DOCUMENT: Base mortality proportion using equation for Dungeness River and chinook (ref) where mortality is a function of peak flow expressed as return interval.

trib_egg_base_mort[Big] $=.88$

DOCUMENT: Base mortality proportion using equation for Dungeness River and chinook (ref) where mortality is a function of peak flow expressed as return interval.

DOCUMENT: Base mortality proportion using equation for Dungeness River and chinook (ref) where mortality is a function of peak flow expressed as return interval. 
trib_egg_R\&M_mort[Tributary] $=0$

DOCUMENT: Proportion of mortality due to research and monitoring activities in tributaries when eggs are present. User can adjust.

trib_fry_disp_pred[Umbrella, Wild] $=.25$

DOCUMENT: Sigmoid curve describing predation mortality as a function of number of fry. Assymptote is $35 \%$. The same equation is used for both tributaries. User can adjust. trib_fry_disp_pred[Umbrella, Hatchery] $=.6$

DOCUMENT: Sigmoid curve describing predation mortality as a function of number of fry. Assymptote is $35 \%$. The same equation is used for both tributaries. User can adjust. trib_fry_disp_pred[Big, Wild] $=.25$

DOCUMENT: Sigmoid curve describing predation mortality as a function of number of fry. Assymptote is $35 \%$. The same equation is used for both tributaries. User can adjust. trib fry disp pred[Big, Hatchery] $=.1$

DOCUMENT: Sigmoid curve describing predation mortality as a function of number of fry. Assymptote is $35 \%$. The same equation is used for both tributaries. User can adjust.

DOCUMENT: Sigmoid curve describing predation mortality as a function of number of fry. Assymptote is $35 \%$. The same equation is used for both tributaries. User can adjust. trib_fry_flow_mort[Umbrella, Wild] $=0$

DOCUMENT: Change in mortality of fry traveling from tributaries to the lake due to adverse or positive flow events. User can adjust.

trib_fry_flow_mort[Umbrella, Hatchery] $=0$

DOCUMENT: Change in mortality of fry traveling from tributaries to the lake due to adverse or positive flow events. User can adjust.

trib_fry_flow_mort[Big, Wild] $=0$

$\overline{D O C U M E N T}$ : Change in mortality of fry traveling from tributaries to the lake due to adverse or positive flow events. User can adjust.

trib_fry_flow_mort[Big, Hatchery] $=.65$

DOCUMENT: Change in mortality of fry traveling from tributaries to the lake due to adverse or positive flow events. User can adjust.

DOCUMENT: Change in mortality of fry traveling from tributaries to the lake due to adverse or positive flow events. User can adjust. trib_max_fish[Umbrella] = trib_spawn_area[Umbrella] $/ 3 * 2$

DOCUMENT: Maximum number of fish that can spawn in each tributary based on the number of redds that can be accommodated by available habitat. Assumes redds occupy $3 \mathrm{~m} 2$. trib_max_fish[Big] $=$ trib_spawn_area[Big] $/ 3 * 2$

DOCUMENT: Maximum number of fish that can spawn in each tributary based on the number of redds that can be accommodated by available habitat. Assumes redds occupy $3 \mathrm{~m} 2$.

DOCUMENT: Maximum number of fish that can spawn in each tributary based on the number of redds that can be accommodated by available habitat. Assumes redds occupy $3 \mathrm{~m} 2$.

trib_R\&M_mort[Umbrella] $=0$

DOCUMENT: Proportion of tributary spawners lost due to research and monitoring activities in tributaries. At present this is thought to be zero. User can ajdust.

trib_R\&M_mort[Big] $=0$

DOCUMENT: Proportion of tributary spawners lost due to research and monitoring activities in tributaries. At present this is thought to be zero. User can ajdust.

DOCUMENT: Proportion of tributary spawners lost due to research and monitoring activities in tributaries. At present this is thought to be zero. User can ajdust.

trib_spawn_area[Umbrella] $=56254$ 
DOCUMENT: Area of useable spawning substrate in tributaries (m2). Default value from LOS Recovery Goals, 2006. User can adjust.

trib_spawn_area[Big] $=66474$

DOCUMENT: Area of useable spawning substrate in tributaries (m2). Default value from LOS Recovery Goals, 2006. User can adjust.

DOCUMENT: Area of useable spawning substrate in tributaries (m2). Default value from LOS Recovery Goals, 2006. User can adjust. trib_spawn_pred_mort[Umbrella] $=0$

DOCUMENT: Proportion of population lost to predators during tributary spawning. User can adjust. trib_spawn_pred_mort[Big] $=0$

DOCUMENT: Proportion of population lost to predators during tributary spawning. User can adjust.

DOCUMENT: Proportion of population lost to predators during tributary spawning. User can adjust. trib spawn WQ mort[Umbrella] $=0$

DOCUMENT: Mortality of spawners in tributariesdue to SSC events. User can adjust. trib_spawn_WQ_mort[Big] $=0$

DOCUMENT: Mortality of spawners in tributariesdue to SSC events. User can adjust.

DOCUMENT: Mortality of spawners in tributariesdue to SSC events. User can adjust. trib_surv_spawners[Umbrella] = SpawnersTrib[Umbrella]*(1-

(trib_spawn_pred_mort[Umbrella]+trib_R\&M_mort[Umbrella]+trib_spawn_WQ_mort[Umbrella]))

DOCUMENT: Proportion of tributary spawners that survive predation plus research and monitoring mortality to spawn.

trib_surv_spawners[Big] $=$ SpawnersTrib[Big]* ${ }^{*}(1-$

(trib_spawn pred_mort[Big]+trib_R\&M_mort[Big]+trib_spawn_WQ_mort[Big]))

DOCUMENT: Proportion of tributary spawners that survive predation plus research and monitoring mortality to spawn.

DOCUMENT: Proportion of tributary spawners that survive predation plus research and monitoring mortality to spawn.

Umbr_weir_mort $=0$

DOCUMENT: Proportion of migrants to Umbrella Creek that die due to the Umbrella weir. weir $=1$

DOCUMENT: Switch indicating status of weir: 1, the weir is present; 0, weir is absent. weir_remove mort $=.4$

DOCUMENT: Proportional decrease in typical (baseline) mortality if weir is absent. (Baseline mortality is estimated from current conditions, which include the weir.) Baseline mortality is calculated as a function of runsize; baseline mortality is reduced by a constant proportion if the weir is absent, rather than by a constant number across all run sizes. User can adjust.

\{ The model has 113 (223) variables (array expansion in parens).

In root model and 0 additional modules with 0 sectors.

Stocks: 26 (48) Flows: 26 (54) Converters: 61 (121)

Constants: 53 (105) Equations: 34 (70) Graphicals: 0 (0)

\} 

Publishing support provided by the U.S. Geological Survey Science Publishing Network, Tacoma Publishing Service Center

For more information concerning the research in this report, contact the Director, Forest and Rangeland Ecosystem Science Center U.S. Geological Survey

777 NW 9th St., Suite 400

Corvallis, Oregon 97330

https://www.usgs.gov/centers/fresc/ 


\section{寍}

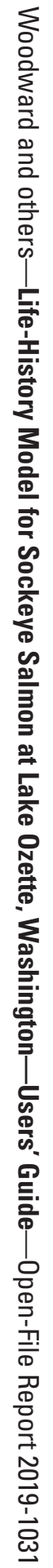

